Florida International University FIU Digital Commons

$11-9-2012$

\title{
Cognitive Competence and Life Course Change in Multi-Problem Adolescents
}

Brent M. Maximin

Florida International University, bmaxi001@fiu.edu

DOI: $10.25148 /$ etd.FI12111901

Follow this and additional works at: https://digitalcommons.fiu.edu/etd

\section{Recommended Citation}

Maximin, Brent M., "Cognitive Competence and Life Course Change in Multi-Problem Adolescents" (2012). FIU Electronic Theses and Dissertations. 731.

https://digitalcommons.fiu.edu/etd/731

This work is brought to you for free and open access by the University Graduate School at FIU Digital Commons. It has been accepted for inclusion in FIU Electronic Theses and Dissertations by an authorized administrator of FIU Digital Commons. For more information, please contact dcc@fiu.edu. 


\section{FLORIDA INTERNATIONAL UNIVERSITY}

Miami, Florida

COGNITIVE COMPETENCE AND LIFE COURSE CHANGE IN MULTI-PROBLEM

ADOLESCENTS

A dissertation submitted in partial fulfillment of the

requirements for the degree of

DOCTOR OF PHILOSOPHY

in

PSYCHOLOGY

by

Brent M. Maximin

2012 


\section{To: Dean Kenneth Furton}

College of Arts and Sciences

This dissertation, written by Brent M. Maximin, and entitled Cognitive Competence and Life Course Change in Multi-Problem Adolescents, having been approved in respect to style and intellectual content, is referred to you for judgment.

We have read this dissertation and recommend that it be approved.

Mary Levitt

Dionne Stephens

Bruce Harvey

$\overline{\text { William M. Kurtines, Major Professor }}$

Date of Defense: November 9, 2012

The dissertation of Brent M. Maximin is approved.

\begin{tabular}{r} 
Dean Kenneth Furton \\
College of Arts and Sciences \\
\hline Dean Lakshmi N. Reddi \\
University Graduate School
\end{tabular}

Florida International University, 2012 
DEDICATION

For Amanda. 


\section{ACKNOWLEDGMENTS}

I would first like to acknowledge my colleagues in the Miami Youth Development Project for their support and camaraderie. I am grateful not just for their contributions to this project, but also for their friendship and good humor. I also owe a great deal of thanks to the members of my committee. Dr. Stephens' enthusiasm and valued feedback was crucial to the evolution of this research. I am lucky enough to have enjoyed the support of Dr. Harvey even before I became a doctoral student, and I thank him for his time, and his insight. I can barely thank Dr. Levitt enough for her patience and generosity of spirit. I also want to express gratitude to my family and friends, who have at various points kept me laughing, kept me humble, and kept me motivated. Above

all, I remain in the debt of my mentor Dr. Kurtines. Without his guidance, patience, and unfailing encouragement, this project would not be possible. 


\section{ABSTRACT OF THE DISSERTATION \\ COGNITIVE COMPETENCE AND LIFE COURSE CHANGE IN MULTI-PROBLEM \\ ADOLESCENTS}

by

Brent M. Maximin

Florida International University, 2012

Miami, Florida

\section{Professor William M. Kurtines, Major Professor}

The dissertation reports on two studies. The purpose of Study I was to develop and evaluate a measure of cognitive competence (the Critical Problem Solving Skills Scale - Qualitative Extension) using Relational Data Analysis (RDA) with a multi-ethnic, adolescent sample. My study builds on previous work that has been conducted to provide evidence for the reliability and validity of the RDA framework in evaluating youth development programs (Kurtines et al., 2008). Inter-coder percent agreement among the TOC and TCC coders for each of the category levels was moderate to high, with a range of .76 to .94. The Fleiss' kappa across all category levels was from substantial agreement to almost perfect agreement, with a range of .72 to .91 . The correlation between the TOC and the TCC demonstrated medium to high correlation, with a range of $\mathrm{r}(40)=.68, \mathrm{p}<.001$ to $\mathrm{r}(40)=.79, \mathrm{p}<.001$.

Study II reports an investigation of a positive youth development program using an Outcome Mediation Cascade (OMC) evaluation model, an integrated model for evaluating the empirical intersection between intervention and developmental processes. The Changing Lives Program (CLP) is a community supported positive youth 
development intervention implemented in a practice setting as a selective/indicated program for multi-ethnic, multi-problem at risk youth in urban alternative high schools in the Miami Dade County Public Schools (M-DCPS). The 259 participants for this study were drawn from the CLP's archival data file. The study used a structural equation modeling approach to construct and evaluate the hypothesized model. Findings indicated that the hypothesized model fit the data $(\chi 2(7)=5.651, \mathrm{p}=.83$; $\mathrm{RMSEA}=.00 ; \mathrm{CFI}=$ 1.00 ; WRMR $=.319)$. My study built on previous research using the OMC evaluation model (Eichas, 2010), and the findings are consistent with the hypothesis that in addition to having effects on targeted positive outcomes, PYD interventions are likely to have progressive cascading effects on untargeted problem outcomes that operate through effects on positive outcomes. 


\section{TABLE OF CONTENTS}

CHAPTER

PAGE

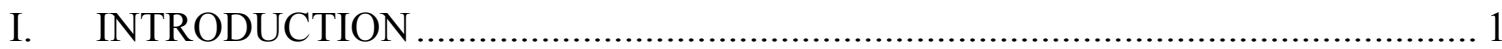

Why is Critical Thinking Important? ......................................................... 1

Positive Youth Development ....................................................................... 2

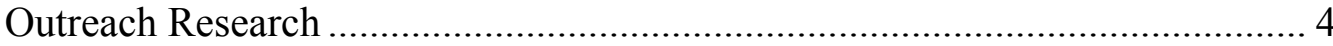

The Changing Lives Program ........................................................................ 7

Developmental Theory: Psychosocial Developmental Life Course Approach .. 9

Intervention Theory: Participatory Transformative Approach .......................... 10

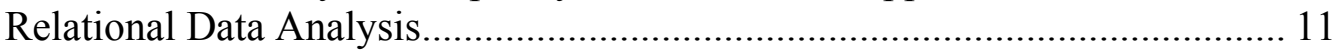

The Outcome Mediation Cascade Model ........................................................ 14

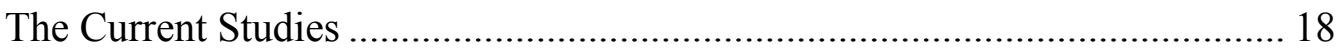

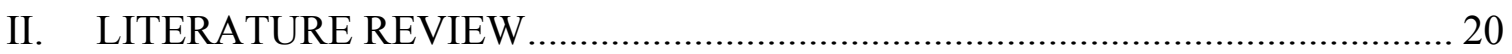

Identity Exploration Style............................................................................ 20

Identity Exploration Competence (Problem-Solving) ....................................... 21

Critical Thinking and Critical Discourse ........................................................ 22

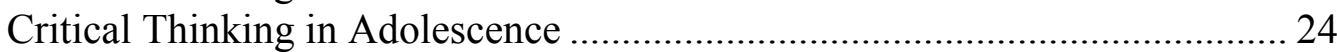

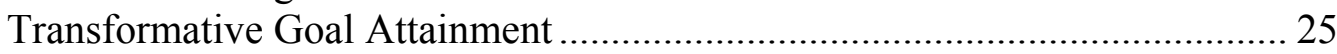

Critical Thinking and the Achievement of Life Goals..................................... 27

Critical Thinking and Problem Outcomes ....................................................... 28

III. STUDY I: THE DEVELOPMENT OF THE CRITICAL PROBLEM-SOLVING

SKILLS SCALE - QUALITATIVE EXTENSION .................................................... 31

The Development of a Free-Response Performance-Based Indicator of Critical

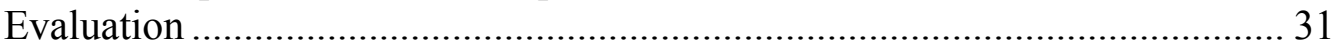

Relational Data Analysis: The Qualitative Extension (QE) Method ................. 31

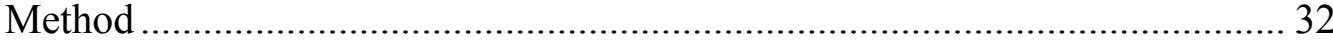

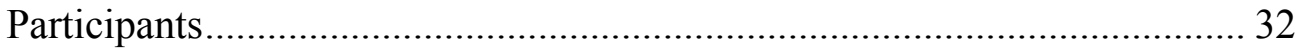

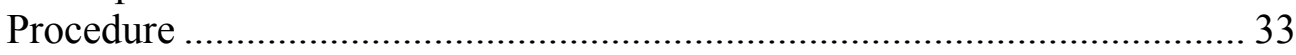

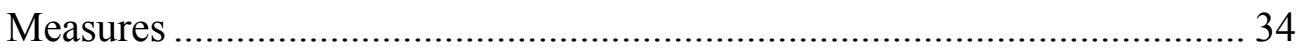

Relational Data Analysis.......................................................................... 36

Conceptual Open Coding (COC) ............................................................ 36

Theoretical Open Coding (TOC) ............................................................. 37

Theoretical Classification Coding (TCC) ……………................................ 39

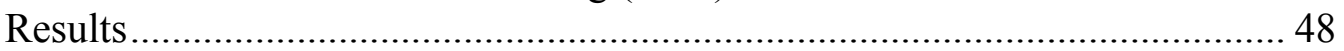

Conceptual Open Coding (COC) .......................................................... 48

Theoretical Open Coding (TOC) ................................................................. 49

Theoretical Classification Coding (TCC) ………………............................. 55

IV. STUDY II: CRITICAL THINKING, LIFE GOALS, AND BEHAVIORAL

OUTCOMES - AN OUTCOME MEDIATION CASCADE MODEL …………..............6 60

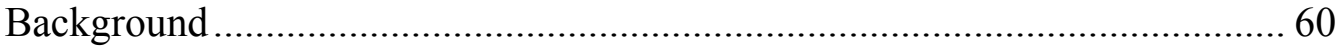

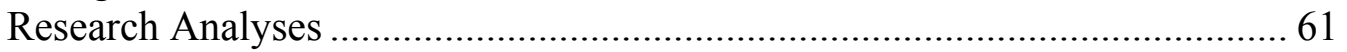


Hypothesized Pathways of Intervention Change: Direct, Mediated, and

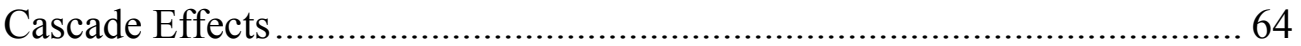

Hypothesized Direct Effects: Positive Outcome.............................................. 65

Hypothesized Direct Effects: Problem Outcomes ........................................... 66

Hypothesized Mediation of Positive and Problem Outcomes ........................ 67

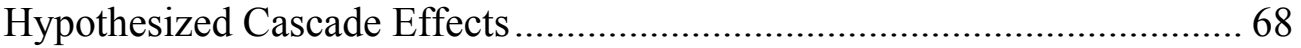

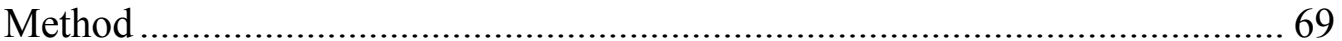

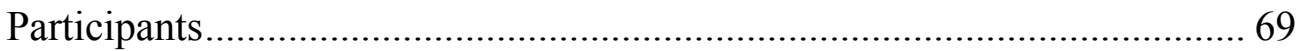

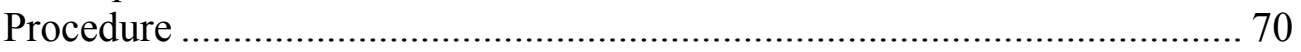

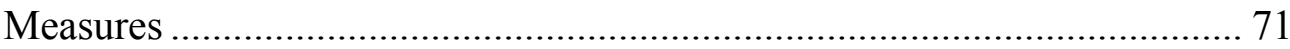

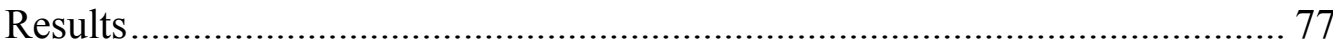

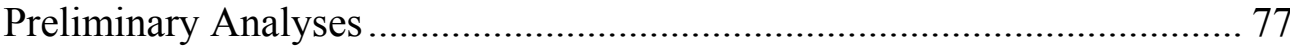

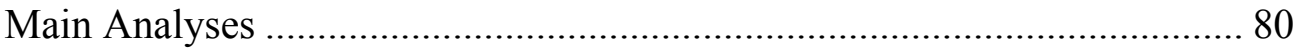

Hypothesized Direct and Moderated Intervention Effects............................ 84

Hypothesized Mediation of Positive Outcomes.............................................. 87

Hypothesized Mediation of Problem Outcomes ………………………….... 89

Hypothesized Cascade Effects ..................................................................... 90

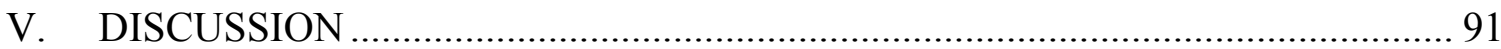

Developing a Qualitative Measure of Cognitive Competence ......................... 91

Evaluating the Intervention: Outcome, Mediated, and Cascade Effects ........... 92

Theoretical and Methodological Contributions ................................................ 96

Directions for Future Research: A Gender Divergence ..................................... 99

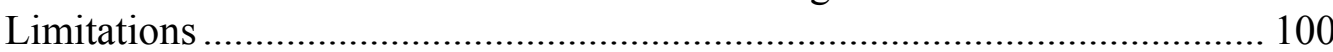

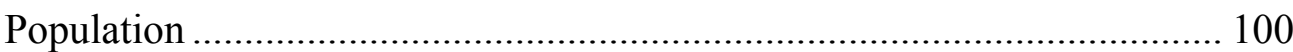

Missing Data and Participant Attrition .................................................... 101

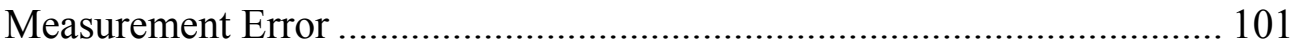

Statistical Power and Sample Size Considerations..................................... 102

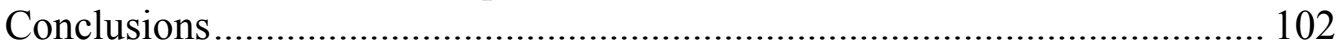

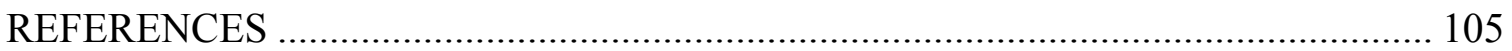

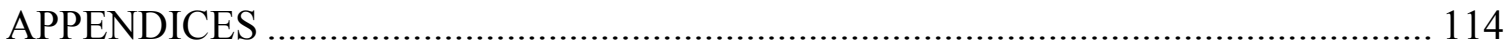

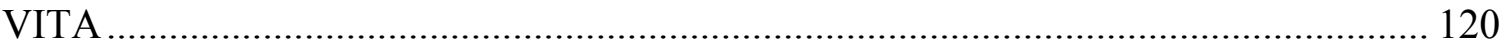




\section{LIST OF TABLES}

TABLE

PAGE

1. Descriptive Statistics for Continuous Outcome Variables.........................................77

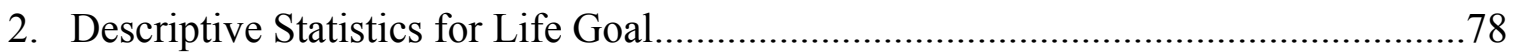

3. Descriptive Statistics for Critical Problem-Solving ................................................ 79

4. Summary of Major Path Analyses for Mediators and Positive Outcomes .................86

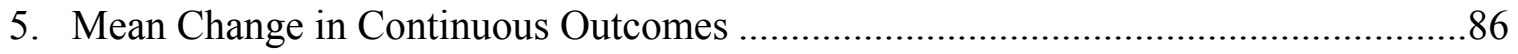

6. Summary of Major Path Analyses for Effects on Problem Outcomes .......................88 


\section{LIST OF FIGURES}

FIGURE

PAGE

1. A Three-Component Outcome Mediation Cascade (OMC) Model............................17

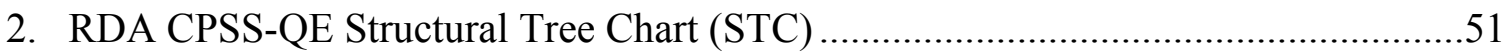

3. Conceptualized Pathways of Intervention Change .............................................62

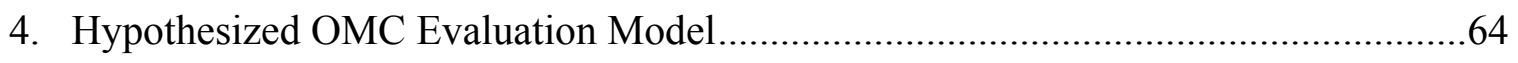

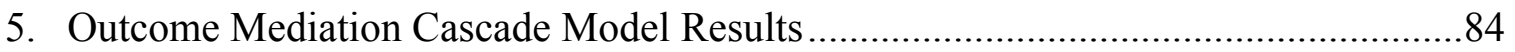




\section{INTRODUCTION}

Why is Critical Thinking Important?

The knowledge and understanding that human beings have of the world emerge as a result of their interactions with it. During the course of development, they acquire certain competencies that are necessary to construct their understanding of the world around them. Furthermore, it is now widely accepted that humans are not mere passive receptors and processors of information; they seek out particular knowledge, transform existing forms of understanding, and actively create new knowledge frameworks. The capacity to generate new forms of understanding in the face of changing conditions is what forms the core of human adaptability. The development of higher order cognitive competencies enables individuals to engage in the most complex forms of theoretical and practical problem-solving activities. As such, cognitive competence - i.e., the capacity to engage in critical and hypothetical thinking - plays a key role in positive development, and indeed can be considered the most important outcome of the cognitive developmental process.

Although considerable current literature exists on critical thinking in problemsolving and decision making (e.g., Anderson, Goddard, \& Powell, 2009; Jaffee \& D'Zorilla, 2003; Hoppman, Coats, \& Blanchard-Fields, 2008) much of it has focused on logical reasoning skills. Logical reasoning skills may be particularly useful in solving "well-structured" problems, but they do not encompass the full range of skills involved in critical thinking. Well-structured problems are characterized by having known problematic properties that lead to single and verifiable solutions. Many "real world" 
problems, however, are not usually this straightforward; they tend to be complex or "illstructured" problems, for which there is often conflicting or incomplete information, unknown or conflicting characteristics, and solutions that are neither certain nor verifiable. Such problems, therefore, involve more than the use of logical reasoning skills. They involve higher order cognitive competencies that include reflective judgment, i.e., the ability to monitor and evaluate one's own performances.

\section{Positive Youth Development}

There has been a growing interest in developing intervention programs designed to affect the lives of people, with the goal of moving their life trajectories in more adaptive directions. More recently, there has also been a growing recognition that interventions need to do more than "treat" problem behaviors (i.e., symptoms) or "prevent" negative developmental outcomes (Lerner, Fisher, \& Weinberg, 2000). As a result, a growing literature focusing on interventions that seek to promote positive development has emerged that are usually termed positive development.

Positive development programs differ from both treatment and prevention programs. Treatment intervention programs, for example, specifically target identified problem behaviors. Prevention intervention programs similarly specifically target risk and protective factors identified as probable antecedents of negative developmental outcomes. Positive development programs, in contrast, lack the specificity of treatment and prevention programs. They often emerge in response to issues and concerns that are local and particular, culturally bound, and historically situated. They are, in other words, open-ended responses that target the intersection of the developmental and historical 
moment - changing lives and changing times. Consequently, they often not specifically aim to treat identified problem behaviors and prevent specific negative developmental outcomes but to intervene across a broad and diverse array of specific and non-specific positive development construct.

Positive development programs thus do more than seek to "treat" problem behaviors or "prevent" negative developmental outcomes; they seek to promote positive development. They seek to change long-term life course trajectories in positive ways. The goal is to promote positive qualitative change relative the individual's specific life course trajectory at the time of entry into the program, i.e., qualitative life course trajectory change that is both positive and long-term. That is, the aim of such programs is to change the lives of people for the better where "change" is to be understood in ways that are particularly local (i.e., in ways that are relative to relative to each individual's specific life course trajectory at the time of entry into the program) as well as culturally, historically, and developmentally appropriate.

Consistent with the view that youth from even the most disadvantaged backgrounds and the most troubled histories are potential resources to be developed rather than "problems to be managed" (Arnett, 2000; Damon, 2004; Roth, Brooks-Gunn, Murray, \& Foster, 1998), a positive youth development (PYD) approach to the development, implementation, and evaluation of interventions arose from the need for intervention strategies that complement and extend treatment (Benson, Scales, Hamilton, \& Sesma, 2006; Csikszentmihalyi, 1998; Damon, 2004; Damon, Menon, \& Bronk, 2003; Kurtines et al., 2008; Lerner, Fisher, \& Weinberg, 2000). The PYD approach emphasizes 
the development of strengths and potentials in order to foster long-term positive development (Schwartz, 2002; Schwartz, Kurtines, \& Montgomery, 2005; Seligman, Steen, Park, \& Peterson, 2005). The PYD approach thus represents a shift away from the view of adolescence as a period of "storm and stress" and while recognizing the developmental challenges faced by adolescents, it sees youths as "eager to explore the world, gain competence, and acquire the capacity to contribute importantly to the world" (Damon, 2004).

There is mounting awareness of the importance, and growing interest in creating positive development programs designed to encourage and empower young people, particularly troubled youth (Brandtstadter \& Lerner, 1999; Catalano et al., 1999; Larson, 2000; Peterson \& Reid, 2003; Pittman, 2000). Adolescence is a time of transition and profound change (LeCroy, 2004), and it has become the life transition during which the individual chooses and makes a commitment to the values, goals, and beliefs that guide the process of intra-individual and inter-individual functioning (Erikson, 1963). It is the developmental period in which the formation of a sense of identity (i.e., "who one is" and "what one means to others") takes on considerable developmental salience (Erikson, $1959 ; 1968)$.

\section{Outreach Research}

In an effort to translate descriptive models into programs that can be implemented in "usual care" practice in community settings, the Miami Youth Development Project's Changing Lives Program, a PYD intervention program (described in further detail in the following section), has adopted an outreach research model. The PYD perspective has 
arisen because of interest among developmental scientists in using developmental systems, or dynamic, models of human behavior and development for understanding the plasticity of human development and, as well, the importance of relations between individuals and their real-world ecological settings as the basis of variation in the course of human development (Lerner, 2005). In the area of intervention science, for example, Jensen et al. (1999) described two distinctly different models of intervention research, one that has been prominent and highly funded, and a second model that has become of growing interest in the recent literature. The first and most traditional model is "efficacy research" or university lab/clinic based research. Efficacy research is defined by its use of well-controlled university clinic or lab based settings for conducting intervention research. The efficacy model has been historically well funded and has resulted in positive support for a wide range of treatment and prevention interventions (Kurtines et al., 2008). The emphasis on well controlled "efficacy research" has resulted in a gap between university based research and its research in "real world" settings (Kurtines et al., 2008). The use of rigorous experimental controls for unwanted sources of variations in research designs proved difficult to transport into usual care practice. The result has been that the utility and validity of the resulting interventions and their "effectiveness" when applied to "real world" settings is unclear, hence, the gap between the lab-based efficacy of interventions and their effectiveness in the "real world."

A second and less prominent type of intervention research described by Jensen et al. (1999) is referred to as "outreach research." In contrast to "efficacy research," outreach research takes a different perspective and starting point with respect to the evaluation of intervention research. Outreach research emerges out of and remains rooted 
in the "real world" setting. In outreach research, when intervention strategies and intervention research are employed in the settings for which they are designed, the effectiveness of the intervention is already built in (Kurtines et al., 2008). Therefore, there is no real need to "transport" an intervention from a lab-based setting to a "real world" setting and there are no issues of implementation, because the research or practice of the intervention has never been in a lab or clinic to begin with. Another advantage of outreach research is its ability to address the difficulty associated with data collection and cost of running an externally funded research project. The need for outreach research to create community commitment and support generates enduring access to resources that provide the foundation for the type of short-term efficacy and long-term effectiveness research designs needed to evaluate both internal and external validity (Kurtines et al., 2008).

Efforts have been made to integrate the two models of intervention research described by Jensen et al., 1999; Kurtines et al., 2008). "Outreach research" and "efficacy research" can be viewed as complementary approaches to intervention research, but their use as separate or "mixed" approaches should be contingent upon factors relevant to the issue in question. Specifically, the type of intervention proposed, type of outcome expected, population being used, area of implementation, etc. The idea is to advance the utilization of the "outreach research" and "efficacy research" approaches for addressing both "narrow-band/short-term problems" and "broadband/long-term problems." As Kurtines et al. (2008) noted, a researcher may choose to initially develop and refine an intervention approach under controlled conditions in a university lab or clinic setting and then extend that approach to usual care practices in the community to address a "narrow- 
band/short-term" problem. On the other hand, in addressing a "broad-band/long-term" problem, the researcher may choose to develop, refine, and implement an intervention in a "real world" setting, then establish its basic utility and validity under these conditions and conduct long-term evaluations of the program itself.

It has been proposed (Lerner et al., 2000) that through the conduct of research consistent with the "outreach" frame described by Jensen, Hoagwood, \& Trickett (1999) the blurring of the distinctions between science and practice in developmental science will be facilitated. Moreover, such scholarship will provide needed vitality for future progress in the field of human development and, according to Lerner et al. (2000), for the very viability of the academy.

\section{The Changing Lives Program}

Recent reviews of positive youth development programs reveal an accumulation of evidence that (a) these programs can have an impact on young people and (b) that the field has made considerable strides, including increased methodological rigor and sophistication. (Catalano et al., 1999; Ferrer-Wreder et al., 2002). Although a relationship has been shown to exist between participating in positive youth development programs and positive intervention outcomes using quantitative measures, the use of these measures have been limited to self-report responses (Ritchie, 2007). Despite the recent availability of new methodology and the extended growth of qualitative research, the use of qualitative measures and its analysis in evaluating the impact of youth developmental programs continues to be limited (Albrecht, 2007). In this context, a call has been made to move in new research directions - particularly, outreach research - that expand the 
capacity to generate useful knowledge (Jensen, Hoagwood, \& Trickett, 1999; Lerner, Fisher, \& Weinberg, 2000). The measures and analytic strategies that have been developed as part of the Miami Youth Developmental Project (YDP) represent a response to this call (Kurtines et al., 2008).

The Miami Youth Development Project (YDP) is a community-supported positive youth development program that draws on community-university collaboration and principles consistent with the outreach research model (Kurtines et al., 2008) to foster positive youth development among the culturally diverse and multi-problem adolescents attending alternative high schools in the Miami-Dade County Public Schools (M-DCPS), the fourth largest school system in the United States. The YDP applies a developmental intervention approach that fuses the intervention change goals of the three main approaches to intervention (treatment science, prevention science, and developmental science) to create, refine, and implement in real-world settings effective, feasible, affordable, and sustainable intervention programs that meet the community needs (Kurtines et al., 2008).

The intervention currently being implemented by the YDP within the MiamiDade school system is a selective/indicated PYD program known as The Changing Lives Program (CLP). The CLP provides on-site counseling services in all four of the M-DCPS alternative high schools. As described in Montgomery et al. (2008), the primary intervention goal is to create contexts that empower troubled adolescents to transform basic features of their sense of self and identity (e.g., life goals, direction and purpose, etc.) and take control and responsibility over their lives in ways that also result in positive 
change in problem domains, thereby changing their "negative" life pathways into positive ones.

\section{Developmental Theory: A Psychosocial Developmental Life Course Approach}

The "developmental theoretical" framework (i.e., the theory of what changes and how it changes) for the Changing Lives Program - which is referred to a "psychosocial developmental life course approach" - draws from both psychosocial developmental theory (Erikson, 1968) and life course theory (Elder, 1998). From psychosocial developmental theory, this approach adopts a view of the transition to adulthood that begins with the onset of adolescence as the developmental period at which the individual is first confronted with the difficult challenge (and responsibility) of choosing the goals, roles, and beliefs about the world that give life direction and purpose, as well as coherence and integration (i.e., a positive sense of identity). From life course theory, it adopts an emphasis on how individuals construct their own life courses through the choices they make and actions they take within the constraints and opportunities of historical and social circumstances.

The concept of identity derived from psychosocial developmental theory, when unified with the concept of life transitions and turning points derived from life course theory, provides a link between development, context, and human agency - i.e., a coherent conceptualization of individuals as producers of their own development (Kurtines, Montgomery et al., 2008). Linking these concepts highlights the role of identity as the "steering mechanism" guiding the individual's life course. A life course (Elder, 1998) is the pathway of the individual's life as it moves through the sequence of 
socially defined, age-graded events and roles over time, and identity (Erikson, 1968) is the "self-structure" (i.e., the self-constructed, coherent, and dynamic structure) that steers the individual along this path. Thus, the conceptualization does not privilege any particular process or determinant (social/historical, biological/maturational, agentic, etc.) in regulating movement through the life course. Rather, it adopts the view that human agency can be numbered among the multiple determinants (e.g., social/historical, biological, etc.) that play an important role in which the life course is followed and how it is followed.

Although human agency is one determinant among many, it is one that is critical to understanding how individuals work out their lives in particular contexts. As Elder (1998) observed, one of the basic principles of life course theory is that "individuals construct their own life course through the choices and actions they take within the constraints and opportunities of history and social circumstances" (p. 961). Moreover, because a life course is a pathway that the individual, through her/his choices, selects from the array of available trajectories (e.g., institutional, developmental, etc.), the individual is in this sense the "producer" of the pathway of her/his life course. Agency in the selection of particular roles or goals represents a mechanism through which life advantages and/or disadvantages may begin to accumulate, according to the Law of Effect in which behavior is sustained or changed by its consequences (Elder, 1998).

$$
\text { Intervention Theory: A Participatory Transformative Approach }
$$

The "intervention" theoretical framework (i.e., the theory of what to change and how to change it) for the Changing Lives Program, referred to as "a participatory 
transformative approach," draws from both Freire's (1983/1970) transformative pedagogy and multicultural counseling theory (Sue \& Zane, 2006) for its strategies to enhance the critical consciousness of marginalized people about their exclusion from the mainstream. Freire referred to such an approach as transformative pedagogy; a pedagogy of dialogue rather than instruction.

The primary intervention goal is empower adolescents; to create contexts in which young people can transform their sense of control and responsibility in ways that optimize the likelihood of them enhancing the quality of their lives. The CLP uses selfdirected transformative activities as its key behavioral intervention strategy for facilitating empowerment (Kurtines, Montgomery, et al., 2008). While intentionally identifying problems and engaging in transformative activities to solve their problems (changing the way things are for the better), participants become the "experts" and in the process become empowered. Because of such mastery experiences, a participant learns "to see a closer correspondence between their goals and a sense of how to achieve them, gain greater access to and control over resources and...gain mastery over their lives" (Zimmerman, 1995).

\section{Relational Data Analysis}

In order to evaluate research hypotheses regarding change in the content, structure, and organization of self and identity and its meaning and significance, the CLP uses a Relational Data Analysis framework (RDA; Kurtines, Montgomery, Arango, et al., 2008). Relational Data Analysis is a multidimensional, multiphasic framework for unifying data analytic strategies across dimensions (quantitative/qualitative, 
causal/structural, observation/interpretation, etc.) and phases of analyses (conceptual, theoretical, and research analyses). Relational Data Analysis was developed within a relational meta-theoretical methodological framework (Overton, 1998; 2006) for overcoming the splits that have historically characterized methodological meta-theory. The aim was to formulate a practical; ready-at-hand framework that the developmental scientist could use to unify the analysis of developmental change in real life "applied" settings as well as clinic and laboratory settings (Kurtines et al., 2008).

As mentioned above, an "efficacy research" model has been traditionally employed to evaluate intervention programs. The growing efficacy outcome research literature that utilizes quantitative measures and variable-oriented data analytic strategies has provided evidence for a relation between participation in youth development interventions and positive change (Catalano et al., 1999; Lerner, 2005). Although accumulating efficacy research in support of such interventions has advanced the field, a primarily reliance on the use of efficacy outcome research places limits on the types of questions that can be asked and the types of answers that can be obtained (Eichas, 2010). In this context, a call has been made to move in new research directions that expand our capacity to generate useful knowledge (Jensen et al., 1999; Kurtines et al., 2008; Lerner et al., 2000).

The response to move in new research directions has involved exploring new directions in developmental theory, resulting in the evolution of the developmental and intervention theories that are implemented in the CLP (i.e., theories of what changes and how it changes and what to change and how to change it) (Kurtines et al., 2008). It was 
also in this arena that the CLP found it most useful to draw on (and extend) emerging relational methodological meta-theory (Overton, 1998; 2006). Moreover, because of the nature of the CLP's population and their problems, the CLP sought to articulate a practical, ready-at-hand framework that the developmental scientist could use to address complex issues of documenting life course change (Kurtines et al., 2008).

Consistent with the intervention aims of the CLP, the research aims of adopting an RDA framework include (1) identifying patterns of differential positive qualitative (structural organizational) change in the subjective meaning and significance of participant life course experiences in general, and of their experiences of self and identity in particular, and (2) identifying the positive and problematic quantitative (dimensional) changes that predict, underlie, or accompany structural organizational change (Eichas, 2010). Within RDA, quantitative (causal) variational change and qualitative (structural organizational) transformational change are viewed as two sides of a unified explanation, a conceptualization that more closely approximates the "relational" meta-theoretical ideal of overcoming the splits that have historically characterized methodological meta-theory (Overton, 1998; Kurtines et al., 2008).

The use of complementary qualitative free-response measures and quantitative fixed response measures in developmental intervention outreach research effectively expands the scope of intervention outcome investigation beyond the examination of properties identified as theoretically meaningful prior to conducting the research, i.e., as is usually done under cross-sectional and longitudinal quantitative research and “efficacy" research designs using fixed response measures (Eichas, 2010). Although there 
are many advantages to the use of such methods of data collection, an important limitation of their use is that fixed response measures rule out in advance, the possibility of detecting response properties that are uniquely meaningful (ordinary language meaning, theoretical meaning, or both) within a specific population not previously studied or newly emergent properties in a previously studied population (Eichas, 2010). Relational Data Analysis, in contrast, provides a method for detecting, isolating, identifying, and rendering explicit and intelligible previously undetected or newly emergent "real world" properties in ways that are not possible using traditional crosssectional and longitudinal research designs using fixed response quantitative measures.

\section{The Outcome Mediation Cascade Model}

The second of the two studies described in this paper builds on previous work by Eichas (2010) in evaluating a hypothesized Outcome Mediation Cascade (OMC) model, an integrated model for investigating the empirical intersection between intervention and developmental processes. Silverman, Kurtines, Jaccard, \& Pina (2009), have highlighted the need within the treatment literature of moving beyond the standard comparative randomized clinical trial outcome studies (Eichas, 2010). A core constraint of such evaluation models is that they are limited to addressing questions of what works and for whom does it work differently and unable to address the issue of how interventions work (outcome and mediation) (Eichas, 2010). As Silverman et al. (2009) noted, during the early stages of developing and evaluating interventions, the focus is necessarily on evaluating whether interventions work (or do not work). As evidence accumulates that interventions work, however, the issue of how they work moves to the foreground 
because of its implications for enhancing and maximizing intervention efficiency, efficacy, and effectiveness (Eichas, 2010).

Drawing on the recommendations of Silverman et al. (2009), Eichas et al. (2010), reported an investigation of the CLP using an integrative quantitative evaluation model that utilized a Structural Equation Modeling (SEM) framework approach for measurable quantitative constructs hypothesized to make up core component processes of self and identity (e.g., exploration, commitment) and measurable qualitative narratives of participant's sense of self and identity. That is, the study utilized an evaluation model integrating treatment, prevention, and developmental perspectives in studying the mechanisms that underlie both intervention change and developmental change in the core components of self and identity. Using a model that drew on treatment outcome mediation models and prevention longitudinal mediation models, the study's findings highlighted the need for developmental intervention scientists to draw on the work of treatment and prevention science in developing evidence based theory-driven PYD intervention strategies for facilitating advances in both efficacy and effectiveness of developmental intervention PYD programs (Eichas et al., 2010).

In an extension of this work, Eichas (2010) went on to update the conceptual and evaluation models for this developmental intervention approach to also include "developmental cascades." The term "developmental cascades" is used to describe the spreading of progressive adaptation processes across domains of functioning. It refers to the cascade that results from the empirical intersection of intervention and developmental processes. At the individual intervention level, an Intervention $\leftrightarrow$ Developmental cascade 
is the result of an intentional antecedent individual intervention process that has an effect on a targeted developmental process (typical or atypical; positive or problem) that, in turn, has a subsequent hypothesized (or not hypothesized) progressive "carry over" effect to other empirically predictable developmental processes (typical or atypical; positive or problem) with a cumulative direction of effects likely to result in an empirically predictable positive or negative longitudinal development outcome (Eichas, 2010). The possibility of developmental cascades, according to Masten and colleagues, has profound implications for intervention and prevention science. "It becomes critically important to study the processes, timing, and conditions of spreading and amplifying effects and to learn when to do what to interrupt negative progressions," (Masten et al., 2005, p. 741). The possibility of developmental cascades and progressive adaptation processes spreading across domains of functioning - particularly those that spread across positive and problem domains - has equally profound implications for developmental intervention science and the effort to integrate positive development and prevention approaches.

Within the current PYD literature, the possible cascading effects of positive interventions on problem outcomes have been so far understudied. Moreover, the more basic question of whether specific intervention strategies to promote positive youth development outcomes are also able to decrease or prevent specific problematic behaviors and the causal mechanisms by which such change may occur (Catalano et al., 2002), has also remained unaddressed. As the primary reasons for this gap in the literature can be attributed to the lack of tools that were well suited to evaluate singleintervention/multi-outcome research designs, the OMC model was developed to address this need. Specifically, the goal was to evaluate the relative contributions of positive 
intervention strategies to promoting positive development and interrupting negative developmental progression via direct effects, hypothesized indirect (mediated) effects, and in the OMC evaluation used in this study, hypothesized cascade effects, i.e. positive outcome $\rightarrow$ problem outcome (Eichas, 2010). Figure 1 illustrates the basic OMC model.

Figure 1: A Three-Component Outcome Mediation Cascade (OMC) Model

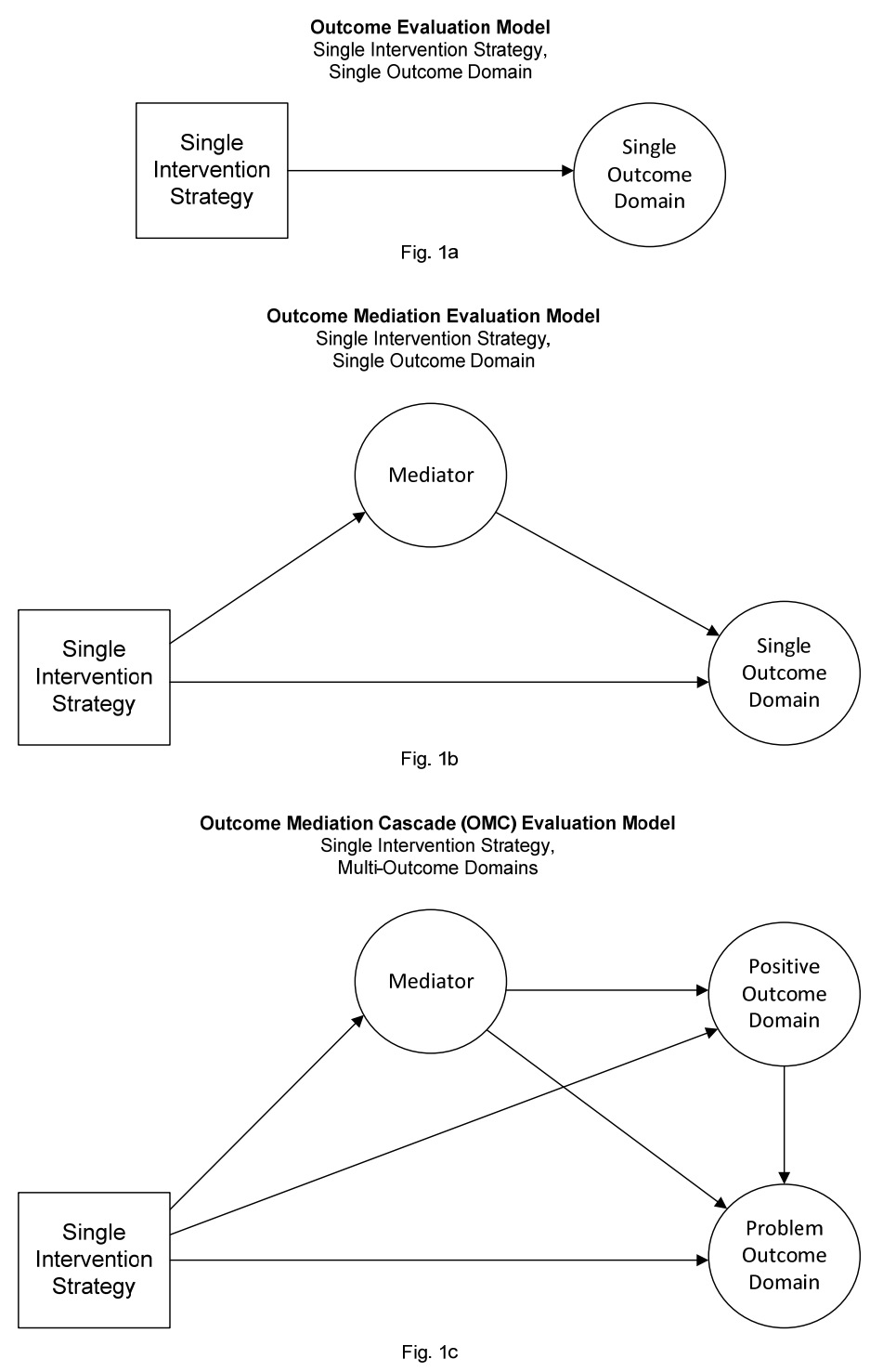


Preliminary investigations into its feasibility have provided evidence consistent with the hypothesis that in addition to having an effect on targeted positive outcomes, PYD interventions are likely to have both direct (unmoderated and moderated) and indirect (mediated) effects on untargeted problem outcomes (Eichas, 2010). Indeed, the second of the two studies reported here attempts to answer the call made in Eichas (2010) for further evaluation of the mediation and moderation of intervention $\leftrightarrow$ developmental cascades.

\section{The Current Studies}

Cognitively-focused identity exploration has been conceptualized as an important mediator of the development of a positive sense of identity and as an intervention target for positive youth development (PYD) interventions (Albrecht, 2007). Recent findings provide evidence that PYD interventions may be effective in promoting differential intervention change in self-reported self-construction among troubled adolescents in the short-term (Eichas et al., 2010). No studies have evaluated the effectiveness of PYD interventions in promoting cognitively-focused identity exploration collected through the use of free-response open-ended qualitative measures of critical thinking as a cognitivelyfocused identity exploration "competence" as part of the identity formation process. One reason for this may be the relative lack of measures that tap the use of cognitive competence and psycholinguistic meaning making in addressing life challenges. The findings reported in Study I attempted to address this need. Study I also seeks to advance the use of qualitative methods employed by developmental researchers by providing support for the practical utility of the use of Relational Data Analysis coding templates. 
In doing so, the current study also seeks to provide researchers with a framework in which to utilize the CPSS and CPSS-QE in evaluation of positive developmental programs for troubled youth.

Following from the development of the qualitative measure of cognitive competence in Study I, Study II investigated hypothesized intervention $\leftrightarrow$ developmental cascades in the Changing Lives Program - a positive youth development intervention using an Outcome Mediation Cascade model, an expansion of the outcome mediation model. The aim was to facilitate the identification of change processes through which specifically targeted prevention and developmental intervention strategies may contemporaneously or progressively generate differential outcome in specific outcome domains (positive, problem, or both; quantitative, qualitative, or both). 


\section{LITERATURE REVIEW}

\section{Identity Exploration Style}

Beginning with the theoretical writings of Erikson $(1950 ; 1982)$, the process of exploration has been viewed as central to the formation of an identity. The recognition of the importance of exploration is evident in the considerable empirical work (e.g., Grotevant and Cooper, 1981; Marcia and Archer, 1993) generated by Marcia’s (1966; 1980) pioneering work on the identity status paradigm. In adapting Erikson's concept of identity for empirical research, Marcia identified exploration and commitment as the two basic dimensions for defining the individual's status with respect to achieving an identity. By simultaneously considering an individual's levels of exploration and commitment, Marcia was able to derive four statuses for characterizing an individual's development toward a mature identity. These statuses are Achievement, Moratorium, Foreclosure, and Diffusion (for further information on the statuses see Marcia, 1980; 1993; Waterman, 1993). Consistent with the psychosocial developmental theoretical tradition, Marcia defined exploration as the search for a revised and updated sense of self, whereas commitment was taken to symbolize "the [adherence] to a course of action, a kind of settling down"' (1988, p. 213). Exploration is thus a process of examination and discovery of whom and what one might be, with commitment to an identity being a consolidation of this process. As such, exploration might be seen as a basic process underlying the formation of an identity.

Extensive literature has established a link between identity exploration style and identity status. Literature has found Informational Identity Style to be positively related 
with Moratorium and Achievement (Berzonsky, 1989), Normative Style with Foreclosure (Berzonsky and Neimeyer, 1994), and Diffuse/Avoidant Style with Diffusion (Berzonsky, 1989; Streitmatter, 1993). A study by Schwartz et al. (2000) yielded similar findings such that Identity Achievers and those in Moratorium status scored significantly higher in Informational Identity Style, while Foreclosures scored significantly higher in Normative Identity Processing Style and participants in Diffused status scored highest for the Diffuse/Avoidant Style (Schwartz et al., 2000).

However, this extensive literature is built upon cognitively-focused identity exploration data collected through the use of fixed-response self-report quantitative measures of identity style, rather than open-ended qualitative measures of critical thinking (as a cognitively-focused identity exploration competence).

\section{Identity Exploration Competence (Problem-Solving)}

The availability of a free-response cognitive performance measure of the use of critical thinking competence as a cognitive self-construction identity formation process, and a free-response narrative expressive performance measure of the use of meaning making as a psycholinguistic self-construction identity formation process, each postulating differing but complementary exploration processes (and with distinct component-appropriate measurement techniques), opens up considerable potential for knowledge development concerning the exploration process. Berman et al. (2001), for example, have noted that cognitive competence constructs have been historically measured using performance-based "tests of limits" (e.g., Flavell and Markman, 1983) rather than self-report methods, and these performance-based measures often lacked 
content relevance for identity issues and revealed only moderate success establishing a link between cognitive competence and identity status. The current identity formation literature, as a consequence, has tended to focus on non-competence indicators of cognitively focused identity exploration. However, recent conceptual advances in the understanding of critical thinking and critical discourse (Habermas, 1979) and advances in the application of Relational Data Analysis (RDA) (Kurtines, et al., 2008) have opened up the specific possibility of the measurement of critical thinking. Relational Data Analysis is a ready at hand method for identifying free-response qualitative categorical linguistic properties of developmental research concepts and constructs that extend and complement the dimensional properties evaluated by existing fixed-response quantitative measures.

\section{Critical Thinking and Critical Discourse}

In developing the theoretical framework for a measure of critical thinking, this paper draws on, and extends, work on critical thinking and critical discourse (Habermas, 1979). In doing so, the focus has been on the process by which individuals acquire a complex set of cognitive and communicative competencies, including the capacity for critical thinking and critical communication (Habermas, 1979). In the current study, the focus has been primarily on critical thinking.

The psychosocial developmental life course approach defines change as developmentally driven only up through childhood, emphasizing instead the self-directed nature of the developmental process in adolescence and adulthood (Brandstadter and Lerner, 1999; Lerner and Busch-Rossnagel, 1981). Thus, after adolescence, the 
emergence of critical cognitive competencies is hypothesized to provide the basis for the emergence of a self-directed agentic self (Sheldon et al., 2003), conceptualized for the purposes of the current study as a construction of the human mind that serves a wide variety of important functions, such as, (a) feeling and thus hopefully determining what is "right" for the organism, (b) generating and selecting long-term goals and plans for the organism, and (c) motivating behavior over long periods of time, particularly adaptive behavior which is not necessarily enjoyable for its own sake.

Drawing on this work, Berman et al. (2001) have identified three problem-solving processes hypothesized to facilitate the exploration process and the emergence of a selfdirected agentic self. Creativity is the degree to which the individual is innovative or inventive in generating alternatives for life choices encountered during the exploration process. Suspension of judgment represents the degree to which the individual is capable of adopting multiple perspectives with respect to life choices, that is, considering positive and negative aspects (i.e., "pros" and "cons") for each alternative. Critical evaluation represents the degree to which the individual is capable of questioning or challenging alternatives and willing to change one's original choice in the context of "a more viable alternative."

Accordingly, a cognitive competence measure that specifically uses both quantitative (dimensional) performance-based and free-response qualitative (linguistic content) data to tap domains relevant to identity issues has been developed, the Critical Problem-Solving Skills Scale (CPSS) (Ferrer-Wreder, 2002). In administering this performance-based measure, participants are encouraged to 1) generate as many potential 
alternatives as possible for solving life-choice dilemmas (thinking creatively), 2) to suspend judgment by providing justifications for alternatives they disagree with (thinking hypothetically), and 3) to indicate a willingness to question or challenge one's own choices (thinking critically). Thus, the four subscales of the CPSS tap the three previously discussed problem-solving processes: creativity, suspension of judgment, and critical evaluation (Berman, Schwartz, Kurtines\& Berman, 2001). Much of the previous work on cognitive competence has tended to focus on creative and hypothetical thinking. Given this, the work on cognitive competence described here has been specifically on the development of a free-response performance-based measure of the willingness to question or challenge one's own choices (critical thinking), rather than on creative or hypothetical thinking.

For the development of the measure, Study I used a Relational Data Analysis (RDA) approach in the development and evaluation of a qualitative measure of a core positive developmental construct, critical thinking. Relational Data Analysis is a multidimensional, multiphasic framework for unifying data analytic strategies across domains (quantitative, qualitative) and phases of analyses (conceptual, theoretical, and research analyses) (Kurtines et al., 2008). The study data were drawn from a gender inclusive, multi-problem, multi-ethnic sample of adolescents in urban alternative high schools in a positive youth development program.

\section{Critical Thinking in Adolescence}

Contemporary developmental theory holds that adolescence is a stage of particular importance for the development of critical thinking skills. Indeed, the 
development of critical thinking skills has long been recognized as a primary goal of education in this period (Marin \& Halpern, 2011). The ability to think critically is essential for success in the contemporary world where the rate at which new knowledge is created is rapidly accelerating. Although most educators agree that it is important to teach adolescents the skills of critical thinking, there is much less agreement about the way in which learning to think critically is best achieved, especially for students in high school. There are few empirical studies of the development of critical thinking at the high school level; most of the research has been confined to post-secondary education (Ruggiero, 1998). Given the fact that adolescence and young adulthood are recognized by brain researchers as optimal for the development of higher order cognitive processes, the current studies focused on critical thinking tools designed especially for adolescents.

\section{Transformative Goal Attainment}

My study draws on previous work on the Transformative Goal Attainment conducted by Swenson (2005) and a Developmental Intervention approach on promoting positive development literature. As Swenson (2005) noted, the concept of Goal Attainment Scaling has a long history. Kiresuk, Smith, and Cardillo (1979) proposed Goal Attainment Scaling (GAS) as a valuable tool for not only describing treatment objectives but also for facilitating measurement and evaluation of program elements. Historically, intervention researchers viewed goal attainment scaling as a flexible, reliable, valid, and systemically useful approach to measuring change within both group and individual settings that could be used with adolescents who display various conduct 
problems (Emmerson \& Neely, 1988; Fleuridas, Rosenthal, Leigh, \& Leigh, 1990; Maher \& Barbrack, 1984; Paritzky \& Magoon, 1982).

Specifically, the GAS method includes a clear, concise statement of a clientgenerated goal, along with a participant, self-reported, outcome rating of goal attainment on a 5 -point Likert scale $(1=$ No progress to $5=$ Complete Success). As traditionally employed, the goal attainment ratings provide quantitative data points that are useful as a means for outcome evaluation. More importantly however, if employed with other complementary outcome measures, the quantitative goal attainment scale ratings could highlight or rule out goal attainment (as an index of mastery experience) as a possible explanatory process component with respect to treatment outcomes (Maher \& Barbrack, 1984). Furthermore, the goal statements themselves could provide various types of qualitative information that may be coded, categorized, and examined across participants for patterned associations with goal attainment success/failure, and/or other developmental domains of interest.

Swenson (2005) reported the development of the Transformative Goal Attainment Scale. According to that study, the TGA provides a quantitative index of the extent to which participants report progress in achieving their most important life change goals, i.e., transformative life course change goals. As Swenson (2005) noted, goals are often considered a necessary element for promoting change, and are frequently incorporated into various types of individual and group treatment settings (de Rosenroll, 1988). Moreover, it has been suggested that the construction of goals within intervention settings not only helps to align the expectations of the facilitator(s) and the participant(s), but also 
helps to initiate and thus foster rapport within a relatively short time span (Moyer \& de Rosenroll, 1984). Furthermore, it helps to improve validity between the facilitators as well as the raters. Thus, in accordance with many emerging perspectives on positive development (Montgomery et al., 2008), the setting and striving for goals seems a reasonable means by which to engage intervention participants in meaningful, selfdirected actions that could result in a sense of mastery and ultimately, empowered agency. Furthermore, in addition to being useful within outcome evaluation, the setting of goals and the monitoring of progress could prove to be an effective method for highlighting and revealing transformational processes or mechanisms of change that occur during intervention participation (Maher \& Barbrack, 1984; Paritzky \& Magoon, 1982). Some of these effective methods are revealed through journal entries as well as ongoing exercises that chart progress from the first session until the termination session. The purpose of these sessions is to promote self-discovery and engage the adolescents in identity-related activities, thus fostering personal expressiveness.

\section{Critical Thinking and the Achievement of Life Goals}

The evaluation of positive identity outcomes drew on the conceptualization that the life goals that emerge during the transition to adulthood are an expression of the future-oriented component of the adolescent's sense of self and identity and represent the means by which youth begin to give direction to their lives as active producers of their own development (Brandtstadter \& Lerner, 1999). The articulation of life goals thus represents an important marker of the development of a sense of self and identity as it emerges during adolescence. As noted, RDA theoretical analyses (Rinaldi et al., 2011) 
identified the emergence of a personally expressive life goal as a theoretically relevant structural organizational change in participants' subjective sense of self and identity.

Under conditions of equilibrium, i.e., under "normal" conditions, goal-oriented behavior tends to be oriented towards goals that are actually or potentially attainable under existing conditions. Problems arise when changing conditions create an environment that disturbs or disrupts such behavior. In this context of disequilibrium, successful problem-solving involves re-establishing an equilibrium that restores successful goal-oriented behavior. The capacity for critical thought, then, implies that individuals develop the ability to create, reconstruct (where necessary) and evaluate goals that could potentially shape the direction of their future lives.

Recent research has provided support for the idea that critical thinking ability has a significant effect on both the selection and the pursuit of life goals in late adolescence, mainly through its interaction with the implicit assumptions that underlie such goals (Tanaka \& Kusumi, 2012). Furthermore, problem-solving skills have been shown to be instrumental in the choosing developmentally relevant goals (Hoppman, Coats, \& Blanchard-Fields, 2008). Given that the setting of these goals are considered to be a key developmental task for this stage of the life course, the importance of cognitive competency development becomes even more salient.

\section{Critical Thinking and Problem Outcomes}

The literature on adolescence suggests that this stage of development is characterized by the onset of and/or increase in a number of co-occurring externalizing problems, including aggression, delinquency, substance use, and other high-risk problem 
behaviors (Arnett, 1999). Continued participation in these activities carries the risk of severe adverse outcomes, such as incarceration, drug abuse, injury and death from automobile accidents, school dropouts, and serious family conflicts. Hence, it is not surprising that efforts to reduce and prevent behavioral problems in adolescents have received considerable attention in recent years (Dryfoos, 1998).

Extrapolating from social problem-solving theory and research with other populations (D'Zurilla \& Nezu, 1999), several investigators have noted the potential importance of social problem solving in adolescents for preventing externalizing behavior. It is assumed that adolescents with greater problem-solving ability will respond more appropriately and adaptively to problematic and choice situations in which externalizing behavior is a response alternative. A number of studies have reported a link between problem-solving deficits and aggression in children (e.g., Lochman \& Dodge, 1994; Lochman \& Lampron, 1986). Similar results have also been found in adolescents (Deluty, 1981; Lochman, Wayland, \& White, 1993; Richard \& Dodge, 1982). Adolescent problem solving has also been found to be associated with "acting out" behavior and delinquency (Freedman et al., 1978; Platt et al., 1974).

Previous research on the links between problem-solving and emotional disorders has consistently linked depression, anxiety, and worry with a deficit in problem-solving skills (Anderson, Goddard, \& Powell, 2009). However, much of this research has failed to directly assess "real-life" problem-solving, relying on self-appraisal or responses to hypothetical problems. Furthermore, the ecological validity of current problem-solving assessment tools has been called into question, and recent investigations suggest that they 
may be insensitive to deficits in "real-life" problem-solving (Anderson, Goddard, \& Powell, 2009). As such, it is important that accurate and valid assessments of problemsolving are developed since social problem-solving plays a significant role in psychological adjustment, constituting an important coping strategy that has the potential to reduce or minimize psychological distress (D'Zurilla \& Nezu, 1990). 


\section{STUDY I: THE DEVELOPMENT OF THE CRITICAL PROBLEM-SOLVING SKILLS SCALE - QUALITATIVE EXTENSION}

The Development of a Free-Response Performance-Based Indicator of Critical Evaluation

As Rinaldi et al. (2011) have noted, the use of qualitative free-response measures in developmental research broadens the scope of the investigation beyond the examination of properties identified as theoretically meaningful prior to conducting the research, i.e., as is usually done under cross-sectional and longitudinal quantitative research designs using fixed-response measures (Eichas et al., 2010). Although there are many advantages to the use of such methods of data collection, an important limitation of their use is that fixed-response measures rule out in advance the possibility of detecting response properties that are uniquely meaningful (ordinary language meaning, theoretical meaning, or both) within a specific population not previously studied, qualitatively transformed, or involving temporal change (e.g., developmental, historical, longitudinal, or intervention change) resulting in newly emergent properties in a previously studied population (Rinaldi et al., 2011).

\section{Relational Data Analysis: The Qualitative Extension (QE) Method}

In response to the need for the inclusion of measures in positive identity research capable of detecting response properties that are uniquely meaningful within a population of interest, $\mathrm{RDA}$ uses the $\mathrm{QE}$ method in the construction and evaluation of qualitative extensions for available fixed-response measures. In doing so, RDA uses a qualitative extension module (QEM) to facilitate the creation of qualitative extensions and for 
maximizing the likelihood of collecting the fullest range of participant generated openended content properties. Specifically, the QEM was designed to provide a set of standardized meaning and significance questions and probes intended to provide a readyat-hand method for adding a qualitative data collection component to each of the core battery of quantitative measures used in our program of research. The use of the QE method with these measures has made it possible to elicit participant free-response data that provide access to the subjective meaning and significance of the content of the theoretical constructs targeted by the diversity of questionnaires, scales, dimensions, etc. in quantitative core battery used in the Changing Lives Program. The present study describes the use of the Qualitative Extension method in the development and evaluation of a qualitative measure of a core positive developmental construct - critical thinking.

\section{Method}

\section{Participants}

Participants for this study were drawn from the Miami Youth Development Project archival data. The Miami Youth Development Project (YDP) is an outreach research program that promotes positive youth development via a partnership between Florida International University in Miami, Florida and local public schools and community resources. Participation in the Changing Lives Program (CLP) is limited to self-referrals, or students referred by the school counselor or teachers. As part of each school's counseling program, the CLP counseling groups are organized and implemented through each school's administration. Alongside the group of students identified to partake in the CLP, a separate group was also selected for the comparison control 
condition. All of the students that participated in the comparison control condition were selected randomly from a pool of students not referred or self-referred by school counselors or administrators. The participants in the comparison control condition were further selected for not having participated in any of the counseling and guidance programs prior to or during their involvement with the YDP. All study participants and a parent or legal guardian completed an Internal Review Board (IRB) approved parent consent and student assent form before participating in any research.

The current study utilized an archival sample of 259 students who have participated in the Changing Lives Program of the YDP since 2002. The multiethnic sample of intervention participants were compromised of approximately $46 \%$ AfricanAmerican, 35\% Hispanic, 8\% White/Non-Hispanic, and 6\% Other - with 56\% females and $44 \%$ males - a constitution that is typical of the schools' demographic make-up. The age of the participants ranged from 14 to 18 years of age. With regard to the socioeconomic characteristics of the sample, $38 \%$ of annual family incomes were below $\$ 21,000$, while $17 \%$ were over $\$ 41,000$. Seventy-four percent of the participants had at least one parent who completed high school, $50 \%$ had two parents who completed high school, and $31 \%$ had at least one parent who completed a bachelor's degree.

Procedure

Every intervention group was structured and implemented by an intervention team that consists of one group facilitator, one co-facilitator, and one or two group assistants. All group facilitators and co-facilitators were graduate level students enrolled in either a doctoral developmental science program, or a master's level mental health counseling 
program. Undergraduate psychology students who have been trained in the administration of the measures and in participant tracking procedures served as group assistants. The group facilitators and co-facilitators served in a counseling capacity that utilized the CLP's participatory transformative approach (Montgomery et al., 2008). The intervention groups met for approximately 45 minutes to 1 hour every week for approximately 8 to 12 weeks during the fall and spring semesters.

Participants' assessments were carried out by undergraduate psychology students serving as research trainees at school grounds and during school hours in the week preceding the commencement of the semester session and the week after its end. The training administered to those undergraduates includes instruction concerning confidentiality issues, assessment administration, dress code, high school regulations, interviewing strategies, and role-playing of interviews.

Measures

The Critical Problem-Solving Skills Scale (CPSS)

The Critical Problem-Solving Skills Scale (CPSS) was used to assess participants' problem-solving competence. The CPSS is a group administered performance-based measure that contains four subscales that tap three problem-solving processes: creativity, suspension of judgment, and critical evaluation (Berman, Schwartz, Kurtines \& Berman, 2001). The concept of creativity includes the degree to which one is innovative in generating alternatives for approaching life change goals. Creativity is tapped by the Generation of Alternatives (GA) score, which is the total number of different and distinct alternatives generated for both dilemmas. The participants were asked to generate a 
number of approaches to achieving a previously indicated life change goal, and their performance appraisal was based on (i) the number of alternatives that were created (quantitative scores), as well as (ii) how many of those alternatives were judged to be qualitatively different from each other, i.e., possessing some unique content properties. Suspension of judgment is the extent to which one is capable of adopting multiple perspectives with respect to these alternatives. Suspension of judgment is tapped by the Decentering, Positive Alternatives (DPA) and the Decentering, Negative Alternatives (DNA) scores (the total number of "cons" and "pros" each participant generated for her/his own "best" and "worst" alternatives). The participants were asked to select one of their alternatives as a "best choice," and another as their "worst choice." The participants were then asked to suspend their judgment with respect to their evaluation of these two alternatives and list as many "good things" about their "worst choice" as they are able to, as well as list as many "bad things" about their "best choice" as they can. Critical evaluation is the degree to which one is capable of questioning or challenging the alternatives and willing to change one's original choice in the context of a more viable alternative. Critical evaluation is tapped by the Modification (MO) score (the number times a participant changes (modifies) his/her original choice and provides a "justification" for the change based on his/her previous "pros" and "cons" for that alternative). In other words, this final item on the CPSS asks participants to reconsider their "best choice" in light of the critical thinking exercise. 


\section{Relational Data Analysis}

The Data Analyses Plan for this study was comprised of the complete RDA threestep psychometric analyses (reliability and validity estimates) of the RDA Coding Template constructed during the RDA Theoretical Analysis Task. A condensed description of the RDA process is provided below.

\section{Conceptual Open Coding (COC)}

During the Conceptual Analysis phase of RDA a set of theoretically neutral conceptual coders (coders systematically selected to represent no particular theoretical perspective) will be assembled to use the grounded theory concept of "open" coding and the method of constant comparison (the process of the comparison of content properties of participant response data) for similarities and differences (i.e., the process of the comparison of the properties of participant response data for creating and eliminating categories) to identify the unique properties that define the basic pool of conceptual categories in the raw response data, to use those properties to identify all qualitatively different (non-overlapping) conceptual categories in the data set, and to formulate and document an explicit description of the unique property that the response data of each conceptual category share in common (similarity) and that they do not share with any other categories (difference) (Lewis Arango, et al., 2008; Kurtines, et al., 2008). This open coding process draws on an ordinary language perspective (Wittgenstein, 1953) and is operationalized as the comparison of the properties of participant response data for the purpose of creating and eliminating "ordinary language" content groups of responses with each group of responses defined by a single unique ordinary language content 
property. In other words, this first set of coders identify all of the unique content properties in a particular data set and thus break the data down into the largest possible set of basic elements, with each element representing the most basic conceptually meaningful units of content from an ordinary language perspective (Eichas, 2010). Theoretical Open Coding (TOC)

During the Theoretical Analysis phase of RDA, a set of theoretically committed coders (coders systematically selected to be representative of a particular theoretical perspective) will be assembled to work collaboratively on five tasks, each of which generates a particular type of outcome. Specifically, during this phase, the theoretical coders will be asked to use the method of constant comparison to review and discuss the content categories identified in the previous phase from the perspective of the guiding theory.

\section{Theoretical Analysis Task 1: Identifying Theoretical Categories}

Using the developmental life course perspective that is described above, the theoretically committed coders are tasked with identifying the smallest number of theoretically meaningful categories and sub-categories from the initial pool of conceptual categories identified in the raw data during the conceptual analysis, and generating a set of property descriptions of the unique properties that define each category (and associated sub-categories). As part of generating this outcome, theoretical coders are asked to formulate and document an explicit description of the unique property that the response data of each theoretical category share in common (similarity) and that they do not share 
in common with any other categories (difference) (Lewis Arango et al., 2008; Kurtines et al., 2008).

Theoretical Analysis Task 2: Identifying Relations Between Categories and Identifying Structural Organizational Properties Between and Within Theoretical Categories

During Task 2, the theoretically committed coders are asked to identify a theoretically hypothesized structural organization between the identified theoretical categories and sub-categories (flat, nested, hierarchical, etc.) and to construct a Structural Tree Chart (STC). An STC is a means for visually representing the structural organization among the categories, sub-categories, and properties identified during the TOC. (Lewis Arango et al., 2008; Kurtines et al., 2008).

Theoretical Analysis Task 3: Identifying Mechanisms of Change

In Task 3, the theoretically committed coders are tasked with identifying and specifying hypothesized plausible mechanisms that provide a theoretically meaningful (and plausible) explanation of change over time (causal/functional, structural/transformational, etc.) in the theoretical categories. This third outcome is only generated when the theoretical analysis involves a temporal analysis of change (e.g., a developmental analysis, an historical analysis, etc.) (Lewis Arango et al., 2008; Kurtines et al., 2008).

Theoretical Analysis Task 4: Constructing a Decision Tree Chart (DTC)

During Task 4, the unique properties that define each category (and associated sub-categories) are translated into decision rule formats and the formulated rules are used in the construction of a Decision Tree Chart (DTC). For this task, the theoretical coders construct a DTC to be used for classification coding of un-coded free-response data into 
the categories and sub-categories that emerged out of the open coding process during the theoretical analysis phase (Kurtines, et al., 2008).

\section{Theoretical Classification Coding (TCC)}

If the psychometric analysis during the Theoretical Analysis Phase yields moderate to high estimates for the reliability of the RDA coding template and preliminary evidence for its discriminant and concurrent (external) validity, the Theoretical Analysis Phase ends and the RDA will begin the transition to the third and final phase, the Research Analysis Phase. During this phase, the theoretical coders assembled now function as an advisory panel of theoretical "researchers" whose theoretical expertise falls within the domain of study's guiding theory. The theoretical researchers will work collaboratively to generate initial research hypotheses that are refined, elaborated, extended, and subjected to appropriate research analysis within the context of the project's research design, population, measures, etc., evaluating both quantitative and qualitative research hypotheses. These tentative research hypotheses are subsequently further refined, elaborated, and extended by the ongoing flow of findings generated during the research analysis phase using analytic methods drawn from both the qualitative and quantitative research traditions (Kurtines et al., 2008).

The TCC is conducted as the last step in the RDA Theoretical Analysis Task 4 by theoretically neutral coders for use as part of the Theoretical Analysis Task 5 psychometric analyses. A new set of theoretical neutral coders is assembled to perform the TCC task of the RDA process. The task of training the TCC coders is essentially the same as the task of training the COC coders, with appropriate modifications. For this 
task, the copies of the same Sample Coding Deck used during the COC and TOC, the Coding Glossary, DTC, and the category descriptions developed during the TOC are provided. The panel then conducts the second coding procedure of the initial sample set using all the information developed during the TOC phase of the RDA process.

Theoretical Analysis Task 5: Psychometric Analyses: Reliability and Validity Analyses of an RDA Coding Template (RDA-CT)

The last task in the RDA Theoretical Analysis Phase is to conduct a three-step preliminary psychometric analysis (reliability and validity estimates) of the DTC constructed in the previous phase, a process referred to as a Psychometric Analysis of the Theoretical Classification Coding Decision Tree Chart (PA-DTC).

Theoretical Analysis Task 5, Step 1: Estimating inter-coder reliability. In the quantitative/experimental research tradition, reliability is the extent to which a measurement method is repeatable and yields consistent results. Given that the most important outcome of the conceptual and theoretical analysis phases of RDA is the identification of conceptual and theoretical categories, an important psychometric property of identified coding categories is the consistency with which they can be used to classify accurately participant response data into the theoretical categories (i.e., the reliability of the coding categories). For purposes of estimating inter-coder consistency of an RDA-CT, RDA standard psychometric analysis of coding templates uses the intercoder agreement percent among the coders for each category level to provide an estimate of inter-coder reliability for the TOC and TCC (Ritchie, 2007, Kurtines, et al., 2008).

Inter-coder agreement is also estimated using Fleiss' kappa. Fleiss' kappa incorporates a correction for chance agreement. Furthermore, the use of Fleiss' kappa 
allows for greater generalizability as it can be used to measure the significance of the agreement among multiple raters with the significance level being adjusted relatively to the number of comparisons made, as opposed to Cohen's kappa which only tests for the significance of two raters at a time (i.e., in pairs of ratings) (Fleiss, 1973). If the agreement is found to be high, it is assumed that the ratings accurately reflect the dimensions they are presumed to. If kappa is found to be low or 0 , this would indicate a high degree of measurement error (Fleiss, 1973). Agreement from 0 to .20 assumes slight agreement, .21 to .40 assumes fair agreement, .41 to .60 assumes moderate agreement, .61 to .80 assumes substantial agreement, and .81 to 1.00 assumes almost perfect agreement.

Theoretical Analysis Task 5, Step 2: Estimating construct validity. In the quantitative/experimental research tradition, validity is said to be the extent to which a measurement method measures what it is supposed to measure. The concept of construct validity was first introduced by Cronbach and Meehl in 1955 to extend the two major types of psychometric validity recognized up to that time, "content" and "predictive" validity. From the time it was introduced, "construct" validity was recognized as the most important type of psychometric validity as well as the most difficult to establish (Anastasia \& Urbina, 1997). Construct validity requires the accumulation of evidence that a measurement method is linked to the theoretical construct it is hypothesized to represent. As a result, estimating construct validity is a process is that is often long and complex, involving at least three basic types of evidence: criterion-related (includes predictive and concurrent), convergent, and discriminant validity (Anastasia \& Urbina, 1997; Campbell \& Fiske, 1959; Nunnally, 1978). 
In the case of construct validity, the evidence that a measurement method is a "valid" measure of a particular construct tends to be indirect, though not necessarily so. In the case of the two IQ measures, for example, if one of the measures is a "newly" developed measure and the other has been more extensively validated, the same correlation coefficient that might be interpreted as providing convergent validity might also be interpreted as providing concurrent validity for the newly developed measure, i.e., that the newer measure (with previously unknown properties) has now been found to share a significant proportion of variance with an already established measure of the same construct. Moreover, if the same high and positive inter-correlations were to be found in multiple IQ measures using multiple methods of measurement, these correlation coefficients might be interpreted as providing construct validational evidence for a particular "theory" of intelligence (e.g., a single factor theory) in addition to whatever evidence it provided for a particular measurement method as an indicator of IQ.

The process of construct validation is not only often long and complex; it is never really finished, i.e., there never comes a time when a measurement method can be finally declared valid. On the contrary, it is generally recognized that the construct validation is a process in which the degree of validity of a particular measurement method for a particular theoretical construct is most accurately represented by the accumulated evidence regarding the multiple psychometric properties of a measurement method within the supporting nomological network of related concepts and constructs (i.e., the theory) that defines the theoretical construct (Campbell \& Fiske, 1959). It is for this reason that at this level of analysis the boundaries between the validation of a method for measuring a theoretical construct and the validation of the theory that defines the theoretical construct 
(and potential measurement models and methods) is blurred, with obtained results often providing (or failing to provide) evidence in support of neither or both (Nunnally, 1978).

In this context, within RDA we consider the level of inter-coder agreement across all of the categories to move beyond the methodological issue of estimating the reliability of each of the categories identified by the emerging grounded theory to begin to address the theoretical issue of the construct validity of the theoretical framework of related concepts and constructs of the emerging grounded theory, i.e., relations among the categories. In grounded theory, the content properties identified by the conceptual analysis are viewed as defining the basic elements of the emerging theory and the theoretical properties of the theoretical categories identified by the theoretical analysis as defining the basic the concepts or constructs of the framework of the emerging theory. The structural organization of the theoretically meaningful categories identified by theoretical coders, in turn, is viewed as defining the theoretical relation among the concepts and constructs that make up the emerging theory. As noted, in RDA the second step in theory construction is the identification of the smallest number of qualitatively different (non-overlapping) theoretically meaningful categories and an explicit description of the properties that define those categories in a specific data set and distinguish them from each other.

Further, because the aim of grounded theory is to construct qualitative theories with respect to the organization of and relations among qualitatively different variables, the theoretical expectation is that in the process of constructing a theoretical structural organization of the categories, each of the identified categories will have a unique (nonoverlapping) property. Evidence that each construct in the theory is unique and non- 
overlapping with every other category (construct) that makes up the theoretical framework provides confirmatory construct evidence for the validity of the emerging theory while evidence that each construct in the theory is not unique and not nonoverlapping with every other category provides non-confirmatory evidence for the validity of the emerging theory. The inter-coder agreement for each category thus provides an estimate of the inter-coder reliability for that specific category, and the average inter-coder agreement across all the categories provides a global index of the "goodness of fit" between a theoretically hypothesized set of relations among the identified theoretical categories and the actual relation among them (Kurtines et al., 2008).

At a concrete and specific level, for example, if the theoretical structure identified by theoretical coders is comprised of four categories (A, B, C, D), a high average intercoder agreement across all of the categories provides evidence for the construct validity of the hypothesized structural organization of the categories. In this case, the structural organization includes all the unique (non-overlapping) categories that make up the theoretical framework of the emerging theory. This newly-developed theoretical framework constitutes the theory within which each identified category is embedded and which the classification coders, explicitly or implicitly, make use of in generating their comparative judgments when coding and classifying participant responses into each category in relation to all the other categories. A high average inter-coder agreement across all of the categories means that the theoretical classification coders were able to classify accurately each of the responses into its appropriate categories. In doing so, each theoretical classification coder's decision to classify a specific response as a belonging to 
specific category (e.g., Category A) involves a simultaneous judgment that the property that defines that particular response is the same property (described in the property descriptions) that the theoretical coders identified as defining Category A and that that property is different from the property (described in the property descriptions) that defines Category B, different from the property that defines Category C, and different from the property that defines Category D. A decision to classify a response as Category B similarly involves simultaneous judgment of the same form, i.e., same as B, different from C, different from D, and different from A. Classifying a response as Category C similarly involves the simultaneous judgment of the same form, i.e., same as C, different from D, different from A, different from B, and Classifying a response as Category D involves the simultaneous judgment: same as D, different from A, different from B, different from C (Kurtines et al., 2008).

A moderate average inter-coder agreement across all of the categories, in contrast, means that the theoretical classification coders were only partially able to classify accurately each of the responses into its appropriate categories and provides moderate evidence for the construct validity of the hypothesized structural organization (Kurtines et al., 2008). A low average inter-coder agreement across all of the categories, in turn, means that the theoretical classification coders were not able to classify accurately each of the responses into its appropriate categories and provides evidence for the absence or lack of construct validity for of the hypothesized structural organization (Kurtines et al., 2008). Finally, a variable inter-coder agreement for each of the categories (e.g., some categories displaying high and some displaying low inter-coder agreement) means that the theoretical classification coders were only able to classify some of the responses into 
its appropriate categories and provides evidence for differential construct validity for a subset of the hypothesized structural organization (with some displaying more construct validity than others) (Kurtines et al., 2008).

In the context of variable inter-coder agreement, high inter-coder agreement for a particular category is interpreted as providing evidence that the particular category (and the subset of the theoretical framework to which that particular category is linked) is theoretically meaningful. Low inter-coder agreement for a particular category, in contrast, is interpreted as providing evidence that the particular category (and the subset of the theoretical framework to which that particular category is linked) is theoretically meaningless (Kurtines et al., 2008). Thus, the second step of provides preliminary evidence (or lack of evidence) for the construct validity of a particular way of organizing the phenomena explained by the emerging grounded theory.

It should be further noted that in those cases where Task 1, Step 2 yields either consistently high or consistently low average inter-coder agreement across all categories, an examination of the results of the inter-coder agreement for each specific identified category in Task 1, Step 1 will yield information redundant with the results of Task 1, Step 2, i.e., if the average inter-coder agreement across all categories are high (or low), inter-coder agreement across all the specific categories will also be respectively either high (or low). However, if the average inter-coder agreement yields mid to moderate inter-coder agreement, the results provide a more useful index of goodness of fit in that an examination of the results of the inter-coder agreement for each specific identified category may yield significant theoretically and empirically useful information with respect to the relative construct validity of each specific identified category, which 
categories merit continuing on to the research analysis phase of the RDA, and which categories need to be returned to an earlier phase of the relational data analysis cycle to undergo further conceptual or theoretical analysis and refinement before moving to the research analysis phase (Kurtines et al., 2008).

Theoretical Analysis Task 5, Step 3: Estimating criterion-related (concurrent) validity. Criterion-related validity consists of concurrent and predictive validity. Concurrent validity estimates the degree to which a measure relates to other manifestations of the same theoretical construct (e.g., the correlation between a measure of patients' self-reported depression symptoms and clinician ratings of depression symptoms in a treatment study). Predictive validity evaluates whether a measure relates to manifestations of other constructs the measurement method is theoretically hypothesized to predict (e.g., the correlation between accounting staff scores on a measure of math aptitude and the accounting supervisor's job performance ratings of the accounting staff). Within RDA, the third step is to use the correlation between the categories identified by the theoretical coders and the theoretical category classifications generated by a second set of theory neutral conceptual coders to estimate the concurrent (external) validity of the coded categories. In Step 3, the resulting correlation coefficient is interpreted as a coefficient of concurrent validity (as a type of criterion-related validity) obtained using a variant of the widely recognized multitrait-multimethod matrix method first introduced by Campbell and Fiske (1959) (Ritchie, 2007; Kurtines, et al., 2008). 
Results

The data analysis for the current study was comprised of the two RDA phases of analyses and the same three-step psychometric analysis (reliability and validity estimates) as described above. The following section reports the psychometric properties generated by the RDA for the Critical Problem-Solving Skills Scale - Qualitative Extension (CPSSQE).

\section{Conceptual Open Coding (COC)}

Conceptual open coding was conducted on each of the study's participant's "raw" interview response data, called a Macro Interview Response (MIR). Macro Interview Responses consisted of the transcription of all the words, phrases, and sentences a specific participant used to describe the meaning and significance of the experience (topic, issue, question, etc.) under investigation. For the first task in the Conceptual Analysis Phase, the material for the COC, which consists of creating MIR coding cards for all the response data to be used for the COC was assembled. A set of 40 "Sample Coding Cards," a theoretically representative set, was then selected from the larger sample under study. Finally, a set of five theoretically neutral conceptual coders was assembled to use the grounded theory concept of "open" coding and the method of "constant comparison" for similarities and differences in the comparison of the properties of participant response data to identify the unique content properties that define the basic pool of conceptual categories in the raw response data, use those properties to identify all qualitatively different (non-overlapping) conceptual categories in the data set, and formulate and document an explicit description of the unique content property that the 
response data of each conceptual category share in common (similarity) and that they do not share with any other categories (difference) (Kurtines et al., 2008) .

After a brief orientation to RDA (and the current study) that included a general explanation of the goals of coding (i.e., to identify and classify answers to interview questions into conceptually meaningful groups or categories) and a brief overview of the process that would be used (i.e., by sorting cards containing a transcription of various segments of the interviewee's answers to the questions), the coders reviewed the sample set and identified a preliminary initial set of seven non-overlapping conceptual categories (Academics, Self-Preservation, Relationships, Conflict Avoidance, Self-Improvement, Approval of Others, Stress Reduction) contained in this particular data set, working blind to Condition.

Theoretical Open Coding (TOC)

The initial set of conceptual categories identified in the COC provided the data for the theoretical analysis conducted in this phase. A panel of five theoretical coders was assembled to review the entire CPSS-QE sample set (40 MIRs) for the seven conceptual categories, to gain an understanding of what the conceptual coders identified as the properties of the conceptual categories. The theoretical coders then discussed to consensus the theoretically meaningful categories, the organizational structure (STC) of the categories, translated the unique properties of the categories into the DTC, and later performed an open coding exercise using the sample set. 


\section{Theoretical Analysis Task 1: Identifying Theoretical Categories}

During the first task in the TOC stage, a theory saturated panel of coders utilized Elder and Paul's Stage Theory of Critical Thinking (described in more detail in previous sections) as the primary theoretical perspective for this theoretical analysis. Theoretical coding differs from content category coding performed in the $\mathrm{COC}$, in that during the conceptual analysis phase, open coding is done by coders with no particular theoretical perspective (or perhaps more accurately, coders with multiple implicit theoretical perspectives). During the Theoretical Analysis phase, in contrast, open coding is performed by coders who explicitly share the same identified and extensively articulated theoretical perspectives.

This first phase of the theoretical analysis was conducted by a panel of five theoretical coders who are given the task of identifying theoretically relevant and meaningful categories contained in the pool of content categories identified by the neutral coders in the COC. The theoretical coders were provided with the sample MIR coding cards grouped into the categories formulated in the $\mathrm{COC}$, as well as descriptions for the categories. They were then asked to review the cards and the content property descriptions and to refine the basic content categories and the structure of the groupings generated by the content coders during the COC, identify theoretically meaningful properties, and organize them into groups (categories) and respective sub-categories in ways that are meaningful with respect to the identified theoretical framework. The theoretical analysis of the CPSS-QE yielded two (Level One) categories - Critical Thinking, and Uncritical Thinking. Uncritical Thinking yielded two (Level Two) sub- 
categories - Unreflective Thinking, and Challenged Thinking. Critical Thinking yielded three (Level Two) sub-categories - Rudimentary Thinking, Advanced Thinking, and Accomplished Thinking. Appendix A presents the structural organization of the theoretical categories and sub-categories as well as the property descriptions of the unique categories.

Constructing an RDA Structural Tree Chart (STC): The last step in finalizing the identification of the theoretical categories was the construction of a visual representation of the structural organization of the categories. In RDA, the Structural Tree Chart (STC) that emerges out of the TOC process not only provides a conceptual framework (a visual tool) for reporting structural organizations, but also for facilitating the identification of theoretical categories during the open coding process. Figure 2 illustrates the STC constructed during this study.

Figure 2: RDA CPSS-QE Structural Tree Chart (STC)

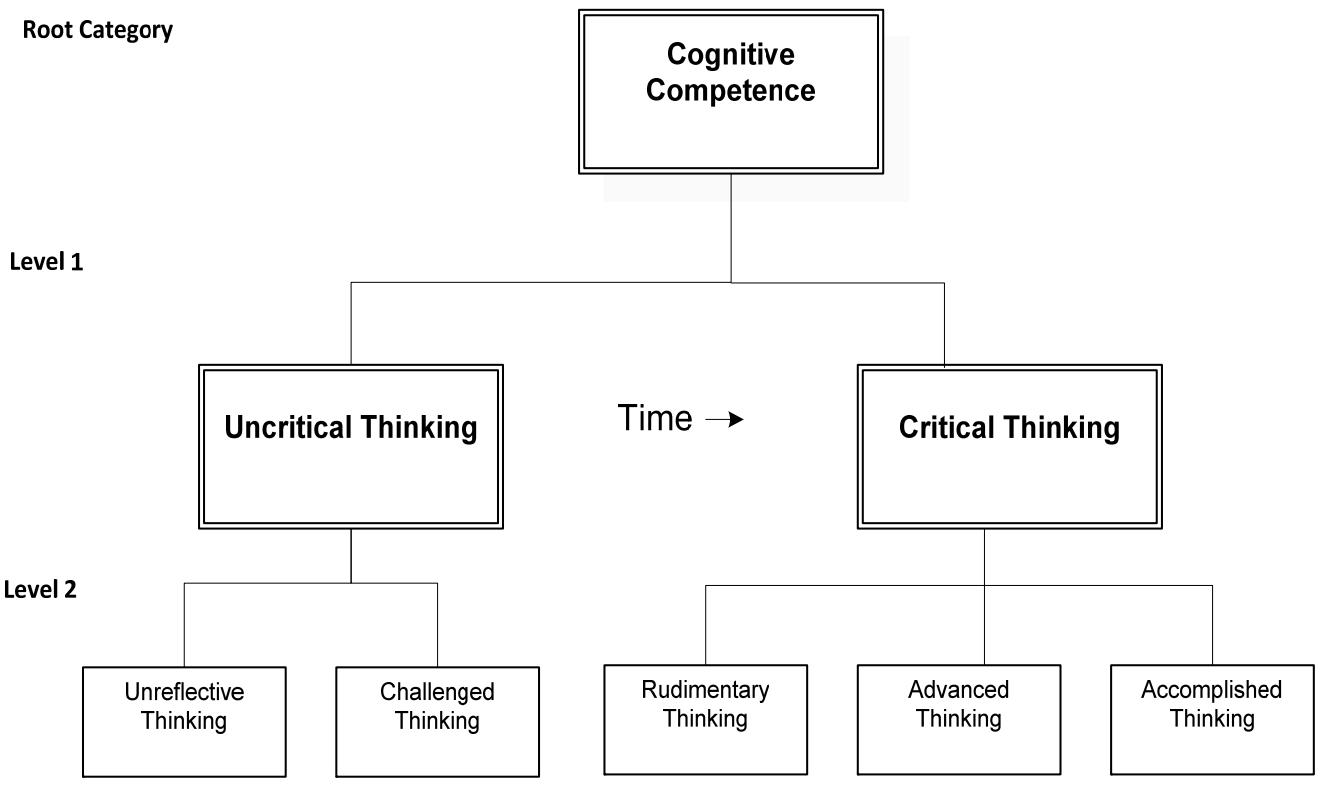


Theoretical Analysis Task 2: Identifying Relations Between Categories and Identifying Structural Organizational Properties Between and Within Theoretical Categories

The second phase of the theoretical analysis had two aims: 1) structural organization of the relations between all of the identified categories, and 2) structural organization of the narrative response data within each of the identified categories (Kurtines et al., 2008). The theoretical coders first examined the pattern of relations between the theoretical categories (i.e., the structural organization) and refined and redefined them in terms of a structural organization (hierarchical) meaningful with respect to the guiding theoretical framework. Then the theoretical coders identified the structural organization of the narrative response data within each of the theoretical categories within each MIR. Drawing on the basic directionality of change over time in critical competence - as conceptualized in much of the current critical thinking literature (Elder \& Paul, 1996; Sun, 2006) - the theoretical coders identified a theoretically meaningful developmental progression. Each of the five (Level Two) sub-categories in the following succession - Unreflective Thinking, Challenged Thinking, Rudimentary Thinking, Advanced Thinking, and Accomplished Thinking - represents an advancement in critical evaluation performance (if not necessarily capacity). It is important to note here that although the terms "performance" and "capacity" are not interchangeable, Norris maintains that, in order to be considered a "critical thinker," one must possess both the ability and the disposition to put that particular competence to use (1989). Another one of the primary structural organizational properties identified in RDA of the CPSS-QE was Structural Coherence - the degree to which the overall structure and organization of an MIR may be considered a cohesive and coherent. The term "consolidated" was used to 
describe a MIR that was characterized as cohesive and coherent. Consolidation is a term that describes a merging of the multiple elements or components (of the self) into of an integrated whole. The panel further identified three sub-categories of consolidation for the MIR data for the RDA CPSS-QE: unconsolidated, partially consolidated, and fully consolidated (see Appendix A for a more detailed explanation of consolidation). Structural Coherence was placed in the DTC at Level Three.

Theoretical Analysis Task 3: Identifying Mechanisms of Change

The aim of the third phase of the theoretical analysis is to identify and specify plausible mechanisms of change (e.g., causal/variational, structural/transformational, etc.) in categories/variables that provide theoretically meaningful explanations from the perspective of a particular theoretical framework. Because of the lack of temporal investigation in the current study, the third phase of theoretical analysis was not performed.

Theoretical Analysis Task 4: Constructing a Decision Tree Chart (DTC) RDA Coding Template (RDA-CT)

Constructing an RDA-CT is normally undertaken as penultimate step in an RDA Theoretical Analysis and uses the STC that is constructed during the completion of steps 1 and 2 of the theoretical analysis. The first step in constructing an RDA-CT is to construct a Decision Tree Chart (DTC) from the relevant RDA-STC and accompanying set of property descriptions. A DTC is typically derived during the construction of an RDA-CT for a specific measure for a specific population, problem, program, etc. RDACTs are intended to provide all the basic information needed for conducting an RDA 
Theoretical Classification Coding (TCC). The components of this study's RDA-CT are as follows: (1) CPSS-QE-STC (2) Theoretical Property Descriptions, (3) Theoretical Category Structural Organization, (4) RDA CPSS-QE DTC, and (5) Coding Glossary.

The basic goal of Theoretical Analysis Task 4 is thus to create a structure for the RDA Decision Tree Chart that sequentially and systematically guides the TOC and later, the TCC coders' decision making with respect to the appropriate category properties to be used at each choice point in the decision making process, so that each MIR is assigned to an appropriate category or sub-category (Kurtines et al., 2008). The logic of decision tree flow charts provide a useful tool for identifying and mapping the most efficient and effective structure for guiding the decision making process.

Level One includes the categories of Critical Thinking and Uncritical Thinking, Level Two includes the five respective sub-categories, and level three includes the consolidation (see Appendix A). A TOC was then conducted by the panel to classify the MIRs of the sample set using the coding template to place the free responses of the sample set into the corresponding categories and sub-categories identified in the previous tasks of the theoretical analysis phase of RDA. Levels were included in CPSS-QE RDACT to evaluate inter-coder reliability at each level as well as overall category reliability. Relational Data Analysis makes it possible to easily and readily switch between poles of the splits (qualitative $\rightarrow$ quantitative, structural $\rightarrow$ causal $\rightarrow$ structural) based on findings or results obtained at any of the phases of analysis and at any level of analysis (theory and data). In this context, the current study implemented the use of category levels to distinguish and further investigate the theoretical meanings of the theoretical categories 
identified in the TOC versus the empirical meaning of the categories identified in the TOC.

Theoretical Classification Coding (TCC)

A TCC was conducted as the last step in the RDA Theoretical Analysis Phase 4 by a panel of theoretically neutral coders. A new set of theoretically neutral coders was assembled to perform the TCC phase of the RDA process. The task of training the TCC coders is essentially the same as the task of training the COC coders, with appropriate modifications. For this task, the copies of the same Sample Coding Deck used during the COC and TOC, the Coding Glossary, DTC, and the category descriptions developed

during the TOC were provided. The panel then conducted the second coding procedure of the initial sample set using all the information developed during the TOC phase of the RDA process.

Theoretical Analysis Task 5: Reliability and Validity Analyses of an RDA Coding Template

The last task in the RDA Theoretical Analysis Phase is to conduct a three-step preliminary psychometric analysis (reliability and validity estimates) of the Decision Tree Chart (DTC).

Theoretical Analysis Task 5, Step 1: Estimating inter-coder reliability. The most important outcome of the conceptual and theoretical analysis phases of RDA is the identification of conceptual and theoretical categories; an important psychometric property of identified coding categories is the consistency with which they can be used to accurately classify participant response data into the theoretical categories (i.e., the 
reliability of the coding categories). For purposes of estimating inter-coder consistency of an RDA CT, psychometric analysis of the Coding Template uses the inter-coder agreement among the TCC coders during the TCC coding, and the inter-coder agreement among the TCC coders of the second set of theory neutral coders, thereby providing an independent estimate of inter-coder reliability for both the theory saturated coders and a second set of theory neutral coders blind to the theoretical meaning and significance of the categories identified by the theoretical coders.

For this study, coder agreement was evaluated by category, sub-category, and consolidation, as identified by the TOC coders. Inter-coder agreement among the five theory-saturated coders of the TOC for each of the specific categories was found to be substantial to high, with a range of .81 to .95 . Inter-coder percentage agreement for the TCC level one was .95, for level two, .81, and for level three, .88, with a total percent agreement across all levels of .88. Inter-coder agreement among the five theory neutral coders of the TCC for each category was also found to be substantial to high, with a range of .75 to .95 . Inter-coder percent agreement for the TCC level one was .95, level two was .75, and level three was .94, with a total percent agreement across all levels of .88. Inter-coder agreement across the TOC and the TCC was also moderate to high, with a range of .76 to .94 . Inter-coder percent agreement for level one across the TOC and the TCC was .94, level two was .76, and level three was .91.

In addition to agreement percentage, Fleiss' kappa was used to estimate the intercoder reliability of each of the levels correcting for chance. Fleiss' kappa for the TOC level one was estimated at .91 showing almost perfect agreement, level two was 
estimated at .74 showing substantial agreement, and level three was estimated at .73, again showing substantial agreement. Fleiss' kappa for the TCC level one was estimated at .90 showing almost perfect agreement, level two was estimated at .78 showing substantial agreement, and level three was estimated at .72, again showing substantial agreement.

Theoretical Analysis Task 5, Step 2: Estimating construct validity. As noted above, the average inter-coder agreement across all the categories is interpreted as providing an indirect estimate of the degree to which the conceptual properties for each of the identified categories are unique and qualitatively different from all of the other identified categories of the emerging grounded theory.

The overall average percent agreement across all the category levels was moderate to high, with a range of .76 to .94 , providing evidence for a relatively high degree of construct validity for the identified categories. Given the particular type of theory used as a framework for the RDA CT reported here (i.e., a type of grounded theory in which all identified theoretical categories are not only hypothesized to be uniquely different from each other but also to represent a specific theoretically hypothesized structural organization), which yields consistently high inter-coder agreement for all the categories - i.e., a high average inter-coder agreement - it is interpreted as not only providing evidence for high reliability for each identified category, but also as evidence for a high level of construct validity for all the categories within the theoretical structural organization identified by the theoretical coders (Kurtines et al., 2008). In the case of grounded theory, this includes all the other categories that 
make up the theoretical framework within which each identified category is embedded and which the classification coders, explicitly or implicitly, make use of in generating their comparative judgments with respect to each category. Thus, the overall accuracy of the coders' classifications of the participants' open-ended response data based on the coders' evaluation of the specific property of each individual category, made in comparison to the properties of all the other categories, provides evidence in support of the theoretically hypothesized structural organization of the categories. Specifically, a high average inter-coder agreement provides evidence that each category has the theoretical meaning it is claimed to have within the context of a theoretically generated structural organization that is defined by all the other categories within which it is embedded. The psychometric properties of the CT thus provide a method for evaluating the hypothesized structural organization of the identified categories generated by the theoretical coders as well as preliminary and indirect evidence for the construct validity of the specific properties of specific categories (Kurtines et al., 2008).

Theoretical Analysis Task 5, Step 3: Estimating criterion-related (concurrent) validity. As noted above, the third step of Task 5 is to use the correlation between the categories identified by the theoretical coders and the category classifications generated by a second set of theory neutral conceptual coders to estimate the concurrent (external) validity of the coded categories. During this stage, the resulting correlation coefficient is interpreted as a coefficient of concurrent validity (as a type of criterion-related validity) (Kurtines et al., 2008). The focus of the analysis is on the concurrent validation of multimanifestations of the same theoretical construct generated by multiple methods (open coding by theory-laden coders versus classification coding by an independent sample of 
theory neutral coders) rather than predictive validity (Kurtines et al., 2008). The correlation between the modal Coding Category, by level, that the theory-laden coders (TOC) assigned to each participant's MIR and the modal Coding Category, by level, that the theory neutral coders (TCC) assigned to each participant's MIR was, $\mathrm{r}(40)=.79, \mathrm{p}<$ .001 , for level one, $\mathrm{r}(40)=.75, \mathrm{p}<.001$ for level two, and $\mathrm{r}(40)=.68, \mathrm{p}<.001$ for level three, providing evidence for medium to high concurrent (external) validity for the identified theoretical categories. As previously noted, theoretical categories consensually identified in the theoretical analysis are not only theoretically "meaningful" but also rooted in content properties that actually exist in the raw data, (i.e., they have conceptual meaning independent of the theoretical meaning ascribed by the theoretical coders). Thus, in contrast to conceptual and theoretical analysis, the concurrent validational analysis does not use open coding to identify concepts (categories); instead, in concurrent validational analysis of the coding categories, the TCC is used to classify the response data into the categories (concepts) identified during the theoretical analysis (Kurtines et al., 2008). The correlation between the theoretical categories generated by the theoretical coders' open coding of the original raw data responses, and the classification of the same original raw data responses into the same theoretical categories by the second set of theory neutral coders provide an estimate of the concurrent (external) validity of the categories. 


\title{
IV. STUDY II: CRITICAL THINKING, LIFE GOALS, AND BEHAVIORAL OUTCOMES - AN OUTCOME MEDIATION CASCADE MODEL
}

\author{
Background
}

The Outcome Mediation Cascade (OMC) evaluation model developed for this study draws on an outcome mediation evaluation model for evaluating intervention process effects, an integration of a comparative outcome evaluation model and a mediation model, recommended by Silverman et al. (2009) and further explored by Eichas et al. (2010). Extending the outcome mediation model to evaluate developmental intervention cascades requires that a research design include a single intervention strategy and more than one outcome domain (in this case, problem and positive outcome domains).

Youth in alternative high schools are at increased risk for multiple problem behaviors (Grunbaum et al., 2000; Windle, 2003). Although the effects of treatment and prevention interventions on problem behaviors have been widely researched, evidence for PYD intervention effects (direct or cascading) on problematic outcomes is scant or nonexistent (Schwartz et al., 2007). The literature that has begun to emerge has largely focused on the potential direct effects of PYD programs in reducing internalizing problem behaviors (e.g., depression, anxiety, etc.; McWhinnie, Abela, Hilmy, \& Ferrer, 2008). There has been little research on the mediational processes by which these PYD effects may occur.

A main conceptual focus of the ongoing program of developmental intervention research on the Changing Lives Program (CLP) intervention has been on the theory 
informed selection of mediators and positive outcome variables, as well as a broad and representative array of problem outcome variables for evaluating CLP outcomes. The CLP uses a participatory transformative intervention process to target the formation of a positive sense of self and identity among multi-problem youth attending alternative high schools. Thus, this study used quantitative and qualitative indices of positive identity development drawn from the literature on self and identity.

The study had four specific research aims. The first research aim was to evaluate the direct effects of the Changing Lives Program (CLP) on positive outcome variables: Transformative Life Goal Attainment (TGA), and Personally Expressive Life Goals (LG). The second was to evaluate the direct effects of the CLP on the quantity of problem solving alternatives (CPSS) and the qualitative content of those alternatives (CPSS-QE). The third was to evaluate the indirect effects of the CLP on TGA as mediated by the CPSS and CPSS-QE. The fourth was to investigate hypothesized cascade effects on negative behavioral outcomes: internalizing behavior (INT), and externalizing behavior (EXT).

\section{Research Analyses}

A main conceptual focus of the ongoing program of developmental intervention research on the Changing Lives Program (CLP) intervention has been on the theory informed selection of mediators and positive outcome variables, as well as a broad and representative array of problem outcome variables for evaluating CLP outcomes. The CLP uses a participatory transformative intervention process to target the formation of a positive sense of self and identity among multi-problem youth attending alternative high 
schools. Thus, this study used quantitative and qualitative indices of positive identity development drawn from the literature on self and identity.

Figure 3: Conceptualized Pathways of Intervention Change

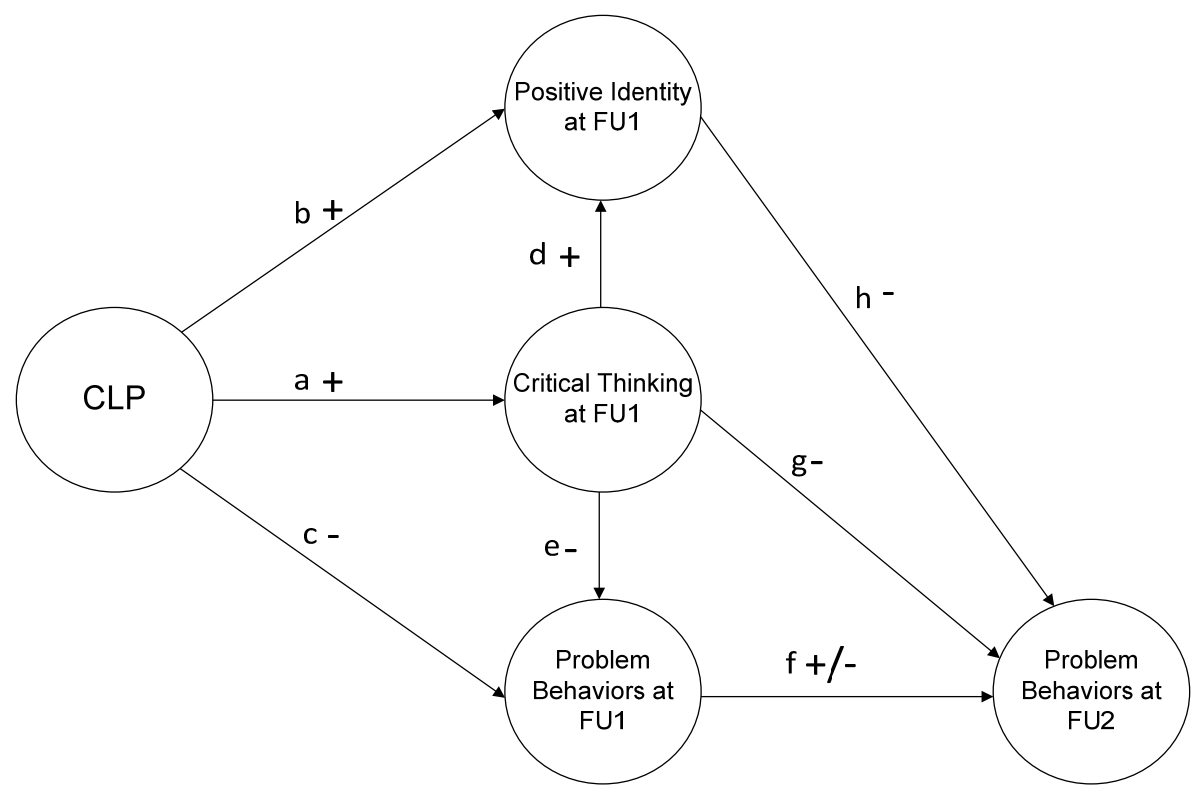

Figure 3 visually depicts the basic conceptualized pathways of intervention change, including (1) direct effects on positive identity outcomes (2) direct effects on problem behavior outcomes, (3) indirect effects on positive identity and problem behavior outcomes mediated by hypothesized identity formation processes, and (4) indirect effects on problem behavior outcomes mediated by positive identity outcomes, that is, cascading positive change that spills over across positive and problem outcomes. As can be seen from Figure 3, the model predicts that the CLP's participatory transformative intervention process will be associated with increases in positive identity outcomes (path b) and decreases in problem behavior outcomes (path c). It further conceptualizes positive identity outcomes to be linked over time with problem behavior outcomes, with increases in positive identity associated with decreases in problem behaviors (path h). 
The model also predicts that increases in critical thinking are associated with increases in both positive identity outcomes (path d) and decreases in problem behavior outcomes (path e) in the short term. However, the model also predicts that engagement in critical thinking is associated with progressive decreases in problem behaviors through its relationship with positive identity outcomes (path $\mathrm{d}$ and path $\mathrm{h}$ ). Furthermore, the model predicts that when the effects mediated by positive identity outcomes are held constant, critical thinking will still be associated with progressive decreases in problem behaviors (path g). 
Hypothesized Pathways of Intervention Change: Direct, Mediated, and Cascade Effects

Figure 4 visually presents the Outcome Mediation Cascade (OMC) evaluation model used to investigate intervention effects (including measures of both positive and problem outcomes).

Figure 4: Hypothesized OMC Evaluation Model

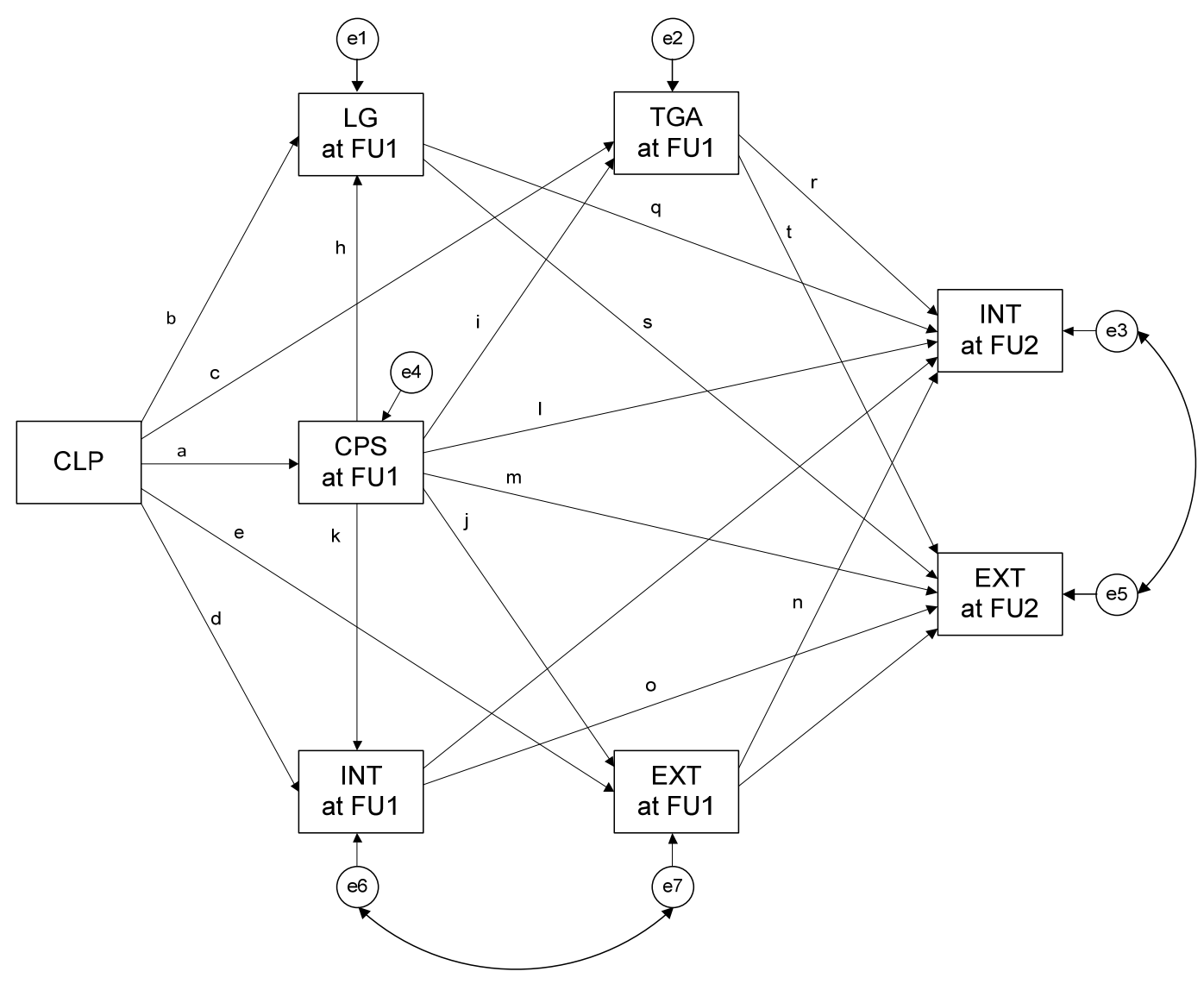

The following section describes the theoretically hypothesized intervention effects for these variables and the specific causal paths hypothesized to underlie the Intervention $\leftrightarrow$ Developmental (I↔D) cascading change. Positive intervention change in positive identity, both structural and dimensional, is hypothesized to "spill over" to generate reductions in internalizing and externalizing problem behavior outcomes. Intervention 
changes in indices of positive identity are thus hypothesized to mediate intervention effects on problem behavior outcomes. Because of the dearth of empirical mediation research in the positive development literature, the mediation construct for the model was derived from previous research on the CLP (Eichas, 2010) and the existing body of theoretical literature on positive identity development and critical thinking.

Hypothesized Direct Effects: Positive Outcome

This study sought to investigate positive identity development by evaluating both dimensional and structural/organizational change in indices of self and identity and its meaning and significance. A strictly quantitative approach cannot capture changes in the meaning and significance of critical experiential components of self and identity because not only are these changes non-linear, discontinuous, and not easily quantifiable, they are also subjective in nature (Eichas, 2010). Thus, both quantitative and qualitative indices of positive identity outcomes were used.

The evaluation model hypothesizes that participation in the CLP intervention promotes an increase in the degree to which the pursuit of life change goals demonstrates critical problem-solving (CPS). Additionally, the model hypothesizes that participation in the CLP intervention promotes an increase in the extent to which life change goals (TGA) are achieved. The evaluation model also hypothesizes that participation in the CLP promotes the qualitative progressive developmental change from a non-personally expressive life goal to a personally expressive life goal (Life Goal). The model thus predicts the following direct intervention effects on positive identity outcomes: CLP $\rightarrow$ + CPS, + LG, + TGA (i.e., paths a, b and c). 
With respect to the relationship between critical thinking and most important life goals, the evaluation model hypothesizes that an increase in CPS will be associated with the change from a non-personally expressive life goal to a personally expressive life goal. The model thus predicts the following indirect intervention effect: CLP $\rightarrow+\mathrm{CPS} \rightarrow+\mathrm{LG}$ (i.e., paths a and h). With respect to the relationship between critical thinking and life change goals, the evaluation model hypothesizes that an increase in CPS will be associated with an increase in transformative goal attainment. The model thus predicts the following indirect intervention effect: $\mathrm{CLP} \rightarrow+\mathrm{CPS} \rightarrow+$ TGA (i.e., paths a and i). Hypothesized Direct Effects: Problem Outcomes

For evaluation of problem behavior outcomes, this study adopted the Behavior Problem Index (BPI; Peterson \& Zill, 1986), a widely used broadband index of problem behaviors, to tap the full range of problem behaviors associated with childhood and adolescence, including internalizing (INT) and externalizing (EXT) problem behaviors. Eichas et al. (2010) found a moderated intervention effect on change in INT. In the absence of other previous empirical evidence regarding the effects of PYD interventions targeting identity outcomes on problem behaviors, participation in the CLP was hypothesized to predict decreases in both INT and EXT. The hypothesized model predicts that participation in the CLP promotes reductions in INT and EXT. The model thus predicts the following direct intervention outcome effects on problem behaviors: CLP $\rightarrow$-INT, -EXT (i.e., paths d and e).

With respect to the relationship between internalizing and externalizing problem behaviors, the evaluation model hypothesizes that contemporaneous change in INT and 
EXT is correlated because changes in INT and EXT are likely to be influenced by similar contextual factors, many of which are not represented by variables in the model (Eichas, 2010). Furthermore, although not shown in Figure 4, the model hypothesizes a reciprocal relationship over time between INT and EXT. Increases in EXT are hypothesized to be associated with increases in INT (path n). However, the literature regarding longitudinal linkages between internalizing and externalizing problem behaviors indicates that internalizing behaviors may index lower risk for external problems, especially in situations in which self-isolating behavior provides protection when peers are deviant (Zahn-Waxler, Klimes-Dougan, \& Slatterly, 2000; Masten et al., 2005). Thus the model hypothesizes that increases in INT are associated with progressive decreases in EXT (path o).

Hypothesized Mediation of Positive and Problem Outcomes

For evaluation of critical thinking skill development as a mediator of intervention outcomes, this study used a measure of critical problem-solving skills (CPSS) developed previously (see Study I above). As can be seen in Figure 4, the evaluation model hypothesizes that participation in the CLP is associated with an increase in CPS: CLP $\rightarrow$ + CPS (i.e., path a).

While there is little empirical literature to guide hypotheses regarding mediation of transformative goal attainment and no empirical literature to guide the hypotheses regarding mediation of life goals, the theoretical literature suggests that engaging in critical thinking creates opportunities for the adolescent to evaluate and reevaluate these ideas and to explore the level of fit between life goals and his or her unique potentials, 
capabilities, and interests. The evaluation model hypothesizes that an increase in CPS is associated with contemporaneous positive changes in LG and TGA. The model thus predicts the following mediated intervention outcome effects on TGA and LG: CLP $\rightarrow$ $+\mathrm{CPS} \rightarrow+\mathrm{LG}$ (paths a and $\mathrm{h}$ ) and CLP $\rightarrow+\mathrm{CPS} \rightarrow+\mathrm{LG}$ (paths a and $\mathrm{i}$ ).

With respect to mediation of INT and EXT, little theoretical or research literature addresses the psychosocial processes or outcomes that mediate the association between PYD intervention programs and problem behavior outcomes. However, Eichas' 2010 exploratory study, along with findings from the critical thinking literature (e.g. Jaffee \& D'Zurilla, 2003), suggest that active development of problem-solving skills is associated with decreases in internalizing and externalizing problem behaviors. The evaluation model hypothesizes that an increase in CPS is associated with contemporaneous decreases in INT and EXT. The evaluation model also predicts that when the effects of CPS mediated by LG and TGA are held constant, an increase in CPS is associated with progressive decreases in problem behaviors. The model thus predicts the following mediated intervention outcome effects on problem behaviors: CLP $\rightarrow+$ CPS $\rightarrow-$ INT, EXT (paths a and k; path a and j; paths a and l; paths a and $\mathrm{m}$ ).

Hypothesized Cascade Effects

With respect to the evaluation of progressive I $\leftrightarrow \mathrm{D}$ cascading change across positive and problem domains, the evaluation model hypothesized that intervention change in positive identity outcomes mediates reductions in problem outcomes. Previous research has suggested that increases in levels of cognitive competence are associated with decreases in adolescent reported problem behaviors (Jaffee \& D'Zorilla, 2003). The 
hypothesized model predicts that an increase in CPS and the change from uncritical thinking to critical thinking are associated with decreases in INT and EXT. The model thus predicts the following progressive cascade effects on problem behaviors: CLP $\rightarrow$ + CPS $\rightarrow-$ INT, -EXT (paths a and 1; paths a and m); CLP $\rightarrow+$ LG $\rightarrow$-INT, -EXT (paths $\mathrm{b}$ and $\mathrm{q}$; paths $\mathrm{b}$ and $\mathrm{w}$ ); and CLP $\rightarrow+$ TGA $\rightarrow$-INT, -EXT (paths $\mathrm{c}$ and $\mathrm{r}$; paths $\mathrm{c}$ and $\mathrm{t}$ ).

\section{Method}

\section{Participants}

Participants for this study were drawn from the Miami Youth Development Project archival data. The Miami Youth Development Project (YDP) is an outreach research program that promotes positive youth development via a partnership between Florida International University in Miami, Florida and local public schools and community resources. Participation in the Changing Lives Program (CLP) is limited to self-referrals, or students referred by the school counselor or teachers. As part of each school's counseling program, the CLP counseling groups are organized and implemented through each school's administration. Alongside the group of students identified to partake in the CLP, a separate group was also selected for the comparison control condition. All of the students that participated in the comparison control condition were selected randomly from a pool of students not referred or self-referred by school counselors or administrators. The participants in the comparison control condition were further selected for not having participated in any of the counseling and guidance programs prior to or during their involvement with the YDP. All study participants and a 
parent or legal guardian completed an Internal Review Board (IRB) approved parent consent and student assent form before participating in any research.

The current study utilized an archival sample of 259 students who have participated in the Changing Lives Program of the YDP since 2002. The multiethnic sample of intervention participants were compromised of approximately $46 \%$ AfricanAmerican, 35\% Hispanic, 8\% White/Non-Hispanic, and 6\% Other - with 56\% females and $44 \%$ males - a constitution that is typical of the schools' demographic make-up. The age of the participants ranged from 14 to 18 years of age. With regard to the socioeconomic characteristics of the sample, $38 \%$ of annual family incomes were below $\$ 21,000$, while $17 \%$ were over $\$ 41,000$. Seventy-four percent of the participants had at least one parent who completed high school, 50\% had two parents who completed high school, and $31 \%$ had at least one parent who completed a bachelor's degree.

Procedure

Every intervention group was structured and implemented by an intervention team that consists of one group facilitator, one co-facilitator, and one or two group assistants. All group facilitators and co-facilitators were graduate level students enrolled in either a doctoral developmental science program, or a master's level mental health counseling program. Undergraduate psychology students who have been trained in the administration of the measures and in participant tracking procedures served as group assistants. The group facilitators and co-facilitators served in a counseling capacity that utilized the CLP's participatory transformative approach (Montgomery et al., 2008). The intervention groups met for approximately 45 minutes to 1 hour every week for approximately 8 to 12 weeks during the fall and spring semesters. 
Participants' assessments were carried out by undergraduate psychology students serving as research trainees at school grounds and during school hours in the week preceding the commencement of the semester session and the week after its end. The training administered to those undergraduates includes instruction concerning confidentiality issues, assessment administration, dress code, high school regulations, interviewing strategies, and role-playing of interviews.

Measures

Psychosocial Mediators: Critical Thinking

The Critical Problem-Solving Skills Scale (CPSS) was used to assess participants' problem-solving competence. The CPSS is a group administered performance-based measure that contains four subscales that tap three problem-solving processes: creativity, suspension of judgment, and critical evaluation (Berman, Schwartz, Kurtines \& Berman, 2001). The concept of creativity includes the degree to which one is innovative in generating alternatives for approaching life change goals. Creativity is tapped by the Generation of Alternatives (GA) score, which is the total number of different and distinct alternatives generated for both dilemmas. The participants were asked to generate a number of approaches to achieving a previously indicated life change goal, and their performance appraisal was determined by (i) the number of alternatives that were created (quantitative scores), as well as (ii) how many of those alternatives were judged to be qualitatively different from each other, i.e., possessing some unique content properties. Suspension of judgment is the extent to which one is capable of adopting multiple perspectives with respect to these alternatives. Suspension of judgment is tapped by the Decentering, Positive Alternatives (DPA) and the Decentering, Negative Alternatives 
(DNA) scores (the total number of "cons" and "pros" each participant generated for her/his own "best" and "worst" alternatives). The participants were asked to select one of their alternatives as a "best choice," and another as their "worst choice." The participants were then asked to suspend their judgment with respect to their evaluation of these two alternatives and list as many "good things" about their "worst choice" as they are able to, as well as list as many "bad things" about their "best choice" as they can. Critical evaluation is the degree to which one is capable of questioning or challenging the alternatives and willing to change one's original choice in the context of a more viable alternative. Critical evaluation is tapped by the Modification (MO) score (the number times a participant changes (modifies) his/her original choice and provides a "justification" for the change based on his/her previous "pros" and "cons" for that alternative). In other words, this final item on the CPSS asks participants to reconsider their "best choice" in light of the critical thinking exercise.

The Critical Problem-Solving Skills Scale - Qualitative Extension (CPSS-QE) adds an open-ended response component to the CPSS to provide a method for eliciting the narrative/linguistic expressions of meaning and significance of participants' "best choices." Specifically, after completing the CPSS (described above) participants were asked to reconsider their "best choice" for achieving a specified life change goal. They were then asked to provide an open-ended description of its meaning and significance. More specifically, participants were asked, "What does this mean to you?" and "Why is this significant or important to you? How significant or important is this to you?" The meaning and significance questions were then followed by three neutral probes (e.g., 
"Can you say more about that?"; "Is there anything else?") to request secondary elaboration when necessary.

The present study used the conceptual and theoretical coding categories for CPSS-QE responses developed in Study I (described in the previous chapter) using Relational Data Analysis (RDA; Kurtines, Montgomery, Arango, et al., 2008). Relational Data Analysis draws on methods for analyzing free response data associated with grounded theory (e.g., open coding and constant comparison) and extends these methods by intentionally manipulating the theoretical saturation of coders across multiple phases of analysis. The previous study used a psychosocial developmental life course theoretical framework to generate a theoretically meaningful developmental hierarchical structural organization of participants' responses. Theory-laden coders consensually derived a hypothesized direction of progressive developmental change at Level 1 of the structural organization, from Uncritical Thinking $\rightarrow$ Critical Thinking. Uncritical Thinking yielded two (Level 2) sub-categories - Unreflective Thinking, and Challenged Thinking. Critical Thinking yielded three (Level 2) sub-categories - Rudimentary Thinking, Advanced Thinking, and Accomplished Thinking. Inter-coder percent agreement among the TOC and TCC coders for each of the category levels was moderate to high, with a range of .76 to .94. The Fleiss' kappa across all category levels was from substantial agreement to almost perfect agreement, with a range of .72 to .91 . The correlation between the TOC and the TCC demonstrated medium to high correlation, with a range of $\mathrm{r}(40)=.68, \mathrm{p}<.001$ to $\mathrm{r}(40)=.79, \mathrm{p}<.001$. 


\section{Positive Outcome: Transformative Goal Attainment}

The Transformative Goal Attainment Scale (TGAS; Swenson, 2005) provides a quantitative index of the extent to which participants report progress in achieving their most important life change goal. Specifically, during administration of the TGAS, participants are asked to rate how much progress they have made in achieving the change goal they set for themselves at the beginning of the semester on a Likert scale from 1 (No Progress) to 5 (Very Much).

\section{Positive Outcome: Personally Expressive Life Goals}

The Personally Expressive Activities Questionnaire - Qualitative Extension (PEAQ-QE) adds an open-ended response component to the PEAQ to provide a method for eliciting the narrative/linguistic expressions of meaning and significance of participants' most important life goals. Specifically, participants were asked to identify up to three life goals and then to identify their most important life goal. They were then asked to provide an open-ended description of its meaning and significance. More specifically, participants were asked, "What does this life goal mean to you?" and "Why is this significant or important to you? How significant or important is this to you?" The meaning and significance questions were then followed by three neutral probes (e.g., "Can you say more about that?"; "Is there anything else?") to request secondary elaboration when necessary.

The present study used the conceptual and theoretical coding categories for PEAQ-QE responses developed by Rinaldi et al. (under review) using Relational Data Analysis (RDA; Kurtines, Montgomery, Arango, et al., 2008). Relational Data Analysis draws on methods for analyzing free response data associated with grounded theory (e.g., 
open coding and constant comparison) and extends these methods by intentionally manipulating the theoretical saturation of coders across multiple phases of analysis. Rinaldi et al. (under review) used a psychosocial developmental life course theoretical framework to generate a theoretically meaningful developmental hierarchical structural organization of participants' most important life goals. Theory-laden coders consensually derived a hypothesized direction of progressive developmental change at level 1 of the structural organization, from Non-personally Expressive $\rightarrow$ Personally Expressive. Analysis of inter-coder agreement for level 1 subcategories indicated agreement of $96 \%$ and a Fleiss' Kappa of .84, suggesting almost perfect agreement (correcting for chance). The Personally Expressive category had two nested subcategories: Personally Expressive through Others and Personally Expressive through Self. The Non-Personally Expressive category had three nested subcategories: Prove to Others, Self-Satisfying, Benefit of Others; and two mixed nested subcategories: Mixed Prove to Others/Self Satisfying and Mixed Self Satisfying/Benefit of Others. Analysis of inter-coder agreement for Level 2 subcategories indicated agreement of $86 \%$ and a Fleiss' Kappa of .69, suggesting substantial agreement (correcting for chance). Analyses of the full model used Level 1 subcategories, that is, personally expressive versus non-personally expressive life goals (Life Goal).

Problem Outcomes: Internalizing and Externalizing Problem Behaviors

The Behavior Problem Index (BPI; Peterson \& Zill, 1986) was used to assess internalizing and externalizing problem behaviors. The 32 items of the BPI were taken from the Achenbach Behavior Problems Checklist (Achenbach \& Edelbrock, 1981), a more extensive measure that is widely used with children and adolescents. The BPI items 
were included in the Panel Study of Income Dynamics - Child Development Supplement II (PSID-CDS II; Mainieri, 2006), a national survey of children and adolescents, to describe a number of behavior problem areas over the past three months, which are scored for EXT and INT problem behaviors. Mainieri (2006) reported Cronbach's alphas of .86 for EXT and .83 for INT in the PSID-CDS II sample. The modification of the BPI used in the CLP was created for the purpose of obtaining self-reports of problem behaviors. Items were reworded to fit the format of self-report, but the contents of the items did not change. Sample items include, "I cheated or told lies," "I cried too much," and "I was impulsive, or acted without thinking." Items are rated on a 3-point scale, labeled "often true," "sometimes true," or "not true." Items were reverse-coded prior to analysis, such that $1=$ "not true" and $3=$ "often true," in order to simplify interpretation. Cronbach's alphas for the present sample were .81 and .85 for the EXT and INT, respectively.

Moderators of Outcome (Gender and Ethnicity)

The Background Information Form (BIF) is a record of demographic information completed by all participants in the YDP program. It provided the demographic data used in the analyses (gender, age, and ethnicity - Hispanic/Latino, African American, NonHispanic White, Bi-ethnic, and Other) as exogenous moderators. 
Results

Preliminary Analyses

Descriptive Statistics

Table 1 presents descriptive statistics (mean, standard deviation, skewness and kurtosis) for continuous outcome variables at Baseline (BL), Follow-up 1 (FU1), and Follow-up 2 (FU2). These include subscales of the Transformative Goal Attainment Scale: Transformative Goal Attainment (TGA) and the Behavior Problem Index: Internalizing (INT) and Externalizing (EXT) problem behaviors.

Table 1: Descriptive Statistics for Continuous Outcome Variables

\begin{tabular}{lcccc}
\hline Outcomes & M & SD & Skewness & Kurtosis \\
\hline CPS at BL & .087 & .263 & 3.501 & 9.115 \\
CPS at FU1 & .116 & .277 & 3.331 & 7.877 \\
LG at BL & .071 & .257 & 3.372 & 9.459 \\
LG at FU1 & .078 & .268 & 3.179 & 8.186 \\
TGA at BL & 3.315 & .899 & .672 & 1.003 \\
TGA at FU1 & 3.954 & .918 & .711 & 1.328 \\
INT at BL & 1.680 & .446 & .462 & -.533 \\
INT at FU1 & 1.571 & .392 & .642 & .066 \\
INT at FU2 & 1.601 & .403 & .475 & -.437 \\
EXT at BL & 1.771 & .401 & .275 & -.185 \\
EXT at FU1 & 1.709 & .412 & .272 & -.671 \\
EXT at FU2 & 1.679 & .376 & .470 & .160 \\
\hline
\end{tabular}


Table 2 presents the number and proportion of responses assigned to Level 1 and Level 2 subcategories of the Life Goal (LG) variable. Baseline evaluation indicated that $92 \%$ of descriptions of participants' most important life goals had the non-personally expressive property and, more specifically, that the majority of responses $(75 \%)$ had the self-satisfying property. This proportion was similar for both males and females and for both Hispanic and African American participants (ranging from 75\% to 76\% within each subgroup), as well as among age subgroups (ranging from $71 \%$ to $83 \%$ ) The variation in proportions by age was not significant $\left(\chi^{2}=1.515, \mathrm{df}=4, p=.82\right)$.

Table 2: Descriptive Statistics for Life Goal

\begin{tabular}{lcc}
\hline Level 1 Subcategories & $\mathrm{n}$ & $\%$ \\
\hline Personally Expressive Life Goal at BL & 18 & $8 \%$ \\
Personally Expressive Life Goal at FU1 & 18 & $8 \%$ \\
Non-Personally Expressive Life Goal at BL & 206 & $92 \%$ \\
Non-Personally Expressive Life Goal at FU1 & 211 & $92 \%$ \\
\hline Level 2 Subcategories & $\mathrm{n}$ & $\%$ \\
\hline Personally Expressive through Self at BL & 17 & $8 \%$ \\
Personally Expressive through Self at FU1 & 15 & $7 \%$ \\
Personally Expressive through Others at BL & 1 & $.4 \%$ \\
Personally Expressive through Others at FU1 & 3 & $1 \%$ \\
Benefit of Others at BL & 12 & $5 \%$ \\
Benefit of Others at FU1 & 6 & $3 \%$ \\
Self Satisfying at BL & 168 & $75 \%$ \\
Self Satisfying at FU1 & 174 & $76 \%$
\end{tabular}


Prove to Others at BL

Prove to Others at FU1

Mixed Prove to Others/Self Satisfying at BL

Mixed Prove to Others/Self Satisfying at FU1

Mixed Self Satisfying/Benefit of Others at BL

Mixed Self Satisfying/Benefit of Others at FU1
3

$2.9 \%$

$13 \quad 6 \%$

$9 \quad 4 \%$

$10 \quad 4 \%$

$20 \quad 9 \%$

Table 3 presents the number and proportion of responses assigned to Level 1 and Level 2 subcategories of the Critical Problem-Solving (CPS) variable. For critical problem-solving, baseline evaluation indicated that $91 \%$ of descriptions of participants' alternatives for achieving their most important life change goal demonstrated uncritical thinking and, the greatest portion of which (76\%) possessed the challenged thinking property. This proportion was similar for both males and females and for both Hispanic and African American participants (ranging from 62\% to 69\% within each subgroup), as well as among age subgroups (ranging from 64\% to 71\%) The variation in proportions by age was not significant $\left(\chi^{2}=1.935, \mathrm{df}=4, p=.79\right)$.

Table 3: Descriptive Statistics for Critical Problem-Solving

\begin{tabular}{lcc}
\hline Level 1 Subcategories & $\mathrm{n}$ & $\%$ \\
\hline Critical Thinking at BL & 21 & $9 \%$ \\
Critical Thinking at FU1 & 28 & $12 \%$ \\
Uncritical Thinking at BL & 220 & $91 \%$ \\
Uncritical Thinking at FU1 & 213 & $88 \%$ \\
\hline
\end{tabular}




\begin{tabular}{lcc}
\hline Level 2 Subcategories & $\mathrm{n}$ & $\%$ \\
\hline Accomplished Thinking at BL & 2 & $.8 \%$ \\
Accomplished Thinking at FU1 & 2 & $.8 \%$ \\
Advanced Thinking at BL & 4 & $2 \%$ \\
Advanced Thinking at FU1 & 6 & $2 \%$ \\
Rudimentary Thinking at BL & 15 & $6 \%$ \\
Rudimentary Thinking at FU1 & 20 & $8 \%$ \\
Challenged Thinking at BL & 183 & $76 \%$ \\
Challenged Thinking at FU1 & 178 & $74 \%$ \\
Unreflective Thinking at BL & 37 & $15 \%$ \\
Unreflective Thinking at FU1 & 35 & $14 \%$ \\
\hline
\end{tabular}

Outliers, Missing Data, and Non-Normality

Prior to the main analysis, data for the continuous variables were evaluated for outliers and normality. Outliers were evaluated by examining leverage statistics for each individual; an outlier was defined as an individual with a leverage score four times greater than the mean leverage. No outliers were found. Kurtosis and skewness for continuous variables were within acceptable ranges (see Table 1).

Main Analyses

Model 1 (Figure 4), the hypothesized Outcome Mediation Cascade (OMC) model, was evaluated using a Structural Equation Modeling (SEM) approach for modeling hypothesized causal pathways of intervention change. Model specification was guided by 
Figure 1. Figure 5 and Tables 4 and 5 present the results (outcome, moderation, and mediation) for Model 1, including relations between the hypothesized mediator (CPS), the two positive identity outcome variables (LG and TGA), and the two problem behavior outcome variables (INT and EXT) for the full sample.

Interaction effects for the moderated relationships were tested using product terms (Jaccard \& Turrisi, 2003). Two-valued dummy variables for two exogenous interpersonal contextual covariates, Gender (G) and Ethnicity (E), were included in the analysis of outcome as measured at pretest, as were all possible interaction terms (i.e., CLP*G, CLP*E, G*E, CLP* $\mathrm{G}^{*} \mathrm{E}$ ), with CLP designated as the focal independent variable. Nonsignificant interactions were dropped from the final model, leaving one significant interaction term $\left(\mathrm{CLP}^{*} \mathrm{G}\right)$. To reduce clutter and improve visual clarity, the model in Figure 5 excludes the paths associated with $\mathrm{G}$ and $\mathrm{CLP} * \mathrm{G}$, however, the simple main effects are included in the model. Participants' age and scores of outcomes at BL were included as covariates.

The fit of Model 1 was evaluated with Mplus 5.0 (Muthen \& Muthen, 1998-2007) using the sample covariance matrix as input and a robust weighted least squares solution. The model is statistically overidentified. Data analysis used the robust WLSMV estimator available in Mplus in order to adjust the parameter estimates, standard errors, and fit indices for the categorical nature of the Life Goal variable. The WLSMV estimator provides weighted least square parameter estimates using a diagonal weight matrix with standard errors and a mean- and a variance-adjusted chi-square test statistic with a full weight matrix (Muthen \& Muthen, 1998-2007). Computation of standard errors and the 
chi-square test of model fit took into account non-independence of observations because of cluster sampling, specifically to account for possible counseling group clustering effects.

The WLSMV estimator allows data to be missing completely at random (MCAR), and it allows data to be missing at random (MAR) if missingness is a function of covariates but not if it is a function of outcomes. Cases with incomplete covariate data were not included in the model analysis, resulting in a data set of 241 cases. These data were assessed for missingness and appear to meet the specified criteria. Although a high percentage of data for the FU2 evaluation was missing ( $42 \%$ missing for INT and EXT at FU2), less than 5\% missing data were identified for FU1. In addition, dummy variables were created for missing data and correlated with gender, ethnicity, age, and school location, as well as all other variables included in the model. Missing data were not strongly correlated (all correlations were less than .17) with any of these variables.

Following recommendations of Bollen and Long (1993), a variety of global fit indices were used, including indices of absolute fit, indices of relative fit and indices of fit with a penalty function for lack of parsimony. First, the chi-square and its probability value ( $p$-value) were examined. The higher the $p$-value is, the closer the fit between the hypothesized model and model fit (Byrne, 2001), with a target $p$-value of greater than .05. The comparative fit index (CFI) was used as an index of fit in the comparison of the hypothesized model with the independence model. A CFI value of greater than .95 was used to indicate model fit. The root mean square error of approximation (RMSEA) accounts for the error of approximation in the population. An RMSEA of less than .08 , 
and a $p$-value for the test of closeness of fit for the RMSEA of greater than .50 were used to indicate model fit. The weighted root mean square residual (WRMR) measures the weighted average differences between the sample and estimated population variances and covariances and is suited for categorical data (Yu \& Muthen, 2002; Finney \& Distefano, 2006). A WRMR of less than .90 was used to indicate model fit, with smaller values indicating better fit.

The overall chi square test of model fit of Model 1 was statistically nonsignificant, $(\chi 2(7)=5.651, \mathrm{p}=.83$. The RMSEA was .00. The CFI was 1.00 . WRMR was .319. Thus, fit indices were consistent with good model fit. The model in Figure 5 presents only statistically significant paths for visual clarity, while Tables 4 and 6 present the parameter estimates for the major analyses. 
Figure 5: OMC Model Results

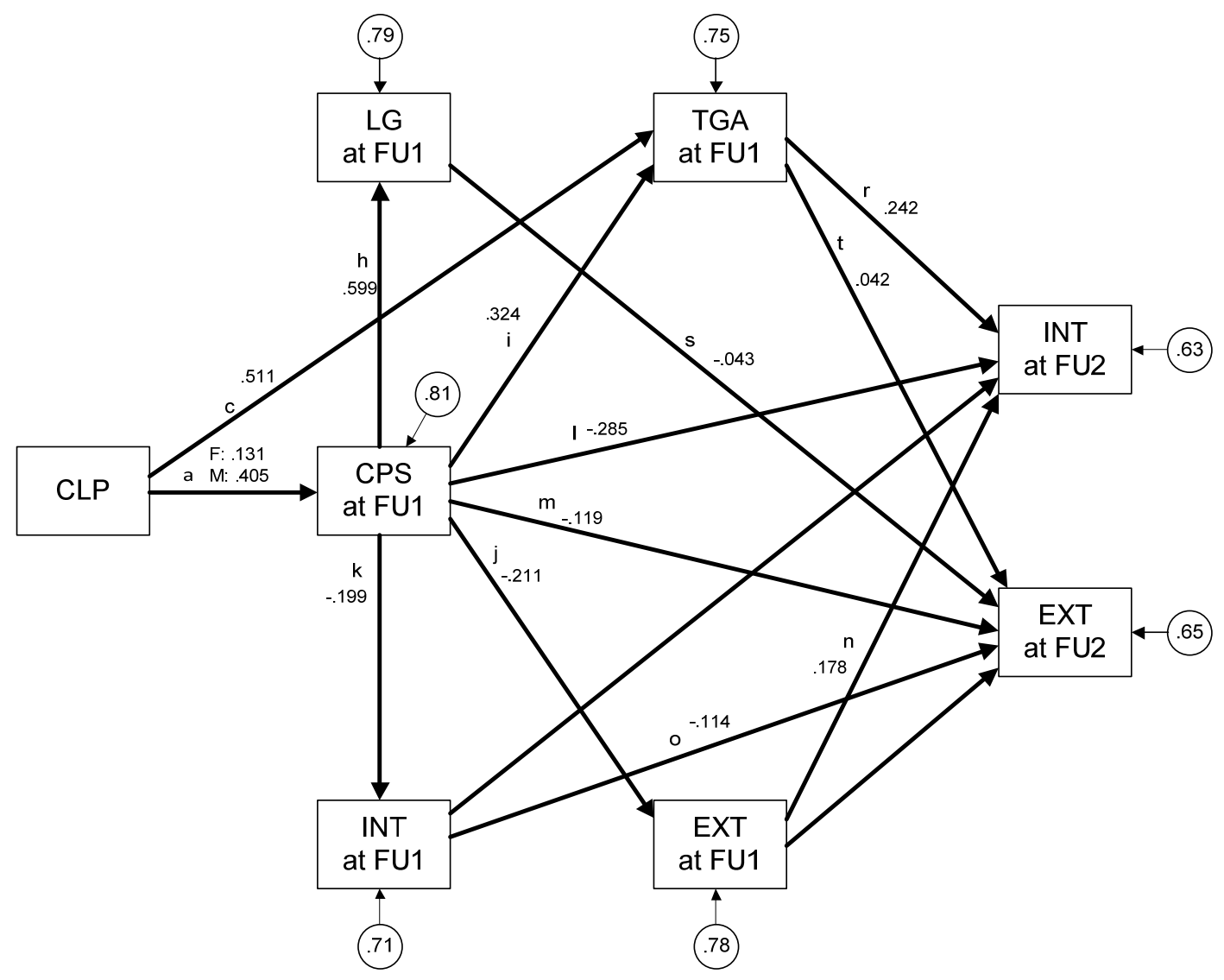

Hypothesized Direct and Moderated Intervention Effects

Following the logic of Rausch, Maxwell, and Kelly (2003), the scores of the baseline measures $\left(\mathrm{CPS}_{1}, \mathrm{LG}_{1}, \mathrm{TGA}_{1}, \mathrm{INT}_{1}, \mathrm{EXT}_{1}\right)$ were used for the analysis of covariance of a quasi-experimental outcome design with two waves of assessment (BL, FU1) to evaluate whether participation in the CLP was associated with change in CPS, LG, TGA, INT, and EXT relative to the comparison control condition. Specifically, CLP was defined as a two-valued dummy variable (scored 1 or 0 ) for the two intervention conditions (CLP vs. comparison control). By design, difference in this variable was 
hypothesized to be related to differential outcome (change in CPS, LG, TGA, INT, EXT) at FU1 $\left(\mathrm{CPS}_{2}, \mathrm{LG}_{2}, \mathrm{TGA}_{2}, \mathrm{INT}_{2}, \mathrm{EXT}_{2}\right)$ controlling for BL $\left(\mathrm{CPS}_{1}, \mathrm{LG}_{1}, \mathrm{TGA}_{1}, \mathrm{INT}_{1}\right.$, $\left.\mathrm{EXT}_{1}\right)$. The hypothesized differences were evaluated using covariate-adjusted change in which the measure of the outcome at BL and the outcome at the FU1 are strategically used as covariates to define different features of change (Rausch et al., 2003).

The pattern of findings provided evidence of a significant relationship between CLP and change in TGA. Examination of group means indicates that TGA scores for the intervention group increased more than TGA scores for the comparison control group (see Table 5 for mean change). For LG, a personally expressive life goal (i.e., life goals with the personally expressive property) versus a non-personally expressive life goal (i.e., life goals without the personally expressive property) was also represented by a twovalued dummy variable (scored 1 = assignment to the Personally Expressive subcategory, $0=$ assignment to the Non-personally Expressive subcategory). Results indicated that the direct relationship between CLP and change in LG (path b) was not significant. As can be seen from Figure 5 and Table 6, the pattern of findings also did not provide evidence of significant relationships between CLP and changes in the untargeted problem outcome variables (INT and EXT; paths $d$ and e). 
Table 4: Summary of Major Path Analyses for Mediator and Positive Outcomes

\begin{tabular}{llccc}
\hline Outcomes & Predictors & Path coefficient & P-value & 95\% CI \\
\hline $\mathrm{CPS}_{2}$ & CLP*G & $.512(.870)$ & .005 & .138 to .881 \\
& CLP - Female (path a) & $.131(.223)$ & .090 & .035 to .231 \\
& CLP - Male (path a) & $.405(.689)$ & $<.001$ & .109 to .696 \\
& Age & $-.077(1.31)$ & .196 & -.096 to -.023 \\
LG $_{2}$ & CLP (path b) & $-.237(-.200)$ & .841 & -2.554 to 2.079 \\
& CPS $($ path h) & $-.599(-.295)$ & .001 & -1.113 to -.246 \\
& Age & $.301(.285)$ & .058 & -.010 to .613 \\
& CLP (path c) & $.511(.541)$ & .006 & .234 to .722 \\
TGA $_{2}$ & CPS $($ path i) & $.324(.382)$ & .057 & .003 to .557 \\
& Age & $.017(.029)$ & .450 & -.004 to .033 \\
\hline
\end{tabular}

Note. Standardized coefficients shown in parentheses.

Table 5: Mean Change in Continuous Outcomes

\begin{tabular}{lllll}
\hline & & \multicolumn{3}{c}{$\mathrm{M}$} \\
\cline { 3 - 5 } Outcomes & & $\mathrm{BL}$ & $\mathrm{FU1}$ & FU2 \\
\hline CPS & CLP & .089 & .116 & \\
& Ctrl & .086 & .090 & \\
INT & CLP & 1.756 & 1.601 & 1.645 \\
& Ctrl & 1.587 & 1.529 & 1.540 \\
EXT & CLP & 1.855 & 1.753 & 1.697 \\
& Ctrl & 1.671 & 1.649 & 1.654 \\
\hline
\end{tabular}

Note. Means are not adjusted for covariates. 


\section{Hypothesized Mediation of Positive Outcomes}

Hypothesized mediation (see Figure 4) was evaluated with the joint significance test (MacKinnon, Lockwood, Hoffman, West, \& Sheets, 2002) by significance of the paths associated with the causal chains between distal variables and change in hypothesized mediating variables (including positive outcomes hypothesized to mediate change in problem outcomes) and, in turn, the association between change in mediating variables and change in outcome variables. In addition, the baseline measures of the hypothesized mediators were modeled as covariates for the outcomes variables (and thus held constant) in order to model the relationship between change in mediators and change in outcomes. All hypothesized mediated relationships were modeled in this manner; these paths were not included in Figure 5 to improve visual clarity.

The variable CLP had a statistically significant relationship with change in CPS, the hypothesized mediator. Specifically, the path coefficient for the relationship between CLP and change in CPS was statistically significant, but the relationship was moderated by gender, indicating a moderated specificity of effect. The 2-way CLP x Gender $(C L P * G)$ interaction term had a statistically significant coefficient when predicting change in CPS $(\beta=.512, p<.01,95 \% \mathrm{CI}=.138$ to .881$)$, indicating that intervention change in CPS differed between males and females. Among female participants, the path coefficient for the relationship between CLP and change in CPS was significant (path a; $\beta$ $=.131, p=.09,95 \% \mathrm{CI}=-.035$ to .331$)$. Among male participants, the path coefficient was also significant (path a; $\beta=.405, p<.001,95 \% \mathrm{CI}=.109$ to .696 ), indicating that the intervention group increased in CPS relative to the comparison control group, and that 
this effect was more pronounced in male participants compared to their female counterparts.

Findings provided support for CPS as a plausible moderated mediator of the relationship between CLP and change in TGA and between CLP and qualitative change in LG. Findings indicated that BL to FU1 change in CPS was significantly associated with contemporaneous change in TGA (path $\mathrm{i} ; \beta=.324, p<.06,95 \% \mathrm{CI}=-.003$ to .557 ).

Table 6: Summary of Major Path Analyses of Effects on Problem Outcomes

\begin{tabular}{|c|c|c|c|c|}
\hline Outcomes & Predictors & Path coefficient & P-value & $95 \% \mathrm{CI}$ \\
\hline \multirow[t]{3}{*}{$\mathrm{INT}_{2}$} & CLP (path d) & $.001(.004)$ & .976 & -.083 to .086 \\
\hline & $\mathrm{CPS}_{2}$ (path k) & $-.199(-.338)$ & .001 & -.272 to -.055 \\
\hline & Age & $.003(.008)$ & .911 & -.049 to .054 \\
\hline \multirow[t]{6}{*}{$\mathrm{INT}_{3}$} & CLP (path f) & $.006(.016)$ & .970 & -.335 to .348 \\
\hline & $\mathrm{CPS}_{2}$ (path 1) & $-.285(-.394)$ & .001 & -.445 to -.077 \\
\hline & $\mathrm{LG}_{2}$ (path q) & $-.153(-.903)$ & .001 & -.241 to -.066 \\
\hline & $\mathrm{TGA}_{2}$ (path r) & $.242(.411)$ & .045 & .065 to .424 \\
\hline & $\mathrm{EXT}_{2}$ (path o) & $.178(.183)$ & .030 & .018 to .339 \\
\hline & Age & $.015(.041)$ & .682 & -.056 to .085 \\
\hline \multirow[t]{3}{*}{$\mathrm{EXT}_{2}$} & CLP (path e) & $.041(.098)$ & .443 & -.064 to .146 \\
\hline & $\mathrm{CPS}_{2}$ (path j) & $-.211(-.358)$ & $<.001$ & -.299 to -.045 \\
\hline & Age & $.030(.083)$ & .158 & -.012 to .073 \\
\hline \multirow[t]{3}{*}{$\mathrm{EXT}_{3}$} & CLP (path g) & $-.016(-.044)$ & .819 & -.156 to .123 \\
\hline & $\mathrm{CPS}_{2}$ (path m) & $-.119(-.202)$ & .054 & -.201 to .013 \\
\hline & $\mathrm{LG}_{2}$ (path s) & $-.043(-.499)$ & .819 & -.137 to .052 \\
\hline
\end{tabular}




$\begin{array}{llll}\mathrm{TGA}_{2} \text { (path t) } & -.042(-.071) & .325 & -.066 \text { to } .111 \\ \mathrm{INT}_{2} \text { (path p) } & -.114(-.118) & .063 & -.234 \text { to } .006 \\ \text { Age } & -.014(-.042) & .653 & -.012 \text { to } .073\end{array}$

Note: Standardized path coefficients shown in parentheses.

The relationship between CPS and LG was modeled using the latent response formulation for categorical outcomes as implemented in Mplus 5.0 with the WLSMV estimator (Muthen \& Muthen, 1998-2007) - an approach which models the observed categorical response variable as the realization of a latent continuous response variable. Specifically, the observed ordinal value changes when a probit threshold is exceeded on the latent continuous variable (Muthen, 1998-2004). In the case of the dichotomous LG variable, there is a single probit threshold for the latent continuous variable such that Life Goal $=1$ (Personally Expressive) when this threshold is exceeded and Life Goal $=0$ (Non-personally Expressive) when the threshold is not exceeded. The probit regression coefficients generated by the analysis were interpreted in terms of probability units (i.e., probits) and reflect the relationship between a one unit change in a mediator and the probability that Life Goal $=1$ (see Agresti, 2007). Findings indicated that change in CPS was significantly associated with the probit of contemporaneous change in LG (path $\mathrm{h} ; \beta$ $=-.599, p<.01,95 \% \mathrm{CI}=-1.113$ to -.246$)$. The relationship between TGA and LG was modeled in the same manner, although no significant association was found.

\section{Hypothesized Mediation of Problem Outcomes}

Findings provided support for CPS as a moderated mediator of the relationship between CLP and changes in INT and EXT. Findings indicated that BL to FU1 change in 
CPS was significantly associated with contemporaneous change in INT (path $\mathrm{k} ; \beta=-$ $.199, p=.001,95 \% \mathrm{CI}=-.272$ to -.055$)$ and EXT (path $\mathrm{j} ; \beta=-.211, p<.001,95 \% \mathrm{CI}=-$ .299 to -.045$)$. In addition, BL to FU1 change in CPS was significantly associated with change in INT at FU2 (path $1, \beta=-.285, p=.001,95 \% \mathrm{CI}=-.445$ to -.077 ). Change in CPS was also significantly associated with change in EXT at FU2 (path $\mathrm{m} ; \beta=-.119, p<$ $.06,95 \% \mathrm{CI}=-.201$ to .013$)$.

Hypothesized Cascade Effects

With regard to hypothesized cascade effects, that is, intervention effects in untargeted problem outcomes mediated by change in targeted positive outcomes, analyses provided support for three plausible causal chains that represent intervention cascade effects mediated by qualitative change in life goals and transformative life goals. The findings provided support for LG and TGA as mediators of the relationship between $\mathrm{CLP}$ and INT and EXT as part of the pathways CLP $\rightarrow \mathrm{CPS}_{2} \rightarrow \mathrm{LG}_{2} \rightarrow \mathrm{INT}_{3}$ (paths a, h, q), $\mathrm{CLP} \rightarrow \mathrm{CPS}_{2} \rightarrow \mathrm{TGA}_{2} \rightarrow \mathrm{INT}_{3}$ (paths a, i, r), and CLP $\rightarrow \mathrm{CPS}_{2} \rightarrow \mathrm{TGA}_{2} \rightarrow \mathrm{EXT}_{3}$ (paths a, i, t). 


\section{DISCUSSION}

\section{Developing a Qualitative Measure of Cognitive Competence}

Prior to the current study, there has been little research done to evaluate the effectiveness of PYD interventions in promoting cognitively-focused identity exploration collected through the use of free-response qualitative measures of critical thinking as a cognitively-focused identity exploration "competence" as part of the identity formation process. The construct of cognitive competence has clear implications in positive youth development, particularly in disempowered populations, but it has still managed to be severely understudied within the context of adolescent development. Even within the limited literature on problem-solving skills as a developmental asset, much of the previous work has tended to focus on creative and hypothetical thinking. Given this, the results of the current study go some way towards addressing a gap in the literature by focusing instead on the willingness to question or challenge one own choices (critical thinking), rather than on creative or hypothetical thinking. The Critical Problem-Solving Skills Scale - Qualitative Extension (CPSS-QE) also taps into the exploration of psycholinguistic meaning making in addressing the frequently overwhelming life challenges multi-problem youth face, whereas the majority of problem-solving measures in use in adolescent populations lack similarly relevant "real world" content.

The emergence of a growing interest in developing and evaluating PYD intervention programs to facilitate the promotion of problem-solving skills has called attention to the need for more detailed and specific knowledge of effective intervention strategies. To this end, the development of workable and effective interventions requires 
knowledge concerning specific components of the cognitive competence development process and how such processes are related to behavioral outcomes in the normal course of development.

The development of the CPSS-QE advances cognitive competence research on troubled youth by extending a measure that, while useful, had previously only produced quantitative estimates of creativity and hypothetical thinking. The CPSS-QE not only introduces a much needed qualitative component to this body of work, but it also attempts to capture a more developmentally advanced subset of problem-solving skills than is usually studied - critical evaluation.

Evaluating the Intervention: Outcome, Mediated, and Cascade Effects

The evaluation of the OMC model's fit to the data used in this study yielded several encouraging results. With respect to direct positive effects, the findings provided empirical support for the hypothesis that participation in the intervention has significant effects on both of the study's positive outcome variables. First, the evaluation of the Changing Lives Program indicated that participation in the intervention was associated with a differential change consistent with the hypothesized aims of the intervention in participants' reported attainment of transformative life goals, relative to comparison control group participants. Transformative goal attainment - i.e., a feeling of successfully negotiating some qualitative change in one's life from a perceived negative to a perceived positive - (as an index of mastery experience) is seen as a key intervention outcome in PYD programs. With respect to the second positive outcome variable included in the model, the full information investigation of the OMC evaluation model did not provide 
evidence of a direct intervention effect on the probability of a personally expressive life goal, a marker of an increasingly integrated and complex self-structure. However, the mediated effects that were discovered (discussed below), shed considerable light on the mechanisms through which the expression of personally expressive life goals are promoted by the intervention.

Although the results of this study did not provide evidence of direct intervention effects on untargeted internalizing or externalizing problem behaviors, the findings did suggest several mediated and cascading causal pathways through which the intervention had an effect on problem outcomes - pathways that were consistent with those identified in the hypothesized model. These effects are described in more detail below. In addition, results suggested that the problem outcomes studied (internalizing and externalizing behaviors) were linked over time.

Turning now to the developmental construct that formed the core of the model under investigation, the pattern of results provided support for the hypothesis that critical thinking mediates intervention effects on positive and problem outcomes. Specifically, results indicated that participation in the CLP was associated with a baseline (BL) to first follow-up (FU1) increase in critical thinking in the intervention group, relative to the comparison control group. Results further indicated that BL to FU1 change in critical thinking was associated with BL to FU1 change in transformative goal attainment, the probability of a personally expressive life goal, and internalizing and externalizing problem behaviors. In addition, BL to FU1 change in critical thinking was associated with FU1 to second follow-up assessment (FU2) change in internalizing and 
externalizing problem behaviors. Thus, the findings provided support for critical thinking as a mediator of contemporaneous changes in transformative goal attainment (CLP $\rightarrow \mathrm{CPS}_{2} \rightarrow \mathrm{TGA}_{2}$ ), the probability of a personally expressive life goal (CLP $\rightarrow \mathrm{CLP}_{2}$ $\left.\rightarrow \mathrm{LG}_{2}\right)$, internalizing problem behaviors (CLP $\rightarrow \mathrm{CPS}_{2} \rightarrow \mathrm{INT}_{2}$ ) and externalizing problem behaviors (CLP $\rightarrow \mathrm{CPS}_{2} \rightarrow \mathrm{EXT}_{2}$ ), as well as progressive changes in internalizing problem behaviors (CLP $\rightarrow \mathrm{CPS}_{2} \rightarrow \mathrm{INT}_{3}$ ) and externalizing problem behaviors (CLP $\rightarrow \mathrm{CPS}_{2} \rightarrow \mathrm{EXT}_{3}$ ).

From the perspective of PYD intervention and prevention programs, which hold that these approaches are meant to promote positive change in person $\leftrightarrow$ context relations (Schwartz et al., 2007), the finding that change in critical problem-solving skills mediated all of this study's positive and problem outcomes is particularly intriguing. The possibility that changes in psychosocial dimensions indicate changes in the person $\leftrightarrow$ context relations targeted by PYD and prevention interventions is in line with Theokas et al.'s (2005) findings highlighting the lack of pure discrimination between positive identity and connections with social contexts, as well as Erikson's (1963) description of identity as an inward and outward sense of continuity and sameness. However, the conclusions that can be drawn from the current findings are limited. Future research should consider pursuing this issue, for example, by investigating person $\leftrightarrow$ context relations that result in change in critical thinking performance, because this line of inquiry has the potential to refine current knowledge of effective intentional person $\leftrightarrow$ context intervention processes. 
The results of the hypothesized OMC model also shed light on some notable "spilling over" or cascading effects of the intervention on problem outcomes, through its (mediated) effects on positive outcomes. This study operationalized the concept of an intervention $\leftrightarrow$ developmental cascade as the statistical mediation of the relationship between participation in the CLP intervention and differential change in problem behavior outcomes (internalizing and externalizing) by differential change in positive identity outcomes (the probability of a personally expressive life goal and transformative goal attainment). The analyses identified several causal pathways through which change in attainment of transformative goals and the presence or absence of a personally expressive life goal mediated the effects of the intervention on progressive change in internalizing problem behaviors, and to a lesser extent, externalizing problem behaviors.

Findings provided support for significant change in critical thinking performance and theoretically meaningful qualitative (categorical) change in participants' most important life goals as mediators of progressive change in internalizing problem behaviors through several causal pathways. The qualitative change in participants' life goals from non-personally expressive to personally expressive from BL to FU1 was associated with a decrease in internalizing problem behaviors from FU1 to FU2. Also, the change in transformative goal attainment from BL to FU1 was associated with a decrease in both internalizing and externalizing behavior from FU1 to FU2. Thus, findings provided support for change in critical thinking performance and qualitative change in participants' life goals as mediators of progressive change in problem behaviors via the following pathways: $\mathrm{CLP} \rightarrow \mathrm{CPS}_{2} \rightarrow \mathrm{LG}_{2} \rightarrow \mathrm{INT}_{3}, \mathrm{CLP} \rightarrow \mathrm{CPS}_{2} \rightarrow \mathrm{TGA}_{2} \rightarrow \mathrm{INT}_{3}$, and $\mathrm{CLP} \rightarrow \mathrm{CPS}_{2} \rightarrow \mathrm{TGA}_{2} \rightarrow \mathrm{EXT}_{3}$ 
These findings make an initial contribution to closing the gap in our knowledge of the relationship between intervention change in positive outcomes and intervention change in problem outcomes. They provide preliminary evidence consistent with the hypothesis that in addition to having an effect on targeted positive outcomes, PYD interventions are likely to have progressive cascading effects on untargeted problem outcomes, that is, mediated intervention effects on problem outcomes that operate through effects on positive outcomes (Eichas, 2010). The pattern of findings was also consistent with the hypothesis that the causal effects that are generated for both positive and problem outcomes are likely to follow complex pathways that interact in multifaceted ways with moderator and mediator variables rather than solely flowing directly from intervention to positive outcomes.

\section{Theoretical and Methodological Contributions}

At the broadest level, the research on the development of free-response qualitative measures of critical thinking as a cognitively-focused identity exploration "competence" reported here is part of a broader effort to advance the unification of psychological/developmental science and sociological/anthropological science. The employment of a grounded theory approach in the development of the CPSS-QE emphasizes theory construction, as it uses data collected on human participants in field or community settings. This is in contrast to the experimental tradition that evolved in psychological/developmental research emphasizing the evaluation of theory (vis-à-vis hypothesis testing) using data collected under rigorously controlled clinic/lab settings and frequently intended to generalize to human and nonhuman species (i.e., species that are 
not language using, culture bearing, meaning making). Consequently, qualitative research methods, such as theoretical sampling and saturation (as developed for use in grounded theory), have tended to be used to develop and refine theory regarding the linkages between inner psychological states (e.g., subjective meaning and significance of life course experiences) and observed human behavior in real time and in real world human ecologies, as interpreted by the researcher and, more important, by the participants themselves - a context in which theory development is justifiably considered still in the discovery stage (Kurtines et al., 2008). In this way, the work undertaken as part of the current study has the potential to enhance the evolution of new theory through the development and refinement of a unified data analytic strategy (RDA), and through the development of a measure that captures in "real time" the temporal dimension of intervention, developmental, and historical change.

The main objective of RDA research analysis is to test and evaluate evolving theoretical perspectives against the evolving developmental and socio-cultural historical reality revealed by the changing content and structural organizational properties of the meaning and significance of the content of participants' free-response data as captured and rendered explicit and intelligible by the $\mathrm{COC}$ and TOC coding processes of RDA (Kurtines et al., 2008). In other words, RDA allows for the construction and evaluation of an array of developmentally appropriate unstructured response measures that are capable of capturing change in the meaning and significance of the life course experiences of participants in the CLP intervention, their positive development, and historical change.

As noted by Kurtines et al. (2008), and in the context of the distinctly different historical evolution of contemporary psychological and developmental science and 
sociological and anthropological science, our broadest aim is to investigate the analytic utility of uniting (within an RDA framework) qualitative and quantitative methods representative of these two distinct research traditions, the quantitative/experimental research tradition associated with clinic/lab based psychological/developmental sciences, and the qualitative/field research tradition associated ethnographic/community based sociological/anthropological sciences. Most important in terms of contributing to the broader process of knowledge development, when RDA is used within a repeated measures design to analyze unstructured free-response data, it helps to ensure that in such research designs the $\mathrm{COC}$ and TOC phases of the RDA analysis will uncover new categories of the meaning and significance of life course experience as they emerge at the leading edge of developmental and historical change (Kurtines et al., 2008). Thus, RDA is designed to be used in ways that maximize the likelihood that new content categories identified during conceptual analysis will not be obscured or overlooked. The challenge for the investigator and the theoretical research team is to transform these conceptual categories into theoretically meaningful constructs and concepts and, ultimately, into data driven theories to be evaluated by both quantitative and qualitative data analytic strategies.

Furthermore, this paper contributes to the evaluation of the theoretical and empirical utility of integrating developmental and intervention science in the service of promoting positive youth development (PYD), through the employment of the Outcome Mediation Cascade (OMC) model. Rooted in concepts and constructs drawn from applied developmental science (Lerner, Fisher, \& Weinberg, 2000), the aims of developmental intervention science include the development and evaluation of evidence-based 
intervention strategies that draw on developmental and intervention science in promoting positive development and in reducing problem behaviors. Using this approach, Study II expanded on previous work that was conducted to evaluate the hypothesized cascade effects of a PYD intervention that specifically targeted positive identity development in at-risk adolescents (Eichas, 2010). The OMC model described in the second study expands on the outcome mediation model described in the treatment literature (Silverman et al., 2009) by adding features of the developmental cascade model described in the developmental psychopathology literature (Masten, 2005; Cicchetti \& Cohen, 2006). Thus, these analyses contributed to advancing our knowledge (both theoretical and empirical) of how interventions work.

\section{Directions for Future Research: A Gender Divergence}

One possible refinement to the investigation of the $\mathrm{OMC}$ evaluation model in the Research Analysis phase is to undertake a more comprehensive analysis of moderation of intervention cascade effects by relevant contextual factors. The moderation analyses conducted by this study represent an initial attempt to identify relevant contextual moderators of intervention effects. The finding that a number of the cascade pathways identified by the analyses were moderated by gender (i.e., the pathways mediated by critical thinking) suggests the need for further research regarding the nature of this moderation. The potential results of future research naturally have significant implications for the design and implementation of targeted interventions. Specifically, a considerable gender divergence was found in the effects of critical thinking on both contemporaneous problem outcomes and progressive problem outcomes, with the effects 
across the board found to be more potent for males. Further research should investigate the factors that contribute to this increased salience of critical thinking skill development for male adolescents, compared to their female counterparts. Although previous research has long identified an existing gender divergence in internalizing problem behavior (particularly depression) during adolescence, the results of this study suggest that these behavior outcomes are highly mediated by the development of core developmental compentencies, particularly critical problem-solving.

In a wider sense, the moderating effect of gender that was found on several pathways in the model used for this study opens the door for further investigation of moderators in PYD interventions. Future research regarding moderation of intervention cascade effects should draw on Edwards and Lambert's (2007) model to investigate contextual moderation by examining second stage moderation (moderation of the relationship between the mediator/positive outcome and the outcome/problem behavior) in addition to direct effect moderation (moderation of the relationship between participation in the intervention and the outcome/problem behavior) and first stage moderation (moderation of the relationship between participation in the intervention and the mediator/positive outcome).

\section{Limitations}

Population

As tends to be the case in many studies on similar populations, limitations on the generalizability of the findings arise when one takes into consideration the nature of the sample utilized, i.e., multi-ethnic, multi-problem background adolescents in an urban 
setting. Although minority groups are largely understudied, a necessary caveat of studies such as this one is that the results may not be replicable in non-minority populations, adult populations, or adolescent populations from less maladaptive backgrounds.

\section{Missing Data and Participant Attrition}

The alternative high schools from which the sample was drawn do not record their own attrition data (Albrecht, 2007), however, Miami-Dade County Public Schools (MDCPS) reports county-wide graduation rates of approximately $59 \%$ and an official dropout rate of $4.5 \%$. On-time graduation rates are reported at $45.3 \%$ (Toppo, 2006). None of these figures account for students who are not officially withdrawn. Because little specific information is available regarding these students, it is possible that selection effects are potentially biasing results. Future YDP research should begin to address this issue.

Thus, the missing data found in the analyses may be associated with the nature of the population the intervention targets, i.e., a population composed of multi-problem adolescents in alternative high schools, many of whom are coming of age in disempowering contexts (Eichas, 2010). In order to allow the use of missing data in future models, researchers have a better understanding of the role that attrition plays in generating observed missing data patterns, as well as an understanding of the factors that contribute to participant attrition.

\section{Measurement Error}

The model analyzed in the present study also did not account for measurement error, in effect assuming no measurement error. Future studies should either use multiple 
indicators of the latent constructs included in the evaluation model or consider adopting the strategy suggested by Joreskog and Sorbom (1996) that involves depicting each measure as a single indicator of the associated underlying construct and constraining the error variances for each measure to values corresponding to a priori determined levels of reliability based on alpha coefficients or previous research (Eichas, 2010).

\section{Statistical Power and Sample Size Considerations}

To determine an appropriate sample size, structural equation modeling requires that in addition to statistical power, issues of the stability of the covariance matrix and the use of asymptotic theory be taken into account (Eichas, 2010). In the case of this study, with a sample of 241 used for the full information analyses, there was an effect on the statistical power available for analyses of the full model, especially with respect to analyses of dichotomous outcomes that require large sample sizes to capture the relationship, if any, between the independent and dependent variables, thereby increasing the likelihood of the occurrence of type II errors, i.e., the inability to detect small effects.

\section{Conclusions}

The first study reported in this paper, undertaken as part of a psychometric evaluation of measures in the evaluation of the Changing Lives Program (CLP), provides evidence that the measure under development (the CPSS-QE) has acceptably high psychometric properties (i.e., reliability and validity), particularly at the first order level of theoretical categories. The study also demonstrates the possibility of an integrated analysis of quantitative dimensional change and qualitative structural organizational change within a Relational Data Analysis framework. These findings provide evidence in 
support of undertaking a full-scale short-term controlled outcome trial, and evidence for a framework in which to utilize the CPSS-QE in evaluation of positive development programs for troubled multi-ethnic adolescents.

The second study reported here provides further support for hypothesized cascade effects in PYD interventions. A main contribution of this study was to provide empirical evidence for intervention $\leftrightarrow$ developmental cascades, specifically effects on positive identity outcomes that "spill over" to generate change in problem behaviors. This cascading dynamic was investigated by analyzing mediation of intervention effects on problem behaviors by positive identity outcomes. The intervention had significant effects on both positive identity outcomes, and both positive identity outcomes mediated intervention effects on problem behaviors. In addition, change in the hypothesized mediator was a significant mediator of change in all positive and problem outcomes. The relationship between the intervention and change in the mediator was moderated by gender. Future research is needed to evaluate moderation of intervention $\leftrightarrow$ developmental cascades.

The use of a structural equation modeling framework allowed for the simultaneous modeling of multiple pathways of intervention change, including direct, mediated, and moderated effects, as well as cascade effects. Specifically, another contribution of the study was the test of hypothesized relationships (direct, mediated, moderated) among theoretically meaningful qualitative structural organizational change in participants' critical thinking performance, quantitative dimensional positive and problematic outcomes, and participation in the CLP. Findings suggested (1) that an increase in critical thinking was associated with an increased probability of a personally 
expressive life goal; (2) that an increase in critical thinking generated by transformative goal pursuit was associated with an increased probability of the attainment of these change goals; (3) that the change from uncritical thinking to critical thinking was associated with a progressive decrease in internalizing problem behaviors; and (4) that participation in the CLP was associated with change from uncritical thinking to critical thinking in choosing alternative ways for achieving a life change goal.

Perhaps the key contribution of both studies described here is further illustration of the complex nature of the developmental processes at play during such a formative stage of the life course, particularly in the construction of a positive sense of identity. As complex as these processes and experiences may be, developmental research is still compelled to evolve to better reflect their nature. As such, studies such as these highlight the need for more integrated and refined models and methods, that is, models and methods that are capable of capturing information that move closer to representing the diversity of adolescent life course experiences. 


\section{REFERENCES}

Achenbach, T., \& Edelbrock, C. (1981). Behavioral problems and competencies reported by parents of normal and disturbed children aged four through sixteen. Monographs of the Society for Research in Child Development, 46(1), 1-82.

Adams, G. R., \& Marshall, S. K. (1996). A developmental social psychology of identity: Understanding the person-in-context. Journal of Adolescence, 19, 429-442.

Adams, G. R., Munro, B., Doherty-Poirer, M., Munro, G., Petersen, A. R., \& Edwards, J. (2001). Diffuse-avoidant, normative, and informational identity styles: Using identity theory to predict maladjustment. Identity, 1(4), 307-320.

Agresti, A. (2007). An introduction to categorical data analysis ( $2^{\text {nd }}$ Edition). Hoboken, NJ: John Wiley.

Albrecht, R. E. (2007). A model of self-transformative identity development in troubled adolescent youth. Unpublished Dissertation. Florida International University, Miami.

Anderson, R. J., Goddard, L., \& Powell, J. H. (2009). Social problem-solving processes and mood in college students: An examination of self-report and performancebased approaches. Cognitive Therapy and Research, 33(2), 175-186.

Arango, L. L., Kurtines, W. M., Montgomery, M. J., \& Ritchie, R. (2008). A multi-stage longitudinal comparative design stage II evaluation of the Changing Lives Program: The Life Course Interview (RDA-LCI). Journal of Adolescent Research, 23(3), 310-341.

Arnett, J. J. (1999). Adolescent storm and stress reconsidered. American Psychologist, 5, 317-326.

Arnett, J. J. (2000). Emerging adulthood: A theory of development from the late teens through the twenties. American Psychologist, 55, 469-480.

Benson, P. L. (2002). Adolescent development in social and community context: A program of research. New Directions for Youth Development, 95, 123-147.

Benson, P. L., Mannes, M., Pittman, K., \& Ferber, T. (2004). Youth Development, Developmental Assets, and Public Policy. In R. M. Lerner \& L. Steinberg (Eds.), Handbook of Adolescent Psychology (2nd ed., pp. 781-814). New York: John Wiley.

Benson, P. L., Scales, P. C., Hamilton, S. F., Sesma, A. Jr. (2006). Positive youth development: theory, research, and application. In W. W. Damon \& R. M. Lerner (Eds.), Handbook of Child Psychology, Volume 1, Theoretical models of human development. New York: John Wiley.

Berman, A. M., Schwartz, S. J., Kurtines, W. M., \& Berman, S. L. (2001). The process of exploration in identity formation. The role of style and competence. Journal of Adolescence, 24, 513-528. 
Berzonsky, M. D. (1989). Identity style: Conceptualization and measurement. Journal of Adolescent Research, 4, 267-281.

Brandtstadter, J. \& Lerner, R. M. (1999). Action and self-development: theory and research through the life-span. Thousand Oaks, CA: Sage.

Bollen, K. \& Long, S. (1993). Testing structural equation models. Newbury Park: Sage.

Byrne, B. M. (2001). Structural equation modeling with AMOS: Basic concepts, applications, and programming. Mahwah, NJ: Laurence Erlbaum Associates, Inc.

Catalano, R. F., Berglund, M. L., Ryan, J. A. M., Lonczak, H. S., \& Hawkins, J. D. (1999). Positive youth development in the United States: Research findings on evaluations of positive youth development programs. Washington, D.C.: U.S. Department of Health and Human Services.

Catalano, R. F., Berglund, M. L., Ryan, J. A. M., Lonczak, H. S., \& Hawkins, J. D. (2004). Positive youth development in the United States: Research findings on evaluations of positive youth development programs. The Annals of the American Academy of Political and Social Science, 591, 98-124.

Catalano, R. F. \& Hawkins, J. D. (1996). The social development model: A theory of antisocial behavior. In J. D. Hawkins (Ed.), Delinquency and crime: Current theories (pp. 149-197). New York: Cambridge University Press.

Catalano, R. F., Hawkins, J. D., Berglund, M. L., Pollard, J. A., \& Arthur, M. W. (2002). Prevention science and positive youth development: Competitive or cooperative frameworks? Journal of Adolescent Health, 31(6S), 230-239

Cicchetti, D. \& Cohen, D. J. (2006). Developmental Psychopathology (2 ${ }^{\text {nd }}$ ed., Vol. 3). New York: John Wiley and Sons.

Csikszentmihalyi, M. (1975). Beyond Boredom and Anxiety. San Francisco: Jossey-Bass.

Csikszentmihalyi, M. (1990). Flow: The Psychology of Optimal Experience. New York: Basic Books.

Csikszentmihalyi, M. (1998). The development of the person: An experiential perspective on the ontogenesis of psychological complexity. In Damon, W. \& Lerner, R.M. (Eds.), Handbook of child psychology, Vol 1: Theoretical models of human development. New York, NY: Wiley.

Damon, W. (2004). What is positive youth development? Annals of the American Academy of Political \& Social Science. Special Positive Development: Realizing the Potential of Youth, 591, 13-24.

Damon, W., Menon, J., \& Bronk, K. C. (2003). The development of purpose during Sdolescence. Applied Developmental Science, 7(3), 119-128.

de Rosenroll, D. A. (1988). Goal Attainment Scaling: A Vehicle for Group Support in Career and Life Issues Exploration. 19.

D'Zurilla, T. J., \& Nezu, A. M. (1999). Problem-solving therapy: A social competence approach to clinical intervention (2nd ed.). New York: Springer. 
Eichas, K. (2010). An investigation of multiple pathways of developmental intervention change. Unpublished Dissertation. Florida International University, Miami.

Eichas, K., Albrecht, R.E., Garcia, A., Ritchie, R.A., Varela, A., Garcia, A., Rinaldi, R., Wang, R., Montgomery, M.J., Silverman, W.K., Jaccard, J. \& Kurtines, W. K. (2010). A developmental intervention approach to promoting positive development: Pathways of intervention change. Child \& Youth Care Forum, 39(4), 211-237.

Elder, G. H. (1998). The life course and human development. In R. M. Lerner (Ed.), Handbook of child psychology, Vol. 1: Theoretical models of human development. New York: John Wiley.

Elder, G. H., Jr., \& Shanahan, M. J. (2006). The life course and human development. In R. E. Lerner (ed.), Theoretical models of human development, (Chapter 12, pp. 665-715), (Volume 1: The Handbook of Child Psychology, 6th Edition). W. Damon, series editor. New York: Wiley.

Elder, L., \& Paul, R. (1996) Critical Thinking: A Stage Theory of Critical Thinking. Journal of Developmental Education, 20(1), 24-35.

Emmerson, G. J. and Neely, M. A. (1988). Two Adaptable, Valid, and Reliable DataCollection Measures: Goal Attainment Scaling and the Semantic Differential. Counseling Psychologist, 16(2), 261-271.

Erikson, E. H. (1963). Childhood and society. New York: Norton.

Erikson, E. H. (1968). Identity: Youth and crisis. New York: Norton.

Erikson, E. H. (1985). The life cycle completed. New York: Norton.

Erikson, E. H., \& Erikson, K. T. (1957). The confirmation of the delinquent. In S. Schlein (Ed.), A way of looking at things: Selected papers from 1930 to 1980 Erik H. Erikson. N.Y: Norton.

Ferrer-Wreder, L. A., Cass-Lorente, C., Kurtines, W. M., Briones, E., Bussell, J. R., Berman,S. L. (2002).Promoting identity development in marginalized youth. Journal of Adolescent Research, 17, 168-187.

Ferrer-Wreder, L., Palchuk, A., Poyrazli, S., Small, M. L., \& Domitrovich, C. E. (2008). Identity and adolescent adjustment. Identity: An International Journal of Theory and Research, 8(2), 95-105.

Finney, S. J. \& DiStefano, C. (2006). Non-normal and categorical data in structural equation modeling. In Hancock, G. R. \& Mueller, R. O. (Eds.), Structural Equation Modeling: A Second Course (pp. 269-314). Greenwich, Connecticut: Information Age Publishing.

Flavell, J. H. and Markman, E. M. (1983). Handbook of child psychology: cognitive development (Vol. 3). New York: Wiley.

Ford, D. H. \& Lerner, R. M. (1992). Developmental systems theory: An integrative approach. Newbury Park, CA: Sage. 
Freedman, B. J., Rosenthal, L., Donahue, L. P., Schlundt, D. G., \& McFall, R. M. (1978). A social-behavioral analysis of skills deficits in delinquent and nondelinquent adolescent boys. Journal of Clinical and Consulting Psychology, 46, 1448-1462.

Freire, P. (1970/1983). Pedagogy of the oppressed. New York: Herder \& Herder.

Graham, J. W. (2009). Missing data analysis: Making it work in the real world. Annual Review of Psychology, 60, 549-576.

Grotevant, H. (1987). Toward a process model of identity formation. Journal of Adolescent Research, 2, 203-222.

Grunbaum, J., Kann, L., Kinchen, S. A., Ross, J. G., Gowda, V. R., Collins, J. L., \& Kolbe, L. J. (1999). Youth risk behavior surveillance: National high school risk behavior survey. Morbidity and Mortality Weekly Report, 48(55), 1-52.

Habermas, J. (1979). Communication and the evolution of society. Boston: Beacon.

Hernandez, L., Montgomery, M. J., \& Kurtines, W. M. (2006). Identity distress and adjustment problems in at-risk adolescents. Identity: An International Journal of Theory and Research, 6(1), 27-33.

Holmbeck, G. N. (2002). A developmental perspective on adolescent health and illness: An introduction to the special issues. Journal of Pediatric Psychology, 27, 409416.

Hoppman, C. A., Coats, A. H., \& Blanchard-Fields, F. (2008). Goals and everyday problem solving: Examining the link between age-related goals and problemsolving strategy use. Aging, Neuropsychology, and Cognition, 15(4), 401-423.

Iacobucci, D. (2008). Mediation Analysis. Thousand Oaks, CA: Sage.

Jaccard, J. and Guilamo-Ramos (2002). Analysis of variance frameworks in clinical child and adolescent psychology: Basic issues and recommendations. Journal of Clinical Child and Adolescent Psychology, 31, 130-146.

Jaccard, J. \& Turrisi, R. (2003). Interaction effects in multiple regression. Thousand Oaks, CA: Sage.

Jaffee, W. B. \& D'Zurilla, T. J. (2003). Adolescent Problem Solving, Parent Problem Solving, and Externalizing Behavior in Adolescents. Behavior Therapy, 34, 295 311.

Jensen, P., Hoagwood, K., \& Trickett, E. (1999). Ivory towers or earthen trenches? Community collaborations to foster "real world" research. Applied Developmental Science, 3(4), 206-212.

Kiresuk, T.J., Smith, A. \& Cardillo, J.E. (1994), (Eds.). Goal attainment scaling: Applications, Theory, and Measurement. Hillsdale, NJ: Lawrence Eribaum Associates.

Kortsch, G., Kurtines, W. M., \& Montgomery, M. J. (2008). A multi-stage longitudinal comparative (MLC) design stage II evaluation of the Changing Lives Program 
(CLP): The Possible Selves Questionnaire-Qualitative Extensions (PSQ-QE). Journal of Adolescent Research, 23(3), 342-358.

Kraemer, H. C., Wilson, G. T., Fairburn, C. G., \& Agras, W. S. (2002). Mediators and moderators of treatment effects in randomized clinical trials. Archives of General Psychiatry, 59, 877-884.

Kroger, J. (1997). Gender and identity: The intersection of structure, content, and context. Sex Roles, 36(11/12), 747-770.

Kurtines, W.M., Eichas K., Briones, E., Ritchie., R.A., Montgomery, M.J., \& Arango, L. (2008). Relational Data Analysis (RDA) Workshop Manual. (I-YDF Technical Report No. 2008-07). Miami, FL: Florida International University, Youth Development Project.

Kurtines, W. M., Ferrer-Wreder, L., Berman, S. L., Lorente, C. C., Silverman, W. K., \& Montgomery, M. J. (2008). Promoting positive youth development: New directions in developmental theory, methods, and research. Journal of Adolescent Research, 23(3), 233-244.

Kurtines, W. M., Ferrer-Wreder, L., Berman, S. L., Lorente, C. C., Briones, E., Montgomery, M. J., Albrecht, R., Garcia, A. J., \&Arrufat, O. (2008). Promoting positive youth development: The Miami Youth Development Project (YDP). Journal of Adolescent Research, 23(3), 256-267.

Kurtines, W. M., Montgomery, M. J., Arango, L. L., \& Kortsch, G. (2004). Does intervention change anything?: New Directions in promoting positive youth development. European Journal of Developmental Psychology, 1(4), 383-397.

Kurtines, W. M., Montgomery, M. J., Arango, L. L., Kortsch, G., Albrecht, R., Garcia, A., Ritchie, R., \& Eichas, K. (2008). Promoting positive youth development: Relational data analysis (RDA). Journal of Adolescent Research, 23(3), 291-309.

Kurtines, W. M., Montgomery, M. J., Eichas, K, Ritchie, R., Garcia, A., Albrecht, R., Berman, S., Ferrer-Wreder, L., \&Lorente, C. C. (2008). Promoting positive development in troubled youth: A Developmental Intervention Science outreach research approach. Identity: An International Journal of Theory and Research, 8, 125-138.

Lerner, R. M. (2002). Concepts and theories of human development ( ${ }^{r d}$ ed.). Mahwah, NJ: Lawrence Erlbaum.

Lerner, R. M. (2005). Promoting Positive Youth Development: Theoretical and Empirical Bases. White paper: Workshop on the Science of Adolescent Health \& Development, NRC/Institute of Medicine. Washington, D.C.: National Academies of Science.

Lerner, R. M. \& Busch-Rossnagel, M. A. (1981). Individuals as producers of their development: conceptual and empirical bases. In Individuals as producers of their development: a life span perspective, R. M. Lerner and M. A. Busch-Rossnagel (Eds). New York: Academic Press, 1-36. 
Lerner, R. M., Fisher, C. B., \& Weinberg, R. A. (2000). Toward a science for and of the people: Promoting civil society through the application of Developmental Science. Child Development, 71(1), 11-20.

Lochman, J. E., \& Dodge, K. A. (1994). Social-cognitive processes of severely violent, moderately aggressive, and nonaggressive boys. Journal of Consulting and Clinical Psychology, 62, 366-374.

Lochman, J. E., \& Lampron, L. G. (1986). Situational social problem-solving skills and self-esteem of aggressive and nonaggressive boys. Journal of Abnormal Child Psychology, 14, 605-617.

Lochman, J. E., Wayland, K. K., \& White, K. J. (1993). Social goals: Relationship to adolescent adjustment and to social problem solving. Journal of Abnormal Child Psychology, 21, 135-151.

Loeber, R., \& Dishion, T. J. (1985). Boys who fight at home and school: Family conditions influencing cross-setting consistency. Journal of Consulting and Clinical Psychology, 52, 759-768.

MacKinnon, D. P., Fritz, M. S., Williams, J., \& Lockwood, C. M. (2007). Distribution of the product confidence limits for the indirect effect: Program PRODCLIN. Behavior Research Methods, 39(3), 384-389.

MacKinnon, D. P., Lockwood, C. M., Hoffman, J. M., West, S. G., \& Sheets, V. (2002). A comparison of methods to test mediation and other intervening variable effects. Psychological Methods, 7(1), 83-104.

Maher, C. A. and Barbrack, C. R. (1984). Evaluating the individual counseling of conduct problem adolescents: The Goal Attainment Scaling method. Journal of School Psychology, 22(3), 285-297.

Marin, L. M. and Halpern, D. F. (2011). Pedagogy for developing critical thinking in adolescents: Explicit instruction produces greatest gains. Thinking Skills and Creativity, 6(1), 1-13.

Montgomery, M. J. (2005). Psychosocial intimacy and identity: From early adolescence to emerging adulthood. Journal of Adolescent Research, 20(3), 346-374.

Montgomery, M. J., Kurtines, W. M., Ferrer-Wreder, L., Berman, S. L., Lorente, C. C., Briones, E., Silverman, W., Ritchie, R., \&Eichas, K. (2008). A Developmental Intervention Science (DIS) outreach research approach to promoting youth development: Theoretical, methodological, and meta-theoretical challenges. Journal of Adolescent Research, 23(3), 268-290.

Moyer, L. S.and de Rosenroll, D. A. (1984). Goal Attainment Scaling: Its use with pregnant and single-parent teenagers in an alternative education setting. Canadian Counsellor, 18(3), 111-116.

Muller, D., Judd, C. M., \& Yzerbyt, V. Y. (2005). When moderation is mediated and mediation is moderated. Journal of Personality and Social Psychology, 89(6), 852-863. 
Muthén, B.O. (1998-2004). Mplus Technical Appendices. Los Angeles, CA: Muthén \& Muthén.

Muthén, B. O. (2002). Beyond SEM: General latent variable modeling. Behaviormetrika, 29(1), 81-117.

Muthén, L. K., \& Muthén, B. O., (2007). Mplus: The comprehensive modeling program for applied researchers. User's guide (5th ed.). Los Angeles: Muthén \& Muthén.

Overton, W. (1998). Developmental psychology: Philosophy, concepts, and methodology. In, R. M. Lerner (Ed.), W. Damon (Series Ed.), Handbook of child psychology: Vol. 1. Theoretical models of human development (5th ed., pp. 107-187). New York: Wiley.

Paritzky, R. S. and Magoon, T. M. (1982). Goal Attainment Scaling Models for Assessing Group Counseling. Personnel and Guidance Journal, 60(6), 381-384.

Peterson, J. L., \& Zill, N. (1986). Marital disruption, parent-child relationships, and behavioral problems in children. Journal of Marriage and the Family, 48(2), $295-$ 307.

Platt, J. J., Spivack, G., Altman, N., Altman, D., \& Peizer, S. B. (1974). Adolescent problem-solving thinking. Journal of Consulting and Clinical Psychology, 42,787-793.

Rausch, J. R., Maxwell, S. E., \& Kelly, K. (2003) Analytical methods for questions pertaining to randomized pretest, posttest, follow-up design. Journal of Clinical Child and Adolescent Psychology, 32(2), 467-86.

Rinaldi, R. (2011). A Developmental Intervention Science Outreach Research Approach to Promoting Positive Youth Development. Unpublished Dissertation. Florida International University, Miami.

Ritchie, R. (2007). The Development and Refinement of a Generic Coding Template for Enhancing the Utility, Reliability and Validity of Relational Data Analysis Theoretical Classification Coding (RDA-TCC).Unpublished Thesis. Florida International University, Miami.

Rosenthal, D.A., Gurney, R. M., \& Moore, S. M. (1981). From trust to intimacy: A new inventory for examining Erikson's stages of psychosocial development. Journal of Youth and Adolescence, 10, 525-537.

Roth, J., Brooks-Gunn, J., Murray, L., \& Foster, W. (1998). Promoting healthy adolescence: Synthesis of youth development program evaluations. Journal of Research on Adolescence, 8(4), 423-459.

Seligman, M., Steen, T., Park, N., \& Peterson, C. (2005) Positive psychology progress: Empirical validation inventions. American Psychologist. 60(5), 410-421.

Schwartz, S. J. (2001). The evolution of Eriksonian and Neo-Eriksonian identity theory and research: A review and integration. Identity: An International Journal of Theory and Research, 1(1), 7-58. 
Schwartz, S. J. (2002). In search of mechanisms of change in identity development: Integrating the constructivist and discovery perspectives in identity. Identity: An International Journal of Theory and Research, 2(4), 317-339.

Schwartz, S. J., , Montgomery, M. J., \&Kurtines, W. K. (2005). A comparison of two approaches for facilitating identity exploration processes in emerging adults: an exploratory study. Journal of Adolescent Research, 20(3), 309-345.

Schwartz, S. J., Mullis, R. L., Waterman, A. S., \& Dunham, R. M. (2000). Ego identity status, identity style, and personal expressiveness: An empirical investigation of three convergent constructs. Journal of Adolescent Research, 15(4), 504-521.

Seligman, M. \& Csikszentmihalyi, M. (2000). Positive psychology: An introduction. American Psychologist, 55(1), 5-14.

Sheldon, K. M., Joiner, T. E., Jr., Pettit, J. W., \& Williams, G. (2003). Reconciling humanistic ideals and scientific clinical practice. Clinical Psychology: Science and Practice, 10, 302-315.

Siegel, A. W., Cousins, J. H., Rubovits, D. S., Parsons, J. T., Lavery, B., \& Crowley, C. L. (1994). Adolescents' perceptions of the benefits and risks of their own risk taking. Journal of Emotional and Behavioral Disorders, 2, 89-98.

Siegel, A. W. \& Scoville, L. C. (2000). Problem behavior: The double symptom of adolescence. Development and Psychopathology, 12, 763-793.

Silverman, W. K., Kurtines, W. M., Jaccard, J., \& Pina, A. A. (2009). Directionality of change in youth anxiety CBT involving parents: An initial examination. Journal of Consulting and Clinical Psychology, 77(3), 474-485.

Skrondal, A., \& Rabe-Hesketh, S. (2004). Generalized latent variable modeling: Multilevel, longitudinal and structural equation models. Boca Raton, FL: Chapman \& Hall/CRC.

Soenens, B., Berzonsky, M. D., Vansteenkiste, M., Beyers, W., \& Goossens, L. (2005). Identity styles and causality orientations: In search of the motivational underpinnings of the identity exploration process. European Journal of Personality, 19, 427-442.

Strauss, A., \& Corbin, J. (1998). Basics of qualitative research: Techniques and procedures for developing grounded theory. Thousand Oaks, CA: Sage.

Sue, D. W. \& Sue, D. (2003). Counseling the Culturally Diverse: Theory and Practice. New York: Wiley \& Sons.

Theokas, C., Almerigi, J. B., Lerner, R. M., Dowling, E. M., Benson, P. L., Scales, P. C., \& von Eye, A. (2005). Conceptualizing and modeling individual asset components of thriving in early adolescence. Journal of Early Adolescence, 25(1), 113-143.

Tanaka, Y., \& Kusumi, T. (2012). The effects of goals, belief in implicit assumptions, and ability on critical thinking performance. Cognitive Studies: Bulletin of the Japanese Cognitive Science Society, 19(1), 56-68. 
Waterman, A. S. (1993). Finding something to do or someone to be: A eudaimonist perspective on identity formation. In L. Kroger (ed.), Discussions on Ego Identity. (p. 147-167). Hillsdale, NJ:Lawrence Erlbaum Associates, Inc.

Waterman, A. (2004). Finding someone to be: Studies on the role of intrinsic motivation in identity formation. Identity: An International Journal of Theory and Research, 4(3), 209-228.

Weisz, J. R., Sandler, I. N., Durlak, J. A., \& Anton, B. S. (2005). Promoting and Protecting Youth Mental Health through Evidence-Based Prevention and Treatment, American Psychologist, 60, 6, 628-648.

Werner, H. \& Kaplan, B. (1956). The developmental approach to cognition: Its relevance to the psychological interpretation of anthropological and ethnolinguistic data. American Anthropologist, 58, 866-880.

Windle, M. (2003). Alcohol use among adolescents and young adults. Alcohol Health Res World, 27, 79-85.

Yu, C. \& Muthen, B. (2002). Evaluation of model fit indices for latent variable models with categorical and continuous outcomes. Paper presented at the annual meeting of the American Educational Research Association, New Orleans, LA.

Zahn-Waxler, C., Klimes-Dougan, B., \& Slattery, M. J. (2000). Internalizing problems of childhood and adolescence: Prospects, pitfalls, and progress in understanding the development of anxiety and depression. Development and Psychopathology, 12, 443-466.

Zimmerman, M.A. (1995). Psychological Empowerment: Issues and illustrations. American Journal of Community Psychology, 23(5), 581-599. 


\section{APPENDICES}

Appendix A: CPSS-QE-RDA-CT

1. The CPSS-QE STC

2. Theoretical Category Property Descriptions

3. Theoretical Category Structural Organization

4. Coding Glossary 


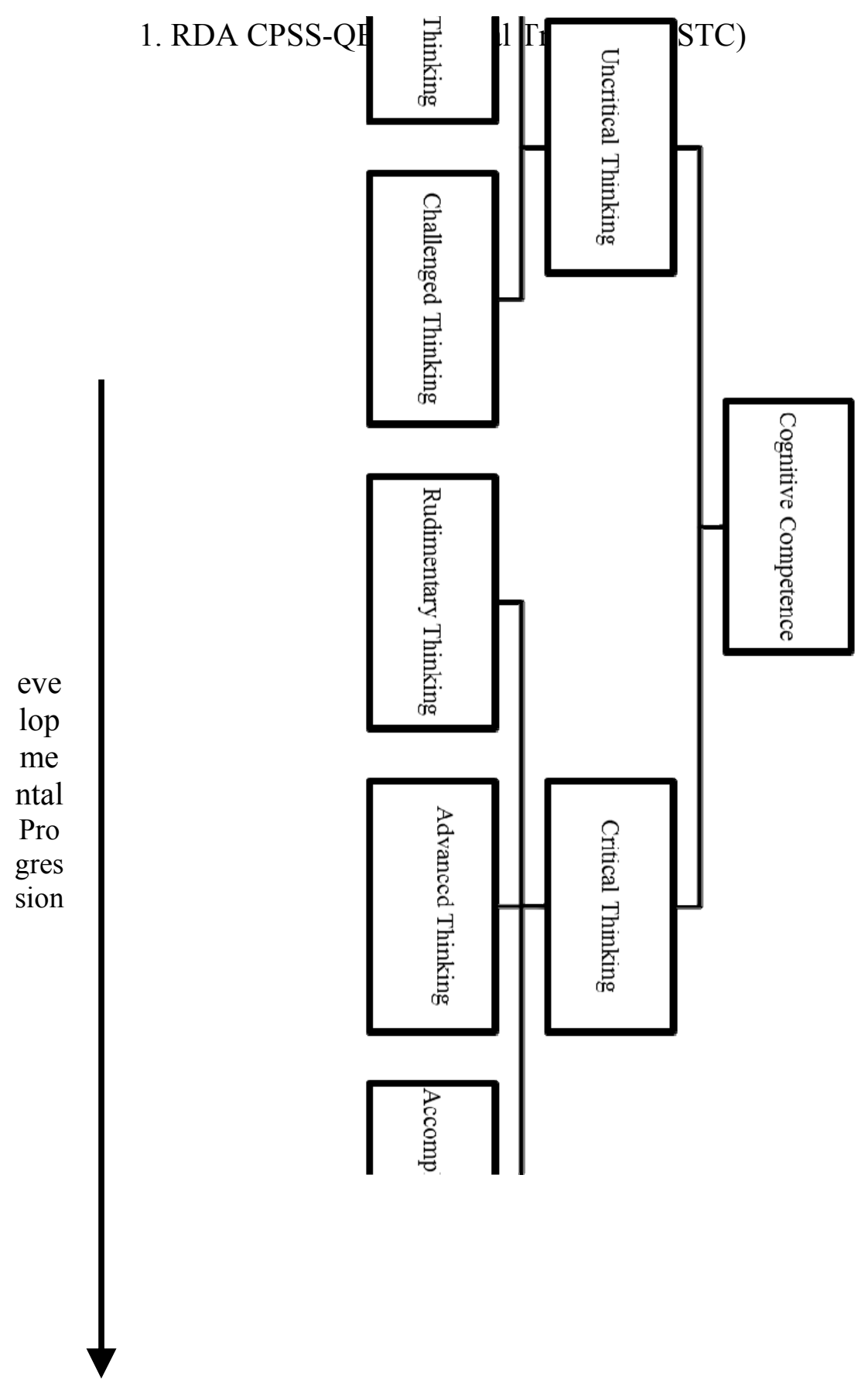




\section{Theoretical Category Property Descriptions}

- Uncritical Thinking: The key property of the Uncritical Thinking category is that the responses demonstrate an unwillingness or inability on behalf of the participant to question his/her original choice. The coders agreed that the properties of this category that made it different from the Critical Thinking responses in this data set is that the Uncritical Thinking responses exclusively included any of the above criteria. The Uncritical Thinking category included two sub-categories, Unreflective Thinking, and Challenged Thinking.

- Unreflective Thinking: The unique properties of this sub-category were a lack of ability on the participant's behalf to assess his/her thinking, and that the quality of the response was undermined by the expression of prejudices and misconceptions. Responses in this sub-category indicated a lack of awareness of the thinking process.

- Challenged Thinking: Responses in this category demonstrate an awareness of the thinking process (distinct from Unreflective Thinking), and some awareness of the role that critical thinking plays in life course change. The unique property of the responses in this category is the difficulty in recognizing the problems inherent in poor thinking.

- Critical Thinking: The key property of the Critical Thinking category is that the responses demonstrate a willingness and ability on behalf of the participant to question his/her original choice. The coders agreed that the properties of this category that made it different from the Uncritical Thinking responses in this data set is that the Critical Thinking responses exclusively included any of the above criteria. The Critical Thinking category included three sub-categories, Rudimentary Thinking, Advanced Thinking and Accomplished Thinking.

- Rudimentary Thinking: The responses in this category show initial signs of attempting to understand, and improve, problematic thinking. Responses in this category have the unique property of possessing some insight into the critical thinking process, but without a plan for adjusting it.

- Advanced Thinking: Responses in this category show evidence of a deeper insight into the consequences of problematic thinking, and also articulate the benefits of critiquing the participant's original choices.

- Accomplished Thinking: Responses in this category demonstrate a "taking charge" of the problem-solving process by the participant. They have the unique property of an effective articulation of the strengths and weaknesses of not only the original choice, but also of the logic underlying it. 


\section{Critical Problem-Solving Skills Scale - Qualitative Extension}

Theoretical Category Structural Organizational Overview

- Macro Interview Response (MIR): a narrative transcription that includes all the words, phrases, and sentences the participant used in describing the meaning and significance of the experience (topic, issue, question, etc.) under investigation.

- Structural Coherence: The primary structural organizational property we have identified for the LCI is Structural Coherence - the degree to which the overall structure and organization of an MIR may be considered a cohesive and coherent expression of a sense of "Who you are." - One's sense of identity

- Consolidation: a merging of the multiple elements or components of the self into of an integrated whole

Three sub-categories of Consolidation have been identified: Unconsolidated, Partially Consolidated, and Fully Consolidated. Each sub-category is defined by variation along the following structural organizational properties: Diversity/Variety, Elaboration/Articulation, and Differentiation/Integration

Diversity/Variety (MIRs are classified according to the number or frequency of distinct and different RCUs an MIR contains and the degree of variability within each different type of RCU)

- Diversity - refers to the number or frequency of distinct and different RCUs. That is, number of explicit references to distinct or different personality variables, affective variables, cognitive variables, etc. that the MIR contains.

- Variety - refers to the degree of variability within each different type of RCU an MIR contains. For instance, variability in different types of personality variables (e.g., traits, goals, accomplishments, etc.), types of affective variables (e.g., feelings or mood states such as anger, confusion, helplessness, etc.), types of cognitive variables (e.g., thoughts, ideas, attitudes, belief, etc). An MIR may contain a single RCU describing only one personality variable, but with extensive primary and secondary elaboration; two, three, or more different types of personality variables with primary and secondary elaboration and no affective or cognitive variables; or two, three, or more different types of personality variables and two, three, or more different types of affective variables with primary and secondary elaboration; etc.

Elaboration/Articulation (MIRs are classified according to the number or frequency of elaboration (primary and secondary) and the degree to which the elaborations are articulated) 
- Primary Elaboration (PE): refers to an initial reason, justification, rationale for a particular narrative response.

- Secondary Elaboration (SE): refers to additional reasons, justifications rationales given to provide more thoughtful attention to parts or details of reason already given.

- Articulation: refers to the degree to which the joining or bringing together words and utterances in elaborations (primary or secondary) is expressed in a creative or refined way and/or is intricate and rich in detail and/or with a great deal of thoughtful specificity and explicitness.

\section{Differentiation/Integration}

- Differentiation (DIF): refers to the degree to which an MIR contains primary or secondary elaboration making distinctions and/or discriminating among RCUs along either a horizontal or vertical temporal dimension. A horizontal temporal dimension refers to making distinctions among two or more RCUs (e.g., personality variables) at the same point in time (either past, present, or future). For instance, "My [current] goals in life are to accomplish A and B, and B is more [or less] important [significant, meaningful, etc.] to me." A vertical temporal dimension refers to making distinctions among two or more RCUs (e.g., personality variables) across (over) time (e.g., from the past to the present or the future). For instance, "When I was younger my goals in life were to accomplish A and $\mathrm{B}$; however, $\mathrm{B}$ is no longer [or less] important [significant, meaningful, etc.] to me now than A." Primary or secondary elaboration making distinctions and/or discriminations involves making comparative (e.g., more than, less than, etc.) or evaluative (e.g., better than, worse than, etc.) judgments between RCUs or across RCUs over time.

- Integration (INT): refers to the degree to which an MIR contains primary or secondary elaboration that describes the relations between RCUs in an effort to identify links or connections between them; unify; or join or unite them with each other. For instance, "When I was younger I used to think that I had to choose between a career and a family; however, now I think I can do both." 
4. Critical Problem-Solving Skills Scale - Qualitative Extension Decision

\section{Coding Glossary}

Articulation: joining or bringing together words and utterances in a creative or refined way.

Category: a group of RCUs that share one non-overlapping (unique) property.

Consolidation: merging multiple elements or entities.

Decision Tree Chart (DTC): a "diagram" for facilitating classification coding decisionmaking processes and its "associated descriptive matrix of classification criteria."

Differentiation: to make distinctions; discriminate.

Diversity/Variety: involving multiple elements or entities.

Elaboration, Primary: the term used to code the initial or (if stated) primary reason, justification, rationale for a particular narrative response.

Elaboration, Secondary: the term used to code additional reasons, justifications, rationales for a particular narrative response for which a Primary Elaboration has already been coded.

Macro Interview Response (MIR): a narrative transcription that includes all the words, phrases, and sentences the participant used in describing the meaning and significance of the experience (topic, issue, question, etc.) under investigation.

Organization: something made up of elements with varied functions that contribute to the whole and to collective functions

Positivity: confident, optimistic, and focusing on good things rather than bad

Response Content Unit (RCU): units of response content (i.e. the ideas, incidents, examples, persons, events, things, actions/interactions, etc.) that are made up of the specific words, phrases, and sentences used in response to the interview questions and probes.

Structure: the interrelation or arrangement of parts in a complex entity.

Structural Tree Chart (STC): a "diagram" for visually representing the structural organization of an identified set of theoretically meaningful categories. 
VITA

BRENT M. MAXIMIN

January 6, 1987

Born, Port-of-Spain, Trinidad \& Tobago

$2004-2007$

B.A., Psychology

Florida International University

Miami, Florida

$2008-2011$

M.S., Psychology

Florida International University

Miami, Florida

$2008-2012$

Teaching Assistant

Florida International University

Miami, Florida

$2011-2012$

Doctoral Candidate, Psychology

Florida International University

Miami, Florida

\section{PUBLICATIONS AND PRESENTATIONS}

Maximin, B., Harari, G., Garcia, A., Kasian, E., Madrazo, V., Meca, A., Quintana, S., Rinaldi, R., Ritchie, R., Varela, A., \& Kurtines, W. (2011). Competence, Content, and Life Change: A Preliminary Investigation of the Critical Problem-Solving Skills Scale (CPSS). Presented at the 18th annual meeting of the Society for Research on Identity Formation (SRIF), Daytona Beach, Florida.

Eichas, K., Rinaldi, R., Quintana, S., Ritchie, R., Garcia, A., Varela, A., Maximin, B., Kasian, E., Madrazo, V., Meca, A., \& Kurtines, W. (2011, February). Evaluating Positive Youth Development: Relational Data Analysis. Presented at the annual meeting of the Society for Research on Identity Formation. Daytona Beach, FL.

Garcia, A., Rinaldi, R., Ritchie, R., Varela, A., Maximin, B., \& Kasian, E. (2011). Participation Evaluation Rating Scale: Psychometric Analyses of a Relational Data Analysis Coding Template (RDA-CT). Presented at the annual meeting of the Society for Research on Identity Formation, Daytona Beach, FL. 
Madrazo V., Meca, A., Eichas K., Ritchie,R., Rinaldi, R., Garcia, A. Varela, A., Quintana,S., Maximin B., Kasian, K., \& Kurtines, W. M. (2011, February). The Evaluation of an Outcome Mediation Cascade Model on Interaction Effects of a Positive Youth Development Intervention. Presented at the annual meeting of the Society for Research on Identity Formation. Daytona Beach, FL.

Quintana, S., Rinaldi, R., Meca, A., Ritchie, R., Garcia, A., Varela, A., Maximin, B., Kasian, E., Madrazo, V., \& Kurtines, W. (2011). The Adult Development Project: A Preliminary Study. Presented at the annual meeting of the Society for Research on Identity Formation, Daytona Beach, FL.

Rinaldi, R., Meca, A., Eichas, K., Ritchie, R., Garcia, A., Varela, A., Maximin, B., Kasian, E., Madrazo, V., Quintana, S., \& Kurtines, W. (2011, February). The Development of a Qualitative Extension for the Personally Expressive Activities Questionnaire. Presented at the annual meeting of the Society for Research on Identity Formation. Daytona Beach, FL.

Ritchie, R., Meca, A., Eichas, K., Madrazo, V., Garcia, A., Varela, A., Rinaldi, R., Maximin, B., Kasian, E., Quintana, S., Harari, G., \& Kurtines, W. M. (2011, February). Mediators of Exploration and Commitment in a Positive Youth Development Project. Presented at the annual meeting of the Society for Research on Identity Formation. Daytona Beach, FL.

Varela, A., Eichas, K., Albrecht, R., Garcia, A., Ritchie, R., Rinaldi, R., Garcia, A., Maximin, B., Meca, A., Kasian, E., Quintana, S., \& Kurtines, W. M. (2001, February). The Development and Evaluation of a Relational Data Analysis Coding Template (RDA-CT) for the Transformative Goal Attainment Scale-Qualitative Extension (TGAS-QE). Presented at the annual meeting of the Society for Research on Identity Formation. Daytona Beach, FL.

Eichas, K., Rinaldi, R., Ritchie, R., Garcia, A., Varela, A., Madrazo, V., Maximin, B., Ekasian, K., Meca, A., O’Dowd, B., Quintana, S., \& Kurtines, W. (2009). Evaluating Positive Youth Development: An Integration of Quantitative and Qualitative Methods. Presented at the 6th biennial conference meeting of the Society for the Study of Human Development, Ann Arbor, Michigan.

Keeler, E., Olarte, S., Mansur, S., Meca, A., Eichas, K., Madrazo, V., Maximin, B., Su. J., Eichas, K., \& Kurtines, W.(2008). Relationships between behavior problems and informational identity style in multi-problem adolescents. Presented at the annual meeting of the Society for the Research of Identity Formation.

Olarte, S., Meca, A., Eichas, K., Keeler, E., Mansur, S., Maximin, B., Madrazo, V., \& Kurtines, W.(2008). Critical Problem Solving Processes and Life Challenges: Interrater Agreement and Inter-rater Reliability of the Critical Problem Solving Scale (CPSS). Presented at the annual meeting of the society for the research of identity formation. 